\author{
UNIVERSIDADE DE SÃO PAULO \\ PROGRAMA DE PÓS-GRADUAÇÃO INTERUNIDADES EM ENSINO \\ DE CIÊNCIAS \\ INSTITUTOS DE FÍSICA, DE QUÍMICA, DE BIOCIÊNCIAS E \\ FACULDADE DE EDUCAÇÃO
}

CAIAN CREMASCO RECEPUTI

PERCEPÇÕES DE PROFESSORES DE LICENCIATURAS

EM QUÍMICA SOBRE “EXPERIMENTAÇÃO”, NA PERSPECTIVA DA TEORIA DAS REPRESENTAÇÕES SOCIAIS

SÃO PAULO 


\section{PERCEPÇÕES DE PROFESSORES DE LICENCIATURAS EM QUÍMICA SOBRE "EXPERIMENTAÇÃO”, NA PERSPECTIVA DA TEORIA DAS REPRESENTAÇÕES SOCIAIS}

\section{Versão Corrigida}

Dissertação apresentada ao Programa de Pós-Graduação Interunidades em Ensino de Ciências da Universidade de São Paulo, para a obtenção do título de Mestre em Ensino de Ciências.

Área de Concentração: Ensino de Química

Orientadora: Prof. ${ }^{a}$ Dr. ${ }^{a}$ Daisy de Brito Rezende

SÃO PAULO

2019 
Autorizo a reprodução e divulgação total ou parcial deste trabalho, por qualquer meio convencional ou eletrônico, para fins de estudo e pesquisa, desde que citada a fonte.

\section{FICHA CATALOGRÁFICA \\ Preparada pelo Serviço de Biblioteca e Informação do Instituto de Física da Universidade de São Paulo}

Receputi, Caian Cremasco

Percepções de professores de licenciaturas em química sobre "experimentação", na perspectiva da teoria das representações sociais. São Paulo, 2019.

Dissertação (Mestrado) - Universidade de São Paulo. Faculdade de Educação, Instituto de Física, Instituto de Química e Instituto de Biociências.

Orientador: Profa. Dra. Daisy de Brito Rezende

Área de Concentração: Ensino de Química.

Unitermos: 1. Química - Estudo e ensino; 2. Formação de professores; 3. Experimentação; 4. PIBID; 5. Coordenador de área; 6. Representação social. 


\section{RECEPUTI, Caian Cremasco}

Percepções de professores de Licenciaturas em Química sobre "experimentação", na perspectiva da Teoria das Representações Sociais

Dissertação apresentada ao Programa de Pós-Graduação Interunidades em Ensino de Ciências da Universidade de São Paulo, para a obtenção do título de Mestre em Ensino de Ciências.

Área de Concentração: Ensino de Química

Aprovado em: 06/06/2019

\section{Banca Examinadora}

Prof. ${ }^{a}$ Dr. ${ }^{a}$ Daisy de Brito Rezende

Instituto de Química, Universidade de São Paulo

Prof. ${ }^{a}$ Dr. ${ }^{a}$ Simone Alves de Assis Martorano

Departamento de Ciências Exatas e da Terra, Universidade Federal de São Paulo

Prof. Dr. Vicente Sarubbi Júnior

Curso de Medicina, Universidade Estadual de Mato Grosso do Sul 


\section{AGRADECIMENTOS}

Aos sujeitos colaboradores desta pesquisa, pelo tempo cedido.

Ao professor Dr. Marcos Vogel, por ter me apontado a direção para a realização desta pesquisa, e pelas contribuições ao longo do meu percurso formativo inicial.

À minha colega Thaiara Magro Pereira, pelas incontáveis discussões, apontamentos, sugestões e revisões.

Ao Prof. Dr. Agnaldo Arroio pelas contribuições apresentadas na qualificação.

Aos professores que compuseram a banca de defesa desta Dissertação, Prof. ${ }^{a}$ Dra. Simone Alves de Assis Martorano e Prof. Dr. Vicente Sarubbi Júnior, agradeço a leitura cuidadosa e as valiosas contribuições.

À minha orientadora, Prof. ${ }^{a}$ Dra. Daisy de Brito Rezende, por compartilhar suas visões de mundo, pela atenção e escrita colaborativa desta Dissertação.

À Coordenação de Aperfeiçoamento de Pessoal de Nível Superior (CAPES), pela concessão da bolsa de mestrado que apoiou financeiramente a realização desta pesquisa. 


\section{RESUMO}

RECEPUTI, C. C. Percepções de Professores de Licenciaturas em Química sobre "experimentação", na perspectiva da Teoria das Representações Sociais. 2019. 134 f. Dissertação (Mestrado em Ensino de Ciências) - Programa de Pós-Graduação Interunidades em Ensino de Ciências, Universidade de São Paulo, SP. 2019.

Esta Dissertação apresenta um estudo sobre as compreensões sobre "experimentação" de professores que lecionam em cursos de Licenciatura em Química de 89 diferentes universidades brasileiras, localizadas em 26 Estados, abrangendo 275 professores. Esta pesquisa teve como objetivo investigar as Representações Sociais (RS) sobre "experimentação" dos formadores de professores de Química, participantes, ou não, de subprojetos PIBID-Química. Para isso, utilizou-se a abordagem estrutural da Teoria das RS, que estabelece a existência de um Núcleo Central (NC) que confere significado à representação. Para a obtenção das informações, empregou-se um questionário com 13 questões, das quais quatro referem-se à técnica de livre associação de palavras a partir do termo indutor "experimentação", enquanto as demais visam caracterizar os sujeitos da pesquisa. Para o tratamento das informações e determinação das RS desses grupos, empregou-se a Análise Prototípica proposta por Vergès e a Análise de Similitude. Posteriormente, utilizaram-se proposições da análise de conteúdo, segundo a abordagem de Bardin para atribuir significado aos termos destas RS. Os resultados mostram RS distintas para os dois grupos pois, enquanto o termo constituinte do NC da RS sobre "experimentação" para os Coordenadores do PIBID é investigação, para os nãoCoordenadores do PIBID, o termo que constitui o NC da RS é laboratório. Identificou-se que tanto Coordenadores como não-Coordenadores do PIBID apresentam uma percepção sobre "experimentação" voltada, em grande parte, para os aspectos educacionais, para a formação de professores de Química. Porém, enquanto os Coordenadores do PIBID tendem a relacionar o desenvolvimento das atividades experimentais ao contexto escolar, levando em consideração as particularidades e problemáticas desse espaço, os não-Coordenadores tendem a pensar no desenvolvimento das atividades experimentais no contexto do Ensino Superior e no desenvolvimento de pesquisas. Conclui-se que há diferenças na RS sobre "experimentação" dos Coordenadores e não-Coordenadores do PIBID. Estas diferenças se dão, principalmente, pelas práticas desenvolvidas no âmbito do subprojeto PIBID-Química, as quais aproximam o Coordenador da realidade da escola da Educação Básica, modificando suas percepções sobre esse contexto e sobre a sua atuação na formação dos futuros professores, conduzindo à reelaboração de sua visão sobre o ensino e a prática docente. Este é um importante indício de que o PIBID tem contribuído para a formação continuada dos professores dos cursos de Licenciatura em Química, o que se reflete na formação dos licenciandos, sejam eles participantes PIBID ou não.

Palavras-chave: Formação de professores; Experimentação; PIBID; Coordenador de Área; Representação Social. 


\section{ABSTRACT}

RECEPUTI, C. C. Perceptions of teachers of initial teacher education courses on "experimentation", in the Social Representations Theory approach. 2019. 134 p Thesis (Master on Science Education) - Interunity Graduate Program on Science Education (Programa de Pós-Graduação Interunidades em Ensino de Ciências), Universidade de São Paulo, SP, Brazil. 2019.

This Master Thesis presents a study concerning the understanding about "experimentation" of 275 teachers of undergraduate courses on Chemistry initial teacher education of 89 different Brazilian universities, located in 26 States. This study aims to investigate the Social Representations (SR) on "experimentation" of these Chemistry teachers that are participants, or not, of PIBID-Chemistry subprojects. We adopted the SR Theory structural approach, which allows the recognition of a Central Core (CC) that confers meaning to the representation. To gather the information, we employed a questionnaire with 13 questions, of which four refer to the technique of free association of words to the inductor term "experimentation", while the others aim at the characterization of the research subjects. For the analysis of this information and determination of the social representations' CC of these groups, we used the Prototypic Analysis proposed by Vergès and the Similitude Analysis. Subsequently, propositions of content analysis, accordingly to Bardin's approach, allowed the assignment of meaning to the CC terms of these SR. The results show different SR for the two groups. The term constituent of the SR' CC concerning "experimentation" means investigation for the supervisors of the PIBID program. In the case of the non-supervisors of this program, the term that constitutes the CC of the RS is laboratory. The perception of both groups about "experimentation" focused, in large part, on educational aspects, for the training of the future Chemistry teachers. However, while the PIBID supervisors tend to relate the development of experimental activities to the school context, taking into account the particularities and problems of this space, non-supervisors tend to think about the development of experimental activities in the context of Higher Education and research development. It was possible to conclude that the participation on the PIBID project has contributed to the PIBID supervisor' SR resignification of "experimentation", which implies in the modification of their conceptions about the formation of teachers. This result should reflect on the undergraduate students formation to become teachers, whether they are PIBID participants or not.

Keywords: initial teacher education; experimentation; PIBID; project supervisor; social representation. 


\section{LISTA DE ILUSTRAÇÕES}

Figura 2.1 - Interações e espaços de atuação do Coordenador de Área. 24

Figura 4.1 - Quadrante de quatro casas proposto por Vergès

Figura 4.2 - Recorte da árvore de similitude máxima para os termos mais representativos sobre o objeto social ser "professor de Química": sub-grupo dos licenciandos não/PIBID .... 52 Figura 6.1 - Crescimento do número de programas de Pós-Graduação na Área de Ensino de

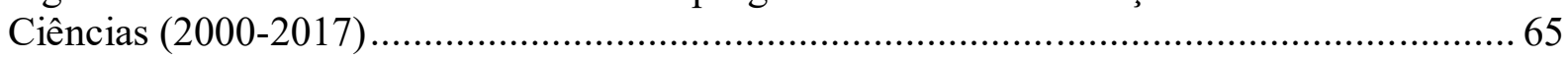

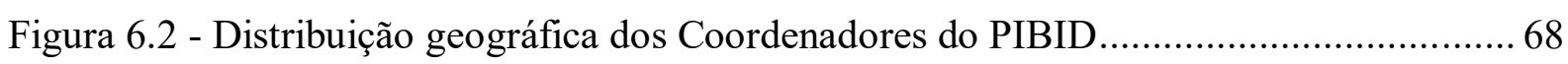

Figura 6.3 - Distribuição geográfica dos não-Coordenadores do PIBID ................................ 69

Figura 6.4 - Quadrante de Vergès para os termos evocados para "experimentação" .............. 74

Figura 6.5 - Árvore de similitude máxima para os termos mais representativos sobre o objeto social "experimentação" para os sujeitos de pesquisa 75

Figura 6.6 - Árvore de similitude máxima para a variável tempo de coordenação do subprojeto

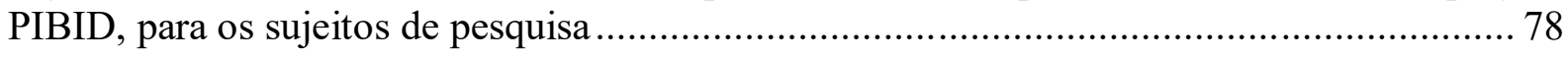

Figura 6.7 - Quadrante de Vergès dos termos de representação sobre "experimentação" para os não-Coordenadores do PIBID. 81

Figura 6.8 - Árvore de similitude máxima para os termos mais representativos sobre o objeto social "experimentação" para os não-Coordenadores do PIBID ........................................ 83

Figura 6.9 - Quadrante de Vergès dos termos de representação sobre “experimentação" para

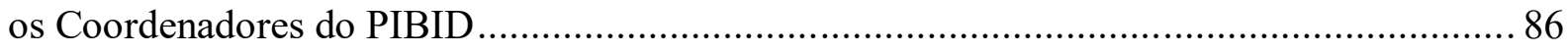

Figura 6.10 - Árvore de similitude máxima para os termos mais representativos sobre o objeto social "experimentação" para os Coordenadores do PIBID. 


\section{LISTA DE TABELAS}

Tabela 6.1 - Tempo de participação dos coordenadores no subprojeto PIBID ....................... 63

Tabela 6.2 - Distribuição dos sujeitos de pesquisa em função do sexo................................ 64

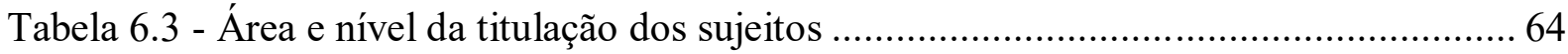

Tabela 6.4 - Tempo de experiência docente no Ensino Básico .............................................. 66

Tabela 6.5 - Tempo de experiência docente no Ensino Superior .......................................... 66

Tabela 6.6 - Área das disciplinas que os sujeitos da pesquisa ministram no Ensino Superior 67

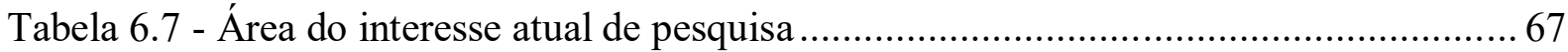

Tabela 6.8 - Distribuição dos termos em função das frequências de evocação ....................... 71

Tabela 6.9 - Quantidade de termos em função das frequências acumuladas.......................... 71

Tabela 6.10 - Termos de maior saliência e conectividade para os sujeitos de pesquisa $(\mathrm{n}=$ 275) 76

Tabela 6.11 - Relação dos termos de maior frequência comuns para os Coordenadores e nãoCoordenadores do PIBID

Tabela 6.12 - Distribuição das frequências de evocações para os não-Coordenadores do PIBID 79

Tabela 6.13 - Número de termos porcentagem 79

Tabela 6.14 - Termos de maior saliência e conectividade para os não-Coordenadores do PIBID 83

Tabela 6.15 - Distribuição das frequências de evocações para os Coordenadores do PIBID.. 84

Tabela 6.16 - Número de termos porcentagem. 84

Tabela 6.17 - Termos de maior saliência e conectividade para os Coordenadores do PIBID . 88 


\section{LISTA DE QUADROS}

Quadro 1.1 - Síntese dos problemas relativos ao modelo de formação de professores ainda presente em grande parte das IES brasileiras ................................................................. 16

Quadro 1.2 - Características do PIBID para a formação de professores................................ 17

Quadro 2.1 - Programas executados pela DEB, entre os anos de 2007 e 2014 ...................... 21

Quadro 2.2 - Atribuições do Coordenador de Área. ........................................................... 23

Quadro 2.3 - Comparação entre aspectos das Portarias 2007 e 2013 .................................... 26

Quadro 2.4 - Contribuição do PIBID para formação continuada dos Coordenadores de Área.

27

Quadro 4.1 - Funções das Representações Sociais ............................................................. 45

Quadro 4.2 - Síntese das características dos Sistemas Central e Periférico das RS ............... 49

Quadro 4.3 - Propriedades dos termos do núcleo central da RS ........................................ 50

Quadro 4.4 - Equações para determinar os valores de corte ............................................... 50

Quadro 5.1 - Critérios para seleção dos Participantes da Pesquisa ....................................... 55

Quadro 5.2 - Momentos da abordagem estrutural ............................................................ 58

Quadro 5.3 - Programas do EVOCATION 2005® utilizados e suas respectivas funções ...... 59

Quadro 5.4 - Modificação dos termos para a construção do banco de dados ......................... 61

Quadro 5.5 - Homogeneização e Categorização Semântica dos termos evocados.................. 62

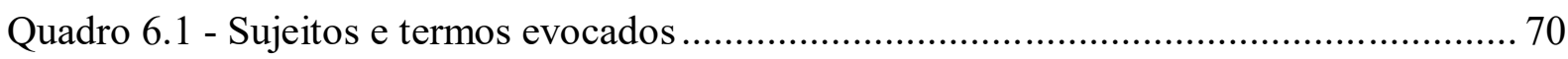

Quadro 6.2 - Relação não-Coordenadores do PIBID e termos evocados .............................. 79

Quadro 6.3 - Relação dos Coordenadores do PIBID e termos evocados............................... 84

Quadro 6.4 - Dimensões de análise para os termos do NC da RS sobre "experimentação" dos

Coordenadores do PIBID 89 


\section{LISTA DE ABREVIATURAS E SIGLAS}

$\mathrm{Ar}$

CAPES

CAQDAS

DEB

DED

$E / E Q$

EJA

ENADE

EVOCATION

$f$

$f_{\text {med }}$

FNDE

$\mathrm{h}$

IES

INEP

IRAMUTEQ

LDB

LiEQui

LIFE

$m$

MEC

$n$

$\mathrm{NC}$

$\mathrm{NdC}$

OBEDUC

OGOE

OME

PARFOR

PDPP
Aresta

Coordenação Nacional de Aperfeiçoamento de Pessoal de Nível Superior

Computer Aided Qualitative Data Analysis Software

Diretoria de Formação de Professores da Educação Básica

Diretoria de Educação a Distância

Educação e Ensino de Química

Educação de Jovens e Adultos

Exame Nacional de Desempenho de Estudantes

Ensemble de Progrmmes Permettant l'Analyse de Évoctions

Frequência

Frequência Média

Fundo Nacional de Desenvolvimento da Educação

Hierarquia

Instituição de Ensino Superior

Instituto Nacional de Estudos e Pesquisas Educacionais Anísio Teixeira

Interface de $R$ pour les Analyses Multidimensionnelles de Textes et de Questionnaires

Lei de Diretrizes e Bases da Educação Brasileira

Grupo de Pesquisa em Linguagem no Ensino de Química

Laboratórios Interdisciplinares de Formação de Educadores

frequência total de evocações dos termos, após a definição do valor de corte

Ministério da Educação

Número de Termos

Núcleo Central

Natureza da Ciência

Observatório da Educação

Ordem Geral de Ordenamento das Evocações

Ordem Média de Evocações

Plano Nacional de Formação de Professores da Educação Básica

Cooperação Internacional para Professores da Educação Básica Programa de Desenvolvimento Profissional para Professores 
PIBID Programa Institucional de Bolsas de Iniciação à Docência

Q Química

PRODOCENCIA Programa de Consolidação das Licenciaturas

PROUNI

Programa Universidade para Todos

REUNI

Reestruturação e Expansão das Universidades Federais

RS

Representação Social

$\Sigma \mathrm{CO}$

Somatório de Concorrências

STEM

Science, Technology, Engineering e Mathematics

TNC

Teoria do Núcleo Central

TRS

Teoria das Representações Sociais

UAB

Universidade Aberta do Brasil

UFPI

Universidade Federal do Piauí

UNICAMP

Universidade Estadual de Campinas

WEF

World Economic Forum 


\section{SUMÁRIO}

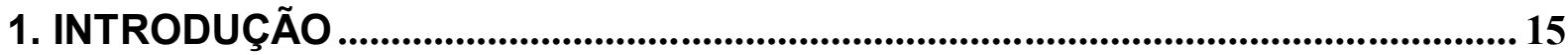

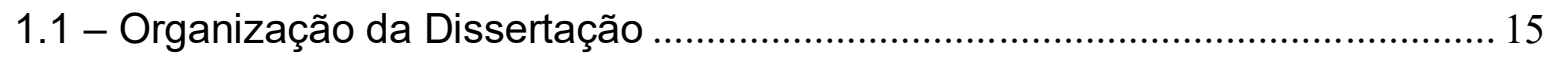

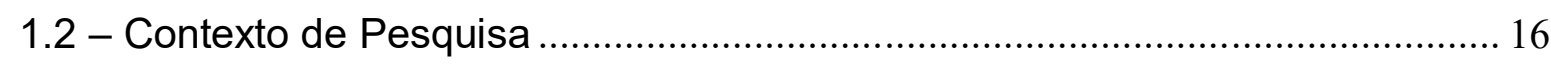

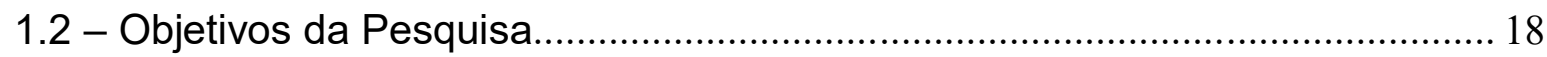

2. PROGRAMA INSTITUCIONAL DE BOLSAS DE INICIAÇÃO À DOCÊNCIA...... 20

2.1 - CAPES e DEB, ações para a Formação de Professores …………………..... 20

2.2 - A construção do PIBID a partir das Portarias Normativas ................................ 21

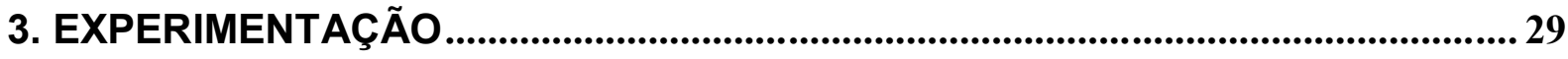

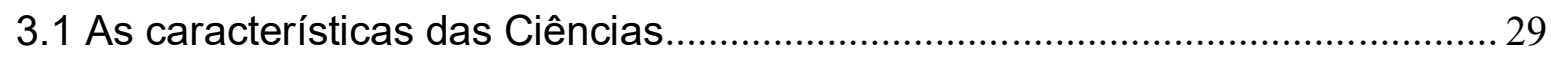

3.1.1 Percepções de estudantes de Nível Básico .................................................. 30

3.1.2 Percepções de estudantes de Nível Superior................................................ 31

3.1.3 Percepções de professores de Ciências ......................................................... 34

3.2 Atividades Experimentais no Ensino de Ciências ………………………….......... 36

3.3 Objetivos das atividades experimentais no Ensino de Ciências ......................... 40

3.3.1 Objetivos das atividades experimentais no Ensino de Ciências .................. 40

3.3.2 As atividades experimentais são realmente eficientes? ............................... 41

4. TEORIA DAS REPRESENTAÇÕES SOCIAIS .......................................................43

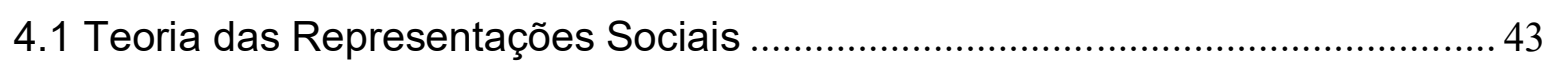

4.1.1 Gênese e princípios epistemológicos .......................................................... 43

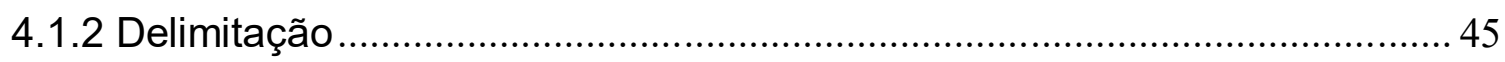

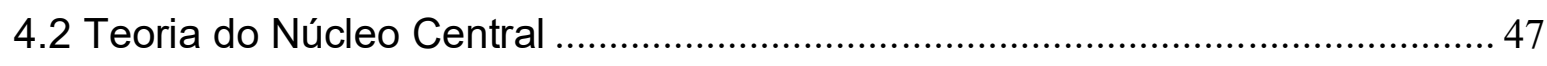

4.2.1 Princípios epistemológicos, Sistema Central e Sistema Periférico.............. 47

4.2.2 Alocação dos termos no Núcleo Central de uma Representação Social... 49

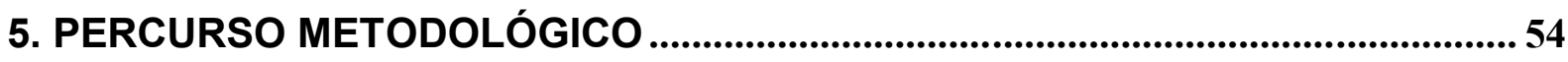

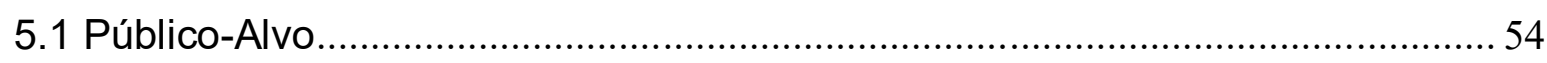

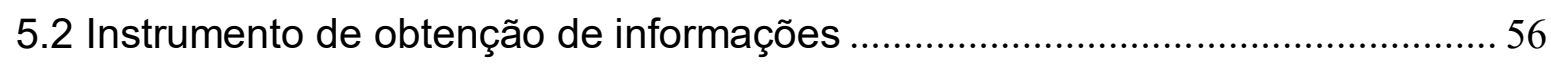

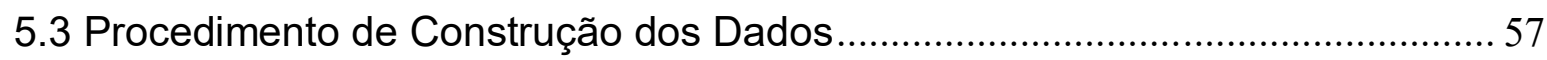

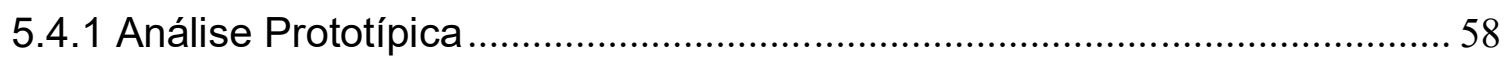

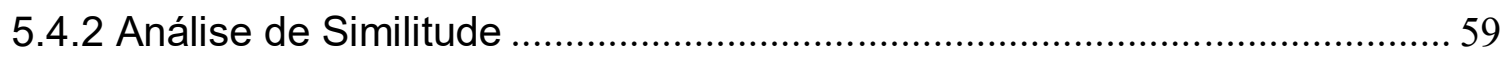

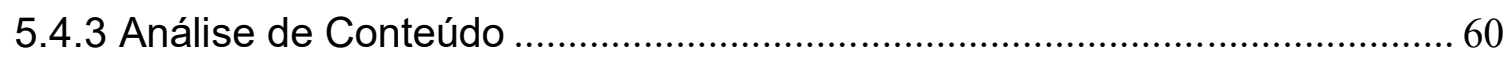

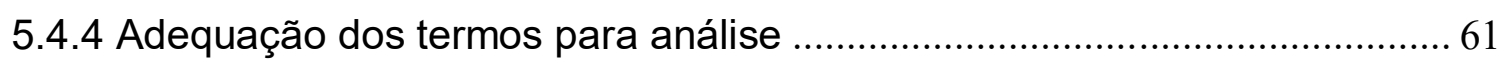

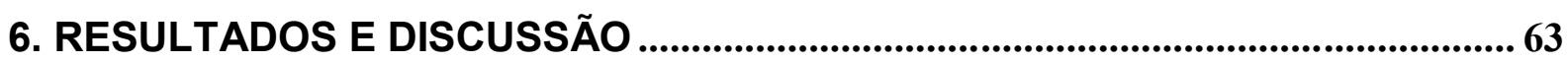


6.1 Caracterização dos Sujeitos de Pesquisa.

6.2 Construção de dados considerando o total de sujeitos investigados .70

6.2.1 Análise Prototípica das Evocações. 70

6.2.2 Análise de Similitude das evocações para o total de sujeitos da pesquisa74 6.3 Representação Social sobre "experimentação" dos não-Coordenadores do PIBID 79

6.3.1 Análise Prototípica das evocações dos não-Coordenadores do PIBID ..... 79

6.3.2 Análise de Similitude das evocações dos não-Coordenadores do PIBID.. 82 6.4 Representações Sociais sobre "experimentação" dos Coordenadores do PIBID

6.4.1 Análise Prototípica das evocações dos Coordenadores do PIBID .............. 83

6.4.2 Análise de Similitude das Evocações dos Coordenadores do PIBID .......... 87

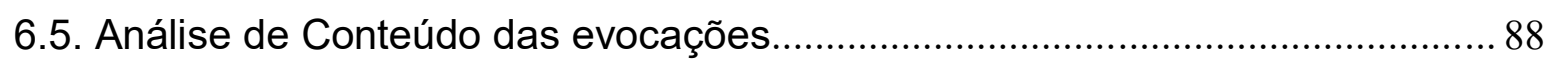

6.5.1 Análise de Conteúdo das evocações dos não-Coordenadores do PIBID.. 89

6.5.2 Análise de Conteúdo das Evocações dos Coordenadores do PIBID

6.6 Síntese: Considerações sobre as Representações Sociais dos Coordenadores

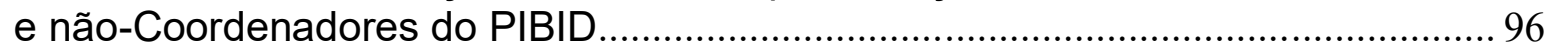

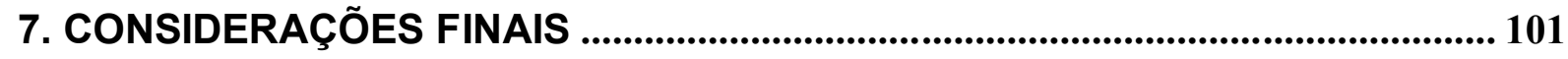

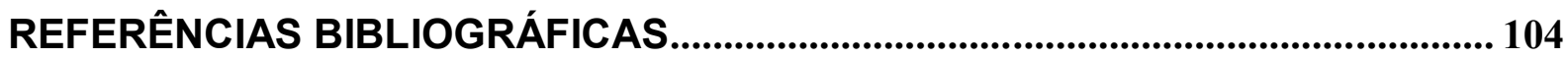

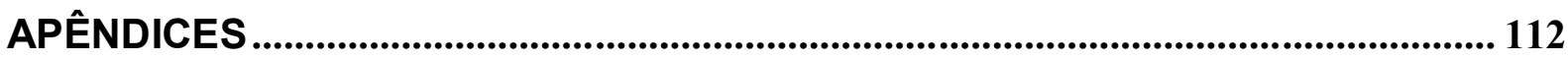

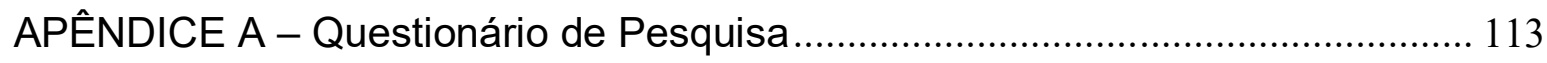

APÊNDICE B - Lista de Palavras Evocadas ....................................................... 117

APÊNDICE C - Lista de Palavras Modificadas ..................................................... 130

APÊNDICE D - Localidade e Instituição dos Colaboradores da Pesquisa............ 133 


\section{INTRODUÇÃO}

\section{1 - Organização da Dissertação}

Este texto está estruturado em sete partes. No Capítulo 1, apresenta-se a organização, o contexto e os objetivos da pesquisa. No contexto da pesquisa apresenta-se a relação entre problemas da formação inicial de Professores da Educação Básica e a criação do Programa Institucional de Bolsas de Iniciação à Docência (PIBID), o que se reflete em suas metas e potencialidades, e se relaciona com resultados anteriores deste grupo de pesquisa (VOGEL, 2016). Este foi o contexto subjacente ao planejamento e desenvolvimento desta pesquisa. $O$ objetivo da pesquisa é o de desvelar as possíveis Representações Sociais (RS) sobre "experimentação" de professores de Licenciaturas em Química, sejam eles Coordenadores do PIBID, ou não, para se ter indicadores da influência deste percurso formativo nas concepções dos formadores de professores.

No Capítulo 2, apresentam-se algumas considerações sobre o PIBID, sua gênese e o contexto em que se insere este programa, o que envolve a descrição da modificação de sua estrutura e organização por meio das várias Portarias Normativas. Apresentam-se, também, as atribuições do coordenador de área, suas ações, interações e espaços de atuação além de se relatar como o PIBID vem contribuindo para a formação continuada desses sujeitos.

No Capítulo 3, apresentam-se as percepções de estudantes da Educação Básica, de graduandos e pós-graduandos e de professores sobre as características das Ciências da Natureza. Apresentam-se, também, as características das atividades experimentais, enfatizando-se os resultados de algumas pesquisas sobre as atividades experimentais de cunho investigativo. Por último, são apresentados os objetivos das atividades experimentais e as várias questões quanto a seu desenvolvimento na Educação Básica relatadas na literatura da área.

No Capítulo 4, apresenta-se o aporte teórico-metodológico utilizado no desenvolvimento desta pesquisa, a Teoria das Representações Sociais (MOSCOVICI, 2007), descrevendo sua gênese e seus pressupostos. Posteriormente, descreve-se a Teoria do Núcleo Central, uma de suas vertentes (ABRIC, 2001).

No Capítulo 5, apresenta-se o percurso metodológico adotado para esta pesquisa, descrevendo-se o público-alvo, o instrumento para a obtenção das informações, o procedimento de construção e análise dos dados. Inicialmente, serão descritos os critérios de seleção dos sujeitos da pesquisa, professores dos cursos de Licenciatura em Química, 
Coordenadores e não-Coordenadores do PIBID, e o questionário semiestruturado utilizado para a coleta de informações. Então, descreve-se a construção dos dados por meio das análises Prototípica e de Similitude, que visam identificar dos termos do Núcleo Central da RS dos sujeitos da pesquisa; a Análise de Conteúdo permite atribuir significado aos termos da representação destes sujeitos.

O Capítulo 6 refere-se à construção dos dados e discutem-se os resultados obtidos. A construção e análise dos dados foram realizadas, primeiramente, admitindo-se que os professores das diferentes Licenciaturas possam constituir um único grupo social e, posteriormente, subdividindo o grupo de professores em Coordenadores do PIBID $(n=172)$ e não-Coordenadores do PIBID ( $n=103)$. Por fim, no Capítulo 7 , apresentam-se as considerações finais desta pesquisa.

\section{2 - Contexto de Pesquisa}

Hoje, reconhece-se que a formação inicial dos professores da Educação Básica não é adequada para enfrentar a problemática da sua área de atuação. $\mathrm{Na}$ literatura especializada, há vários trabalhos acerca dessa temática, desvelando-a e propondo modelos de formação que visam a superação desse problema (PICONEZ, 2006; MALDANER, 2008; SILVA; SCHNETZLER, 2008; ZEICHNER, 2010; TARDIF, 2014). Os pontos mais relevantes de alguns desses estudos sobre aspectos da formação de professores estão sumariados no Quadro 1.1.

\section{Quadro 1.1 - Síntese dos problemas relativos ao modelo de formação de professores ainda presente em grande parte das IES brasileiras.}

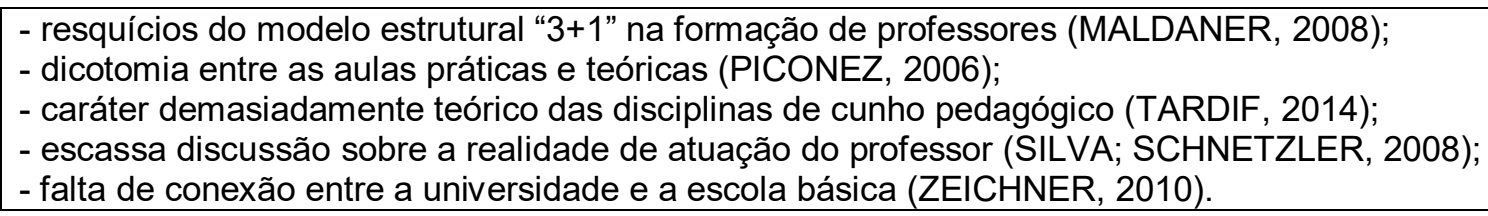

Nesse contexto, o Governo Federal implementou políticas de formação de professores no âmbito das Instituições de Ensino Superior (IES) para fomentar a formação de professores, no ano de 2007 (GATTI et al., 2014). Nesse cenário, surge o Programa Institucional de Bolsas de Iniciação à Docência (PIBID), com o objetivo de melhorar a qualidade da Educação nacional, estabelecendo parceria entre IES e as redes de Educação Básica Pública Municipais, Estaduais e Federais, para atender à formação inicial de licenciandos, relacionando o saber universitário com o saber prático da sala de aula, o que se reflete nas atividades de ensino e aprendizagem desenvolvidas nas escolas públicas e na própria IES, que seria o alvo principal do PIBID, um programa voltado à formação inicial de professores. 
Para isso, esse programa incentiva, dentre outras práticas, o estudo do contexto escolar; o desenvolvimento de ações em diferentes espaços, tais como salas de aula e laboratórios; o desenvolvimento de ações coletivas e interdisciplinares; a leitura e discussão de textos da área do ensino; o desenvolvimento, teste e avaliação de estratégias de ensino e a participação em ações da escola (CAPES-DEB, 2013).

Os resultados de várias pesquisas (STANZANI; BROIETTI; PASSOS, 2012; FELÍCIO, 2014; LIRA, 2016; LOCATELI, 2016; MARTIN; ARRUDA; PASSOS, 2016; ROSA; MENDES; OBARA; BROIETTI; PASSOS, 2017) mostram que o PIBID constitui-se em um espaço propício tanto para a interação entre licenciandos, professores da Educação Básica e os professores do Ensino Superior, como para a integração dos conhecimentos práticos profissionais ao acadêmico (Quadro 1.2).

Essas características advêm da dinâmica e estrutura dos subprojetos PIBID, os quais fomentam o trabalho colaborativo, apoiado em atividades de discussão, trocas de experiências e saberes entre bolsistas, supervisores e coordenador de área, visando a superação das problemáticas enfrentadas na escola (SANTOS; ARROIO, 2015).

\section{Quadro 1.2 - Características do PIBID para a formação de professores.}

- permite a inserção antecipada do licenciando no ambiente de sua futura atuação (LIRA, 2016).

- incentiva a interlocução entre universidade e escola (STANZANI; BROIETTI; PASSOS, 2012).

- fomenta o diálogo constante entre licenciando, coordenador de área e supervisor da escola (MARTIN; ARRUDA; PASSOS, 2016).

- admite o movimento de reflexão-ação-reflexão como pressuposto fundamental para o desenvolvimento das atividades (FELÍCIO, 2014).

- favorece a construção de conhecimentos fundamentados em teorias e práticas (ROSA; MENDES; LOCATELI, 2016).

- propicia a legitimação dos conhecimentos adquiridos no curso de formação inicial pela prática do ensino reflexivo (OBARA; BROIETTI; PASSOS, 2017).

Também constam na literatura especializada vários trabalhos referindo-se à constituição seja da identidade, seja da profissionalidade docente. Nesses trabalhos, um aspecto importante na formação dos professores de Química relaciona-se à sua constituição como profissionais ao longo de seu percurso formativo, reflexo de visões que são construídas paulatinamente sobre as questões que cercam o Ensino, a Educação e a Química. Essa visão é influenciada pelos professores da Licenciatura quer nas disciplinas, quer em projetos de Iniciação Científica, de Iniciação à Docência ou de Extensão.

Em um estudo realizado por Vogel (2016), referente à Representação Social sobre "professor de Química" de licenciandos, participantes e não participantes de subprojetos 
PIBID de várias IES brasileiras da região Sudeste do País, constatou-se haver diferenças na composição do Núcleo Central (NC) da Representação Social desses dois subgrupos. O NC, no caso dos estudantes participantes do PIBID era constituído pelos termos dedicado, experimentação e responsabilidade. No caso do grupo formado por licenciandos que não participaram do projeto os termos do NC da RS sobre esse objeto social são dedicado, experimentação e inteligente. Desses resultados pode-se inferir que as várias experiências e vivências propiciadas aos pibidianos durante seu percurso formativo foram suficientes para a modificação de sua RS sobre ser professor. Embora à primeira vista esses NC pareçam muito semelhantes, a análise de conteúdo das respostas desses alunos mostra que os termos do NC têm significados diferentes. Assim, a compreensão do termo "experimentação" está associada ao fazer científico para os licenciandos que não participaram do PIBID enquanto, para os participantes do programa, está associada à melhoria do ensino de Química.

Esse resultado mostra a importância de se buscar o significado dos termos polissêmicos nas pesquisas sobre ensino, para que se possa compreender os resultados no contexto de pesquisa. No que se refere ao Ensino de Química, esse termo é utilizado de duas formas; por um lado, como parte constitutiva da pesquisa científica nas Ciências empíricas e, por outro, como atividade prática laboratorial no processo de ensino (DUIT; TESCH, 2014). Tal polissemia conduz às diferentes representações que os graduandos em Química atribuem a esse termo, as quais refletem diferentes concepções sobre a atividade científica (GYLLENPALM; WICKMAN, 2011) e o ensino de Química (VOGEL, 2016).

Considerando o contexto descrito acima, a pergunta que norteia o desenvolvimento desta pesquisa é se haveria diferenças, em um ou vários aspectos, nas Representações Sociais sobre "experimentação" dos professores Coordenadores do PIBID e daqueles que não participam desse projeto. A identificação e compreensão destas possíveis RS podem contribuir para a reflexão acerca de como os professores coordenadores de subprojetos PIBID pensam sobre os processos de "experimentação" para o ensino e de como o fazem os professores da Licenciatura que não participam do PIBID. Este aspecto é importante pela sua possível influência nos currículos praticados nas Licenciaturas, que configuram o processo formativo inicial do futuro professor, que irá se manifestar durante sua prática em sala de aula.

\section{2 - Objetivos da Pesquisa}

O objetivo geral desta pesquisa é o de estudar as possíveis RS sobre "experimentação" dos formadores de professores de Química, participantes ou não do Programa PIBID- 
Química, para compará-las e, eventualmente, ter resultados que permitam explicar os resultados obtidos em trabalho anterior de nosso grupo de pesquisa sobre licenciandos em Química participantes desse programa.

Para isso, foram investigadas as RS dos professores de Licenciatura coordenadores ou não Coordenadores do PIBID-Química em relação à experimentação, especialmente no que se refere à composição do NC das RS dos dois subgrupos, visando compará-las para inferir se as eventuais diferenças observadas poderiam refletir-se nos processos formativos dos estudantes.

Para que se possa alcançar este objetivo geral, os objetivos específicos do trabalho são:

i) identificar possíveis Representações Sociais dos professores das Licenciaturas sobre "experimentação";

ii) identificar as possíveis Representações Sociais dos professores de Licenciaturas participantes do PIBID-Química sobre "experimentação";

iii) identificar as possíveis Representações Sociais dos professores de Licenciaturas nãoparticipantes do PIBID-Química sobre "experimentação";

iv) estabelecer aproximações e distanciamentos da Representação Social sobre "experimentação" dos professores Coordenadores do PIBID-Química com aquela daqueles não participantes desse programa.

O desenvolvimento desta Dissertação pode contribuir para as reflexões que vêm sendo feitas no Brasil sobre a formação de professores. Espera-se que seus resultados colaborem para o debate sobre a contribuição do PIBID na formação de professores, principalmente nesse momento, em que se faz necessária a defesa desta política de Estado que tem levado, em todo o Brasil, à aproximação frutífera entre a Universidade e a Escola Básica. 


\section{PROGRAMA INSTITUCIONAL DE BOLSAS DE INICIAÇÃO À DOCÊNCIA}

\section{1 - CAPES e DEB, ações para a Formação de Professores}

A Coordenação Nacional de Aperfeiçoamento de Pessoal de Nível Superior (CAPES) foi criada pelo Decreto no 29.741, de 1951 tendo, como um dos seus idealizadores e primeiro secretário-geral, Anísio Teixeira. Com o objetivo de suprir a demanda por pessoal especializado, uma das primeiras ações da CAPES foi o apoio ao trabalho universitário e de alta especialização, impulsionando o processo de consolidação e valorização da pósgraduação no Brasil para, assim, atender as demandas da sociedade, tanto da esfera pública, quanto privada (GOUVÊA, 2010).

No ano de 2007, passadas cinco décadas desde sua criação, a CAPES recebe novas atribuições, por meio da Lei no 11.502 de 11 de julho de 2007, que modifica suas competências e estrutura organizacional. Além de gerir o Sistema Nacional de PósGraduação, essa agência passa a ter o objetivo de fomentar e elaborar políticas de desenvolvimento de atividades para a formação inicial e continuada de profissionais da Educação Básica e estimular a valorização do magistério em todos os níveis e modalidades de ensino. Uma das primeiras ações implementadas foi a de autorizar a concessão de bolsas de estudo e de pesquisa a participantes de programas de formação inicial e continuada de professores para a Educação Básica, como indicado no $\S 2^{\circ}$ do Art. $2^{\circ}$ da Lei no 11.502 de 11 de julho de 2007

No âmbito da educação básica, a Capes terá como finalidade induzir e fomentar, inclusive em regime de colaboração com os Estados, os Municípios e o Distrito Federal e exclusivamente mediante convênios com instituições de ensino superior públicas ou privadas, a formação inicial e continuada de profissionais de magistério, respeitada a liberdade acadêmica das instituições conveniadas [...] (BRASIL, 2007).

Para atender às novas responsabilidades, foram criadas duas diretorias: a Diretoria de Educação à Distância (DED) e a Diretoria de Educação Básica Presencial (DEB), alteradas, em 2012, pelo Decreto no 7.692, de 2 de março, para Diretoria de Formação de Professores da Educação Básica, mas mantendo sua sigla e funções (CAPES-DEB, 2014).

Em 2013, visando implementar uma política de Estado voltada à formação inicial e continuada, a DEB organiza seus principais programas (Quadro 2.1) segundo quatro linhas de ação, considerando diferentes momentos da formação docente, que abrangiam sua formação inicial e continuada. 
Quadro 2.1 - Programas executados pela DEB, entre os anos de 2007 e 2014.

\begin{tabular}{|c|c|}
\hline Linhas de Ação & Programas \\
\hline Formação Inicial & $\begin{array}{ll}\checkmark & \text { Programa Institucional de Bolsas de Iniciação à Docência (PIBID) } \\
\checkmark & \text { Plano Nacional de Formação de Professores da Educação Básica } \\
& \text { (PARFOR) } \\
\checkmark & \text { Laboratórios Interdisciplinares de Formação de Educadores (LIFE) }\end{array}$ \\
\hline $\begin{array}{l}\text { Formação Continuada } \\
\text { e Extensão }\end{array}$ & $\begin{array}{ll}\checkmark & \text { Programa Novos Talentos } \\
\checkmark & \text { Programa de Consolidação das Licenciaturas (PRODOCÊNCIA) } \\
\checkmark & \text { Cooperação Internacional para Professores da Educação Básica - } \\
& \text { Programa de Desenvolvimento Profissional para Professores } \\
& \text { (PDPP) } \\
\checkmark & \text { Formação dos Professores das Olimpíadas de Matemática e } \\
& \begin{array}{l}\text { Química } \\
\checkmark\end{array} \\
\text { Programas Especiais de Apoio à Docência }\end{array}$ \\
\hline $\begin{array}{l}\text { Formação Associada à } \\
\text { Pesquisa }\end{array}$ & $\begin{array}{ll}\checkmark & \text { Observatório da Educação (OBEDUC) } \\
\checkmark & \text { Observatório da Educação Escolar Indígena }\end{array}$ \\
\hline Divulgação Científica & $\begin{array}{ll}\checkmark & \text { Programa de Apoio a Feiras de Ciências e Mostras Científicas } \\
\checkmark & \text { Programa de Apoio a Olimpíadas Científicas }\end{array}$ \\
\hline
\end{tabular}

Fonte: CAPES-DEB (2014).

Vários desses programas (Quadro 2.1) articulam mais de uma linha de ação, mas o PIBID é o único que envolve as quatro linhas, pois "é um programa de formação inicial para os alunos de licenciatura mas, para coordenadores e supervisores, pode adquirir o caráter de formação continuada e gerar ações de pesquisa, extensão e divulgação científica" (CAPES-DEB, 2014, p. 15).

Outra característica relevante é a dimensão do PIBID. De 3.088 bolsas disponibilizadas em 2007, há um crescimento de cerca de 30 vezes na abrangência do programa até 2013, quando são implementadas 90.254 bolsas. O PIBID sofre uma redução de bolsas, em 2014, para 81.993, em 2016, para 73.300 bolsas e em 2018 há uma limitação do número de bolsas para no máximo 45 mil (CAPES-DEB, 2014, 2018c; CAPES-MEC, 2016; 2017). Em 2014, das 316 IES contempladas com um ou mais programas da DEB, o PIBID esteve presente em 313 (tendo uma limitação de até 350 IES no Edital e 2018; CAPES-DEB, 2018c), o que indica seu potencial como indutor para a formação de professores (CAPESDEB, 2014).

\section{2 - A construção do PIBID a partir das Portarias Normativas}

Em 2007, em uma ação do Ministério da Educação, por intermédio da CAPES e do Fundo Nacional de Desenvolvimento da Educação (FNDE), implementa-se o Programa Institucional de Bolsas de Iniciação à Docência (PIBID) por meio da Portaria Normativa no 38, de 12 de dezembro de 2007 (MEC-CAPES-FNDE, 2007). Esta Portaria esclarece, dentre outras coisas, que a implementação do PIBID visa incentivar a formação de 
professores para a Educação Básica e valorizar o magistério, promovendo a melhoria da qualidade da Educação Básica. Esta Portaria restringiu-se aos cursos de formação de professores das Instituições Federais de Educação Superior. A prioridade de atendimento foram os cursos de formação de professores de Química, Física, Biologia e Matemática voltados para a atuação no Ensino Médio, em consequência da carência desses profissionais qualificados para atuarem nessas disciplinas, em muitas regiões do País.

A implementação do PIBID foi sistematizada através de convênios entre as Instituições Federais de Educação Superior e a CAPES. Esses convênios concediam bolsas de Iniciação à Docência (alunos dos cursos de Licenciaturas), para o professor supervisor (professor do Ensino Básico) e para o professor coordenador (professor do Ensino Superior). Os alunos de licenciatura recebem essas bolsas para exercer atividades pedagógicas nas escolas públicas de Educação Básica; a função do coordenador é a de orientar os alunos nas atividades desenvolvidas na universidade em sintonia com os professores da Escola Básica que orientam os licenciandos nas escolas onde eles atuam. Assim, potencialmente, o PIBID contribui para a articulação entre teoria e prática, universidade e escola e formadores e licenciandos.

Porém, não ficam explícitas as atribuições dos bolsistas. No caso do professor coordenador, há mais requisitos do que atribuições, como pode ser observado no trecho abaixo. O professor coordenador deverá

I - pertencer ao quadro efetivo da instituição; II - ser, preferencialmente, docente de curso de licenciatura; III - possuir experiência mínima de três anos no magistério superior; e IV - selecionar os professores supervisores dos bolsistas de iniciação à docência, necessariamente com prática de sala de aula na educação básica (MEC-CAPES-FNDE, 2007, p. 39).

Destaca-se que não havia especificações quanto às competências do professor coordenador, exigindo-se apenas que pertencesse ao quadro efetivo da Instituição com, no mínimo, três anos de experiência no Ensino Superior.

Do primeiro edital (2007) até o ano de 2018, houve algumas alterações nos aspectos inerentes ao Programa. Em 2009, é lançada a Portaria no 122 de 16 de setembro de 2009, essa portaria aponta as diretrizes para o PIBID, ampliando sua atuação para outras licenciaturas, assim como para as Instituições Estaduais de Ensino Superior. Insere o Coordenador Institucional e esclarece que as atribuições e os requisitos dos bolsistas serão definidos em edital, segundo as normas da CAPES (CAPES-DEB, 2009).

A Portaria no 72, de 09 de abril de 2010, amplia a atuação do PIBID às IES Públicas Municipais e Universidades e centros comunitários filantrópicos, confessionais e comunitários, sem fins lucrativos; dá prioridade às instituições que participaram de 
programas estratégicos do MEC como o Exame Nacional de Desempenho de Estudantes (ENADE), Programa de Apoio a Planos de Reestruturação e Expansão das Universidades Federais (REUNI) e programas de valorização do magistério (CAPES-DEB, 2010a).

A Portaria no 136, de 01 de julho de 2010, altera a modalidade de aplicação da dotação orçamentária referente ao PIBID, ampliando o orçamento. Essa medida visou o atendimento às Instituições Municipais e Particulares, através de convênios (CAPES- DEB, 2012).

A Portaria n 260, de 30 de dezembro de 2010, aprova as normas gerais do PIBID, apresentando de forma mais clara e detalhada os requisitos e atribuições dos bolsistas, além de incluir o Coordenador de Área de Gestão de Processos Educacionais, responsável por apoiar o Coordenador Institucional no desenvolvimento do projeto institucional (CAPESDEB, 2010b). Por exemplo, as atribuições do Coordenador de área estão apresentadas no Quadro 2.2.

\section{Quadro 2.2 - Atribuições do Coordenador de Área.}

I. responder pela coordenação geral do subprojeto de área perante a coordenação institucional;

II. fazer um diagnóstico da situação de sua área de conhecimento na rede pública do estado e município;

III. garantir, acompanhar e registrar o planejamento, a organização e a execução das atividades previstas no subprojeto;

IV. constituir e participar de comissões de seleção de bolsistas de iniciação à docência e de Supervisores para atuarem no subprojeto;

V. orientar e acompanhar a atuação dos bolsistas de iniciação à docência, inclusive a frequência às atividades e atuar conjuntamente com os Supervisores das escolas envolvidas, sempre no âmbito do subprojeto que coordena;

VI. apresentar ao Coordenador Institucional relatório anual contendo descrições, análise e avaliação do desenvolvimento do subprojeto que coordena;

VII. manter o Coordenador Institucional informado de toda e qualquer substituição, inclusão ou desistência de Supervisores, bem como de bolsistas de iniciação à docência de sua área;

VIII. elaborar relatórios sobre o subprojeto, informando sobre a participação dos Supervisores, repassando-os ao Coordenador Institucional do projeto;

IX. garantir a capacitação dos Supervisores nas normas e nos procedimentos do PIBID bem como sua participação em eventos e em atividades de formação dos futuros docentes, assegurando-lhes oportunidades de desenvolvimento profissional;

X. realizar o acompanhamento técnico-pedagógico do subprojeto sob sua coordenação;

XI. participar de reuniões e seminários locais e regionais do Programa Institucional de Bolsa de Iniciação à Docência (PIBID), realizando todas as atividades previstas, tanto presenciais quanto à distância, quando convocados; e

XII. enviar ao Coordenador Institucional do projeto documentos de acompanhamento das atividades dos bolsistas de iniciação à docência sob sua orientação, sempre que solicitado.

Fonte: CAPES-DEB (2010b p. 8). 
Analisando-se o Quadro 2.2 percebe-se que o Coordenador de Área é responsável pelo planejamento das atividades dentro e fora da escola e pela articulação das ações do subprojeto nos dois espaços, Universidade e Escola, as quais envolvem três atores, o Coordenador de Área, o licenciando-bolsista e o supervisor, que é um professor da escola básica. Assim, o Coordenador de Área tem um papel importante na definição das ações e procedimentos do subprojeto que coordena, como mostrado na Figura 2.11.

Figura 2.1 - Interações e espaços de atuação do Coordenador de Área.

Programa Institucional de Bolsas de Iniciação à Docência

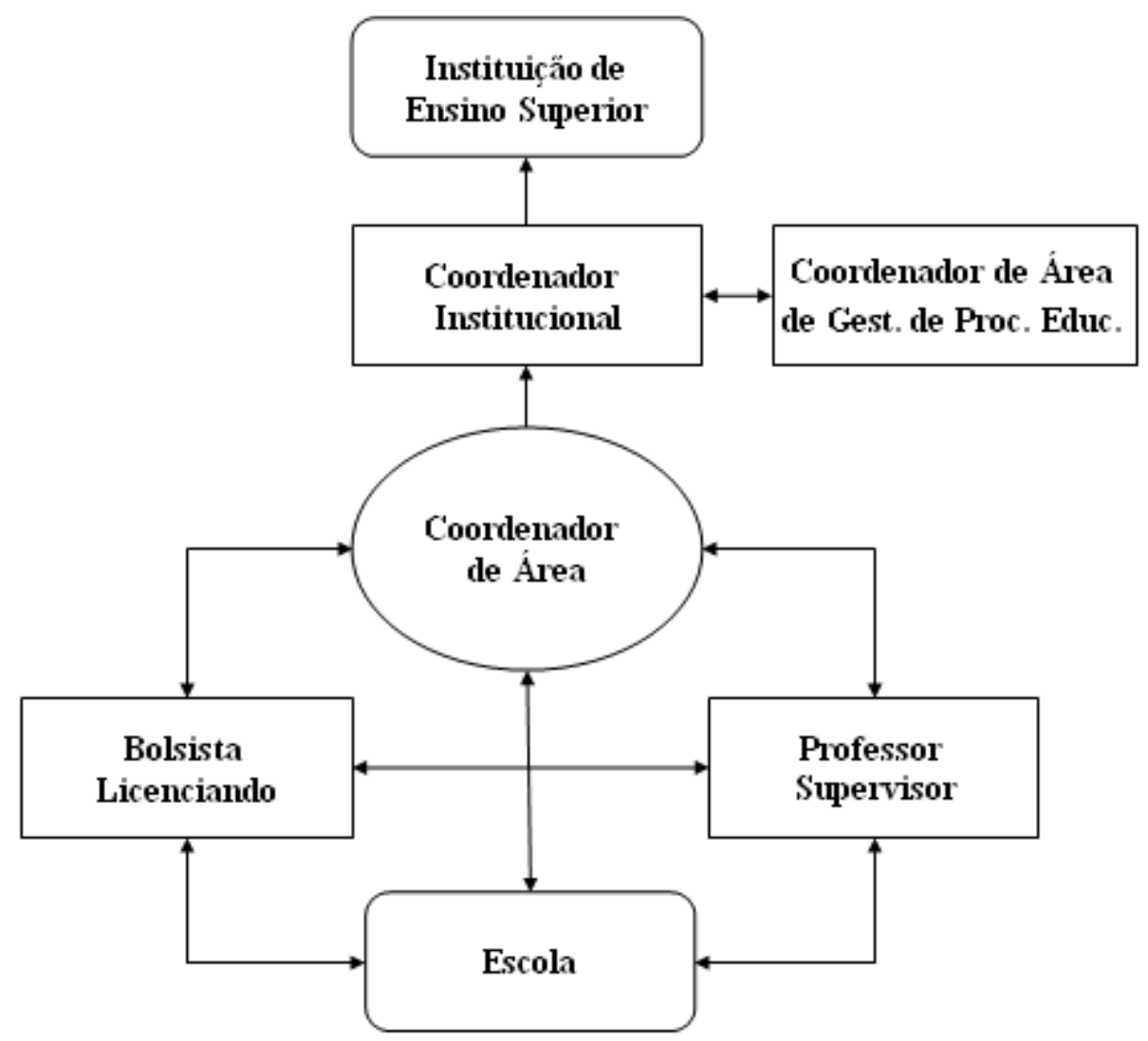

A Portaria no 96, de 18 de julho de 2013, estabelece novas normas para o PIBID, visando regulamentar a ação do programa. Na nova configuração, podem participar, além das instituições já mencionadas, as instituições de direito privado que têm como público alunos do Programa Universidade para Todos (PROUNI; CAPES-DEB; 2010a). Este é um ponto crítico no público-alvo do PIBID, que inicialmente atendia apenas IES Federais, foi progressivamente sendo alterado até contemplar instituições de direito privado. $\mathrm{O}$ resultado

${ }^{1}$ O Coordenador de Área de Gestão de Processos Educacionais não foi incluído na Portaria no 175 , de 7 de agosto de 2018 como um dos atores do PIBID. 
disto é que em 2014 as instituições privadas com e sem fins lucrativos representam 18\% das concessões do PIBID, o que refletia em 47\% das IES parceiras (GIMENES, 2016).

Ainda, há duas portarias; a primeira delas é a Portaria no 46, de 11 de abril de 2016, que muda o regulamento do PIBID na tentativa de agrupá-lo a outros programas que visam à melhoria da qualidade da Educação Básica. Porém, houve resistência das Universidades, pois essa nova configuração descaracterizava o PIBID ao priorizar o reforço escolar e a melhoria dos índices de aprendizagem em detrimento da formação do licenciando. Assim, a Portaria no 46 é revogada pela Portaria no 84, de 15 de junho de 2016 (CAPES-DEB, 2016a; 2016b).

A Portaria no 175 , de 7 de agosto de 2018, regulamenta a concessão de bolsas e o regime de colaboração no âmbito do Programa de Residência Pedagógica² e no PIBID, sendo desenvolvidos em regime de colaboração entre o Governo Federal (por meio da CAPES), Estados e municípios (CAPES-DEB, 2018b). Essa é a portaria em que houve um número maior de modificações quanto às especificidades do PIBID. Dentre as principais modificações está a retirada do coordenador de área Coordenador de Área de Gestão de Processos Educacionais, a ampliação do público-alvo para o Sistema Universidade Aberta do Brasil (UAB), a limitação a 45 mil bolsas ${ }^{3}$, o limite de até 350 IES, a obrigatoriedade do bolsista licenciando estar matriculado na primeira metade do curso de Licenciatura (discente que não tenha concluído mais de $60 \%$ da carga horária regimental do curso), a limitação em até 18 meses para a permanência do bolsista licenciando e a possibilidade institucionalizada da participação do licenciando sem a remuneração da bolsa (CAPES-DEB, 2018b, 2018c).

De modo geral, ao analisarem-se as Portarias que normatizam o PIBID, constata-se que, embora os objetivos sofreram poucas mudanças, houveram diversas alterações em sua organização (Quadro 2.3) e sua estrutura. O Programa ainda incentiva a formação de professores para a Educação Básica e a valorização do magistério visando promover a melhoria da qualidade da Educação Básica, como previsto já na implementação do programa na Portaria Normativa no 38, de 12 de dezembro de 2007, permanecendo na Portaria no 96, de 18 de julho de 2013 e na atual Portaria no 175 de 7 de agosto de 2018, a

\footnotetext{
2 O Programa de Residência Pedagógica foi instituído por meio da Portaria no 38 , de 28 de fevereiro de 2018. A implementação deste programa teve como objetivo dar o apoio às IES na implementação de projetos que estimulem a articulação entre teoria e prática nos cursos de licenciatura. Para tanto, o programa concede bolsas para o Residente, Coordenador Institucional, Docente Orientador e o Preceptor. O Residente é o licenciando matriculado em curso de licenciatura e que tenha cursado no mínimo $50 \%$ do curso, o Coordenador Institucional é o docente da IES responsável pelo projeto institucional de Residência Pedagógica, o Docente Orientador é o docente que orientará o estágio dos residentes estabelecendo a relação entre teoria e prática e o Preceptor, é o professor da escola de educação básica que acompanhará os residentes na escola-campo (CAPES-DEB, 2018a).

${ }^{3}$ Outras 45 mil bolsas foram disponibilizadas para o Programa de Residência Pedagógica (CAPESDEB, 2018d).
} 
qual detalha ações mais específicas, pertinentes à aprendizagem da docência. Porém, é necessário se discutir e investigar o possível impacto que as alterações mencionadas possa ter na formação inicial dos professores.

Quadro 2.3 - Comparação entre aspectos das Portarias 2007, 2013 e 2018.

\begin{tabular}{|c|c|c|c|}
\hline & $\begin{array}{l}\text { Portaria no } 38, \text { de } \\
12 / 12 / 2007\end{array}$ & $\begin{array}{c}\text { Portaria no } 96 \text { de } \\
18 / 07 / 2013\end{array}$ & Portaria no 175 de 07/08/2018 \\
\hline Projeto & Não existe limitação & 1 por IES & 1 por IES \\
\hline Subprojeto & Não existe limitação & $\begin{array}{l}1 \text { por licenciatura em } \\
\text { cada campus e os } \\
\text { interdisciplinares }\end{array}$ & $\begin{array}{l}1 \text { por licenciatura em cada campus } \\
\text { e os interdisciplinares }\end{array}$ \\
\hline $\begin{array}{l}\text { Coord. } \\
\text { Institucional }\end{array}$ & Não consta & 1 por projeto & $\begin{array}{l}1 \text { por projeto, especifica a } \\
\text { competência técnica }\end{array}$ \\
\hline $\begin{array}{l}\text { Coord. de } \\
\text { Gestão }\end{array}$ & Não consta & 1 por projeto & Não consta \\
\hline $\begin{array}{l}\text { Coord. de } \\
\text { Área }\end{array}$ & $\begin{array}{l}\text { Não existe } \\
\text { limitação, não } \\
\text { especifica a } \\
\text { competência } \\
\text { técnica }\end{array}$ & $\begin{array}{l}\text { Mínimo de } 1 \text { por } \\
\text { subprojeto, especifica a } \\
\text { competência técnica }\end{array}$ & 1 por subprojeto \\
\hline $\begin{array}{l}\text { Prof. } \\
\text { Supervisor }\end{array}$ & Não existe limitação & $\begin{array}{l}\text { Mínimo de } 1 \text { por } \\
\text { subprojeto }\end{array}$ & 3 por subprojeto \\
\hline $\begin{array}{l}\text { Bolsista } \\
\text { Licenciando }\end{array}$ & Não existe limitação & $\begin{array}{l}\text { Mínimo de } 5 \text { por } \\
\text { subprojeto }\end{array}$ & $\begin{array}{l}\text { Mínimo de } 24 \text { e máximo de } 30 \text { por } \\
\text { subprojeto, sendo que é possível } \\
\text { que dentro dessa quantidade } \\
\text { contemple até } 6 \text { voluntários }\end{array}$ \\
\hline Licenciaturas & $\begin{array}{l}\text { Preferência: Física, } \\
\text { Química, } \\
\text { Matemática e } \\
\text { Biologia }\end{array}$ & $\begin{array}{l}\text { Atende a todas as } \\
\text { Licenciaturas }\end{array}$ & Atende a todas as Licenciaturas \\
\hline Escolas & $\begin{array}{l}\text { com baixos índices } \\
\text { no IDEB ou baixas } \\
\text { médias no ENEM }\end{array}$ & $\begin{array}{l}\text { com baixos índices no } \\
\text { IDEB ou com } \\
\text { experiências bem- } \\
\text { sucedidas }\end{array}$ & Da Rede Pública de Ensino \\
\hline
\end{tabular}

As alterações fizeram-se necessárias pelo expressivo crescimento do Programa e sua modificação, de política de governo, para política de Estado, pela Lei 12.796, de abril de 2013, que insere o PIBID como uma das políticas da Lei de Diretrizes e Bases da Educação Brasileira (LDB), um novo marco para o programa (CASA CIVIL, 2013).

Estudos (CAPES-DEB, 2012; 2013, 2014) envolvendo mais de dois mil depoimentos, questionários e relatórios anuais dos Coordenadores de área do PIBID enviados para a DEB apontam que esse programa tem proporcionado aos Coordenadores de área oportunidades de desenvolvimento profissional. Os resultados desses trabalhos foram corroborados por um amplo estudo (GATTI et al., 2014) cujo objetivo era o de contribuir para a melhor 
compreensão do papel do PIBID, pela análise qualitativa de respostas a questionários contendo questões abertas e de múltipla escolha, que foram disponibilizadas on-line pela CAPES para Supervisores, Coordenadores de Área, Coordenadores Institucionais e Licenciandos Bolsistas. Foram analisadas as respostas de 1.486 Coordenadores de área.

As principais contribuições do PIBID para a formação do Coordenador de área, segundo sua própria perspectiva, estão sumariadas no Quadro 2.4 .

Quadro 2.4 - Contribuição do PIBID para formação continuada dos Coordenadores de Área.

Assim, a participação no PIBID, dentre outros aspectos, contribui para

a. a formação continuada e o desenvolvimento profissional do docente, pois contribui para sua atualização quanto aos aspectos pedagógicos das disciplinas e das tecnologias, criando, devido à aproximação do contexto escolar, o estímulo para a busca de soluções para o ensino e para o atendimento das ocorrências escolares;

favorece o desenvolvimento de novas compreensões sobre educação, escola e práticas educativas pela aproximação de professores e licenciandos com a escola.

conduz à adoção de novas linguagens e tecnologias da informação e comunicação e ao incentivo à inovação nas ações de formação de professores

favorece sua aproximação à realidade e às necessidades da Escola Básica, propiciando novas visões sobre o ensino e a prática docente;

b. o diálogo com as escolas;

c. o questionamento sobre a qualidade das práticas formativas no âmbito da docência na própria IES, que promove a revisão dos projetos pedagógicos das disciplinas ofertadas nas Universidades devido à modificação de posturas em relação ao curso de licenciatura: maior interesse, participação e novas perspectivas sobre a relação teoria-prática;

d. a produção, publicação e apresentação de artigos científicos sobre a formação de professores;

e. a elevação da auto-estima e o reconhecimento entre os pares.

Fonte: CAPES-DEB $(2012,2013,2014)$, Gatti et al., (2014), adaptado.

Silva (2015) investigou os impactos da participação no PIBID sobre o desenvolvimento profissional de 11 coordenadores de subprojetos PIBID-Física. Para a obtenção das informações realizou-se entrevistas semiestruturadas. A análise das entrevistas possibilitou a criação de quatro categorias: i) a parceria universidade-escola; ii) as articulações com a pesquisa; iii) a relação com a instituição universitária; e iv) os impactos na própria prática como formador de professores. Os resultados mostram que a coordenação dos subprojetos PIBID possibilita que esses sujeitos reflitam sobre a sua formação e sobre a formação dos licenciandos, o que resulta na transformação de suas práticas formativas a partir dessas reflexões, e que incorporem resultados obtidos por meio das ações do PIBID em suas pesquisas. Essas mudanças foram consequência, principalmente, do trabalho colaborativo 
realizado com os supervisores e do conhecimento obtido sobre a realidade das escolas de Educação Básica por meio das ações desenvolvidas no PIBID.

Portanto, enquanto por um lado, os Coordenadores de Área passam por um processo de formação continuada, repensando as ações e estratégias de ensino e suas concepções sobre Educação, por outro, são os responsáveis diretos pela execução do subprojeto, planejamento de atividades e auxílio aos bolsistas licenciandos e por relatar as ações ao Coordenador Institucional. Nesse contexto é de se supor que as Representações Sociais sobre "experimentação" dos Coordenadores de Área orientem a ampla e complexa rede de ações desenvolvidas no PIBID, influenciando o processo formativo vivenciado pelos licenciandos que participam dos subprojetos que coordenam. 


\section{EXPERIMENTAÇÃO}

Neste Capítulo, serão apresentadas as percepções sobre as características das Ciências de estudantes da Educação Básica, de graduandos e pós-graduandos e de professores. Apresentam-se, também, as características das atividades experimentais, enfatizando-se as atividades experimentais de cunho investigativo e os resultados de algumas pesquisas. Por último, são apresentados os objetivos das atividades experimentais e as problemáticas relatadas nas pesquisas da área quanto ao seu desenvolvimento na Educação Básica.

\subsection{As características das Ciências}

As visões de estudantes e de professores acerca das características das Ciências são o objeto de pesquisa de vários estudos da área de Ensino de Ciências (HASHWEH,1996; HARRES, 1999; KOSMINSKY; GIORDAN, 2002; SIMÕES; SIMÕES, 2009; MELO; TENÓRIO; ACCIOLY, 2010; SILVA; CUNHA, 2012; UCAR, 2012; LEMES, 2013; GOLDSCHIMIT; GOLDSCHIMIT; LORETO, 2014; PEREIRA, 2016; 2016b; AZEVEDO; SCARPA, 2017). Os resultados dessas pesquisas mostram três aspectos importantes para o Ensino de Ciências. Primeiro, as concepções sobre as características das Ciências têm, muitas vezes, um caráter ingênuo, remetendo a visões idealistas ou empiristas acerca da atividade científica, não obstante a faixa etária e o nível de escolaridade dos sujeitos. Essa percepção foi identificada para os casos de alunos do Ensino Fundamental, do Ensino Médio, de graduandos, de pós-graduandos e de professores do campo das Ciências Naturais. Para grande parte desses sujeitos, há predominância da perspectiva do caráter experimental da Ciência, ligado à imagem do laboratório, espaço em que se realizam atividades vistas como sinônimo de uma sequência pré-determinada de passos na realização dos experimentos, visando a obtenção de verdades ou a comprovação de teorias.

O segundo aspecto relaciona-se às variações observadas nas concepções. Embora haja um núcleo comum em relação às características das Ciências compartilhado pelos sujeitos, há pequenas mudanças nessas percepções ao longo do seu percurso formativo. Essas mudanças ocorrem no sentido da incorporação de novas características às características já existentes; fazendo com que as percepções dos sujeitos em relação às características das Ciências fossem menos empiristas. Por exemplo, a partir da transição ao longo da escolaridade dos sujeitos, vão-se integrando à sua percepção ideias que sinalizam os conceitos científico-escolares. Outra evidência disso foi observada para os estudantes de cursos de formação de professores e os próprios professores. Para esses, houve não só a integração de novos termos à sua estrutura representacional, quanto às características da 
Ciência, que sinalizam os conceitos científico-escolares, como também termos que remetem ao processo de ensino e aprendizado.

Por fim, embora não sejam consensuais, as pesquisas apontam para uma relação entre as concepções epistemológicas dos professores sobre a Ciência e suas concepções pedagógicas sobre o Ensino de Ciências. Essa relação influencia as estratégias e ações que o professor desenvolve em sala de aula, sendo, também, necessário levar em consideração as características do contexto de ensino. A análise dos artigos mostra que a experimentação apresenta um aspecto central nas concepções epistemológicas dos professores sobre as Ciências Naturais sendo, portanto, importante investigar suas concepções sobre as atividades experimentais no Ensino de Ciências. Os resultados desses artigos serão descritos a seguir.

\subsubsection{Percepções de estudantes de Nível Básico}

Dentre essas pesquisas, Harres (1999) salienta que, entre os anos 1960 e 1980, houve uma profusão de pesquisas que investigavam as concepções acerca da Natureza da Ciência ( $\mathrm{NdC}$ ). Essas pesquisas se concentraram em quatro grandes eixos, concepções de estudantes sobre a NdC, concepções permeadas nos currículos de Ciências, concepções de professores e a tríplice relação entre a concepção do professor, sua práxis e a concepção dos estudantes. Por um lado, os resultados dessas pesquisas mostram uma aproximação entre as concepções dos estudantes, as dos professores e o currículo de Ciências no que se refere a uma visão empírico-indutivista da Ciência, em que a proposição de leis e teorias, que são a base para se realizarem previsões e para o planejamento de novos experimentos, apoia-se fortemente na experimentaçãos; por outro lado, não estão claras as relações entre as concepções dos professores e suas práticas de ensino (HARRES, 1999), embora seja de se supor que elas existam.

Com relação à visão dos estudantes sobre os aspectos da Ciência, Goldschmidt, Goldschmidt e Loreto (2014) investigaram as concepções sobre "cientista" e "Ciência" de 25 estudantes do $2^{\circ}$ ano e 48 estudantes do 3 o ano do Ensino Fundamental. Para tanto, os autores solicitaram aos sujeitos de pesquisa que escrevessem o que entendiam sobre os termos "cientista" e "Ciência" e, posteriormente, foi solicitado que registrassem, em uma folha de ofício, a descrição por meio de desenhos. Os resultados desse estudo mostram, por um lado, que esses estudantes compreendem a Ciência como uma atividade experimental realizada em um local específico, o laboratório, com equipamentos sofisticados, como o microscópio. Mas, em contrapartida, a Ciência é representada pelos conteúdos disciplinares das aulas de Ciências Naturais, sendo a disciplina Biologia a mais expressiva. 
Simões e Simões (2009) utilizando a abordagem estrutural das RS chegaram a resultados similares ao investigarem a RS sobre "cientista", "Ciência" e "tecnologia" de 527 estudantes do Ensino Fundamental (6ำ ao 9 ano). A RS sobre Ciência desses estudantes remete-se ao "cientista", um sujeito responsável por "descobertas" e "invenções". Esta atividade é realizada em um local específico, o laboratório, local onde a realização das ações como "estudo" e o "experimento" são viáveis por haver equipamentos apropriados, por exemplo, o microscópio. O objetivo da atividade científica é a produção de remédios e de invenções, ligadas à tecnologia e à elaboração de "ferramentas" para o uso social.

Kosminsky e Giordan (2002) investigando a concepção de "Ciência" e do fazer científico de 15 estudantes do Ensino Médio, verificando que a compreensão desses sujeitos remetia a características reducionistas das Ciências, com predominância do caráter experimental, desconsiderando-se a troca de informações entre pares, as elaborações teóricas e as próprias Ciências não experimentais; observou-se, também, a predominância da figura do cientista como sendo do sexo masculino, solitário e interagindo somente com seu mundo.

Resultados similares foram apontados pela pesquisa desenvolvida por Pereira e Rezende (2016), a qual utilizou o aporte teórico-metodológico da abordagem estrutural das RS para investigar a RS sobre "Química" de 186 estudantes do Ensino Médio, modalidade de Educação de Jovens e Adultos (EJA). Pôde-se identificar que os termos constituintes do NC da RS desses estudantes sobre o termo indutor investigado eram: remédios, oxigênio, $\mathrm{H}_{2} \mathrm{O}$, transformação, elemento químico, massa e moléculas. Percebe-se que a RS desses estudantes sobre Química remete ao conteúdo científico-escolar da Química, sugerindo a necessidade da reformulação do currículo de forma a favorecer a contextualização dos conceitos aprendidos pois apenas remédios refere-se a algum aspecto da vivência desses estudantes.

\subsubsection{Percepções de estudantes de Nível Superior}

Em outro estudo, Pereira (2016) investigou como licenciandos em Química representam o termo "Química". Para isso, aplicou-se um questionário semiestruturado planejado com base na abordagem estrutural das RS para 148 estudantes, que apresentavam diferentes graus de integralização do curso de Licenciatura. Os resultados desse trabalho mostram que os termos constituintes do NC de sua RS eram: reações, experimentos, transformações, laboratório e átomo. A RS sobre Química desses estudantes remete à Química como uma Ciência, mas de uma forma genérica, em que se ressalta a característica experimental que o grupo possui acerca da Química. 
Em pesquisa já relatada, que objetivava comparar as concepções sobre Ciências de estudantes do Ensino Fundamental e estudantes de cursos de formação de professores, Goldschmidt, Goldschmidt e Loreto (2014) investigaram 89 estudantes do curso Normal e 31 estudantes do curso de Pedagogia. Os resultados apontam que as concepções desses estudantes é a da Ciência do caráter experimental, que se relaciona à imagem do laboratório como local apropriado para a realização de uma descoberta ou solução de um problema. Para esses sujeitos, o conhecimento científico é desenvolvido de forma sistemática, metódica e crítica visando torná-lo demonstrável e universal. Esses sujeitos ressaltaram, ainda, conteúdos da Ciência que são ensinados na escola, mostrando a relação entre a Ciência e o Ensino de Ciências. Porém, enquanto para os estudantes do curso Normal, o Ensino de Ciências ganha destaque em relação aos aspectos da Ciência, para os estudantes do curso de Pedagogia a Ciência tem uma relação com a tecnologia.

Colagrande, Martorano e Arroio (2016) investigaram as concepções de 21 licenciandos em Física, Química e Biologia sobre a construção do conhecimento científico, o trabalho dos cientistas e a relação entre ciência e sociedade. Para tanto, solicitou-se que esses licenciandos expressassem de diversas maneiras (desenhando, diagramando ou até mesmo escrevendo) suas concepções sobre a NdC quanto a 5 temas: i) a Ciência na vida humana; ii) a construção do conhecimento científico; iii) o trabalho de um cientista; iv) a relação entre Ciência e Tecnologia; e v) Ciência e Sociedade. Dois terços dos entrevistados estão na fase final do curso. Os resultados dessa pesquisa mostram que os licenciandos relacionam a Ciência e Sociedade e Ciência e vida humana de forma utilitarista, um empreendimento que visa fornecer benefícios para os seres humanos. Para isso, os cientistas trabalham no laboratório, por meio de uma sequência de etapas (o método científico) visando realizar descobertas, provar teorias ou produzir novas tecnologias. A tecnologia apresenta grande importância, pois possibilita o aprimoramento das ferramentas utilizadas pelos cientistas, auxiliando no seu trabalho. Outra característica mencionada pelos licenciandos foi a possibilidade de os cientistas cometerem erros, o que torna a reflexão de grande importância em sua atividade.

Melo, Tenório e Accioly (2010) investigarem a RS sobre "Ciência" de 26 concluintes de Licenciatura em Física (5 ano). Para tanto, utilizaram a abordagem estrutural das RS e verificaram que a RS sobre Ciência desses sujeitos está centrada em uma visão idealista da Ciência, em que, a partir da dúvida e com persistência, as teorias se desenvolvem e descobertas são realizadas. Os termos alocados na zona periférica da RS indicam a existência de uma visão empirista da Ciência, uma vez que o desenvolvimento da Ciência é atrelado à atividade experimental, visando à comprovação científica; sendo a curiosidade a 
mola propulsora para a formulação de hipóteses e a realização de testes. Foi identificado, ainda, que os termos alocados na zona de contraste refletiam a visão de um Ensino de Ciências interdisciplinar, em que se compreende que a interação entre disciplinas e o domínio da linguagem científica são importantes para o bom desenvolvimento do Ensino de Ciências.

Azevedo e Scarpa (2017) investigaram as concepções sobre NdC de 691 graduandos em Biologia. Para tanto, utilizaram um questionário contextualizado cujo tema é a pesquisa em Ecologia. Os principais resultados dessa investigação sugerem que as concepções dos graduandos sobre a $\mathrm{NdC}$ não variam entre os diferentes momentos da formação. A participação dos graduandos em projetos de iniciação científica também não foi um fator que contribuiu para a modificação dessas concepções. Além disso, os graduandos que cursavam apenas a licenciatura apresentaram concepções de $\mathrm{NdC}$ menos informadas dentre os 11 aspectos de $\mathrm{NdC}$ investigados, relacionados à instrumentação e às práticas experimentais, em comparação a um grupo de bacharelandos e, outro grupo, formado de bacharelandos e licenciandos.

Enquanto as pesquisas anteriores visavam, de um modo geral, identificar em que medida estudantes do Ensino Básico e do Ensino Superior das diferentes áreas das Ciências da Natureza ou da formação de professores compreendiam os diversos aspectos dessa Ciência, Lemes (2013) investigou as concepções sobre aspectos da filosofia da Química de 10 doutorandos em Química. Os resultados dessa pesquisa mostram que os doutorandos apresentam uma concepção da Química apoiada em radicalizações de aspectos componentes da $\mathrm{NdC}$, por exemplo, o empirismo extremo. Outra característica identificada foi o caráter peculiar que os experimentos desempenham para a construção do conhecimento químico: os fenômenos investigados através dos experimentos produzem evidências concretas e sensíveis, fazendo com que as teorias ganhem ampla aceitação na comunidade científica e que os químicos adotem uma postura realista com relação aos átomos e moléculas. Por fim, esses doutorandos compreendem que o fazer química e o ensinar química necessitam de aportes filosóficos diferentes; enquanto para fazer química pode-se ser realista sem que haja grande prejuízo aos objetivos pretendidos, para se ensinar química, em contrapartida, seria necessária maior reflexão sobre diferentes posicionamentos filosóficos, de forma a apresentar aos alunos alguma abordagem sobre a epistemologia do conhecimento químico, incluindo eventuais controvérsias na construção desse conhecimento.

O estudo de Ucar (2012) sobre as percepções de licenciandos sobre "Ciência", "cientistas" e "Ensino de Ciências" ao longo de sua formação inicial também contribui para a 
compreensão de como o currículo influi na visão dos alunos sobre Ciência. Para tanto, utilizou técnicas de desenho e questionário do tipo escala Likert com 145 licenciandos, matriculados em momentos diferentes da graduação. Como principal resultado menciona-se que o curso de licenciatura influenciou as percepções dos licenciandos em relação à Ciência, aos cientistas e ao Ensino da Ciências em diferentes graus. O maior impacto do curso foi nas percepções sobre o Ensino de Ciências. Se por um lado, ao longo do processo formativo, as opiniões dos participantes em relação aos cientistas e à Ciência não mudaram expressivamente, por outro lado, as imagens dos licenciandos em relação ao Ensino de Ciências modificaram-se de uma perspectiva centradas no professor para aquela centrada no aluno.

De um ponto de vista mais amplo, essas pesquisas apontam que programas voltados para a formação de cientistas e para a formação de professores de Ciências contribuem pouco para mudar a concepção dos estudantes sobre a NdC. Porém, dependendo da estrutura dos programas voltados para a formação de professores de Ciências, as concepções de licenciandos sobre Ensino de Ciências podem se modificar ao longo de sua formação.

\subsubsection{Percepções de professores de Ciências}

Silva e Cunha (2012) investigaram as RS de professores de Ciências sobre o "método científico" e as relações dessas representações com suas práticas docentes. Para a obtenção das informações, 37 professores de Ciências do Ensino Fundamental responderam a um questionário sobre "método científico" e, posteriormente, foram entrevistados 10 desses professores. A análise dos dados mostra uma prevalência de representações construtivistas da Ciência, ressaltando a problematização e proposição de hipóteses, o entendimento da inexistência de um método universal, com etapas rígidas, o conhecimento prévio, a razão, a imaginação, a intuição e a criação como aspectos importantes para a condução da pesquisa e proposição de explicações. Porém, mesmo para os casos em que a concepção sobre Ciências é marcadamente construtivista, as práticas mencionadas pelos docentes entrevistados demonstram incoerências, apresentando resquícios de concepções tradicionais, de forma análoga ao que ocorre com as representações tradicionais sobre as Ciências. Já as práticas educativas relatadas pelos professores apresentam menção às etapas do processo científico, ênfase na observação, a importância do laboratório, a ênfase na experimentação como uma característica definidora das Ciências e a ideia de comprovação, aspectos que sugerem uma visão tradicional das Ciências empíricas. 
Essa aparente contradição entre discurso e prática também foi apontada em outras pesquisas (e.g. HARRES, 1999; HOFSTEIN; LUNETTA, 2003; ABRAHAMS; MILLAR, 2008), algumas indicando a importância de se investigar a relação entre as concepções acerca da $\mathrm{NdC}$ de professores e suas práticas; outras pesquisas relataram a complexidade de se investigar essa relação, pois o ambiente de ensino e aprendizado é influenciado por diversas características, tanto ao nível do professor, seu conhecimento, experiências prévias, personalidade e seus valores, como características contextuais do ambiente de ensino, tais como: currículo, tempo e recursos disponíveis (HARRES, 1999; THIBAUT et al., 2018).

Hashweh (1996) investigou a relação entre as concepções epistemológicas e as práticas pedagógicas de 35 professores de Ciências. Após responderem a um questionário, com questões objetivas e discursivas, a respeito do ensino, da aprendizagem e da $\mathrm{NdC}$ eles foram separados em dois grupos, professores com concepções construtivistas e professores com concepções empiristas. Os professores que apresentavam concepções construtivistas, se comparados a professores com concepções empiristas, detectam melhor as concepções alternativas de estudantes, apresentam um repertório mais rico de estratégias de ensino, mencionam estratégias de ensino que são potencialmente mais eficazes, relatam o uso mais frequente dessas estratégias em sala de aula e atribuem maior valor às estratégias potencialmente mais eficazes. Portanto, pode-se concluir que as concepções de professores sobre ensino, aprendizagem e $\mathrm{NdC}$ influenciam sua prática de ensino.

Outro estudo chega a resultados semelhantes. Assim, por meio de um questionário na perspectiva quantitativa, Thibaut e colaboradores (2018) investigaram se as características do professor e características contextuais do ambiente de ensino influenciam nas práticas instrucionais dos professores. Os dados da amostra foram obtidos por meio de um questionário online, de escala Likert. Os sujeitos de pesquisa selecionados foram 244 professores que indicaram estar envolvidos no ensino na perspectiva STEM (Ciência, Tecnologia, Engenharia e Matemática), integrando essas temáticas. Entende-se por características do professor, as atitudes, os valores e a formação, por exemplo, enquanto as características contextuais do ambiente de ensino referem-se às expectativas escolares, ao currículo, ao tempo disponível, aos recursos, dentre outros aspectos. Os resultados da pesquisa mostram que as características dos professores estão significativamente relacionadas a suas práticas em sala de aula, ou seja, as características dos professores afetam suas práticas instrucionais. Em relação ao contexto escolar, verificou-se que o apoio, orientação e liderança dos diretores e administradores escolares são importantes para que os professores tenham possibilidade de modificar seu estilo de ensino. 


\subsection{Atividades Experimentais no Ensino de Ciências}

Há diversas abordagens sobre as atividades experimentais no Ensino de Ciências, sendo mais usuais as voltadas à verificação de conteúdos já apresentados aos estudantes e as de caráter investigativo. Essas abordagens apresentam diferenças quanto ao papel do professor e do aluno, a posição que a atividade ocupa na aula e a forma como ela é desenvolvida (ARAÚJO; ABIB, 2003; OLIVEIRA, 2010). As atividades experimentais de verificação são, geralmente, realizadas após a explicação do conteúdo e tendem a ter uma sequência de etapas mais fechada, sendo centradas no professor ou no aluno. As atividades investigativas tendem a ser mais abertas, centradas no aluno e demandam uma série de aulas.

Os artigos que serão sumariados nesta seção mostram que a forma de avaliação das atividades e o tipo de pergunta proposta para os estudantes influenciam no nível cognitivo em que eles são capazes de argumentar sobre a atividade experimental (por exemplo, SUART; MARCONDES, 2009; HOFSTEIN; LUNETA, 2004). O caráter investigativo da atividade experimental é, também, um fator para o envolvimento dos alunos no processo.

Entretanto, as atividades experimentais de cunho investigativo, embora recorrentemente citadas na literatura, raramente são desenvolvidas no contexto escolar (ABRAHAMS; MILLAR, 2008). Isso porque essas atividades necessitam de maior tempo de preparo e realização pelos professores e alunos, assim como de maior experiência de ambos, demandam mais recursos materiais e de infraestrutura, currículo específico para esse tipo de atividade, classe com menor número de alunos, programação flexível e formas de avaliação específicas. Porém, se bem desenvolvidas, apresentam grande potencialidade de desenvolver habilidades investigativas, conceitos científico-escolares e uma visão mais elaborada sobre a NdC (HOFSTEIN; LUNETTA, 2003; HOFSTEIN, 2004; DUIT; TESCH, 2010; OLIVEIRA, 2010; SUART; MARCONDES, 2009; 2018).

Baptista, Freire e Freire (2013) investigaram como os alunos abordam tarefas de investigação, identificando quais dificuldades encontram e o modo como as superam. Para tanto, acompanharam as aulas de uma professora de Física e de Química em duas turmas da $8^{a}$ série do Ensino Fundamental, composta por 39 alunos. Os resultados da pesquisa mostram que as dificuldades enfrentadas exigem que o aluno assuma um papel ativo na sua própria aprendizagem. As principais dificuldades pertencem a três domínios. Primeiro, dificuldades referentes à forma de trabalho, principalmente no compartilhamento de ideias com os colegas, ao trabalho em grupo e ao desempenho de um papel mais autônomo. A segunda dimensão, dificuldades relacionadas à natureza das tarefas, refere-se a ações tais como: formular questões, fazer previsões, planejar investigações, obter evidências e tirar 
conclusões. Essas dificuldades estão relacionadas com o tipo de linguagem, os estudantes não compreendiam o significado dessas ações e não estavam acostumados com os vocábulos científico. Porém, as dificuldades foram diminuindo ao longo do desenvolvimento das tarefas, exceto para a realização de previsões. Isso se deveu à orientação da professora, que ofereceu os meios necessários para que os alunos conseguissem desenvolver as atividades.

Suart e Marcondes (2009) investigaram as habilidades cognitivas manifestadas por alunos do primeiro ano do Ensino Médio em uma atividade experimental investigativa de Química. Na atividade proposta, os alunos deveriam elaborar hipóteses para investigar quais fatores afetavam a temperatura de ebulição de um material, elaborar um experimento, executá-lo, analisar os dados e comunicá-los para a sala. Para tanto, gravou-se em áudio e vídeo uma sequência de três aulas (pré-laboratório, laboratório e pós-laboratório), analisaram-se os materiais escritos pelos alunos e realizou-se anotação de campo. Os resultados dessa pesquisa mostram que, embora tenham predominado respostas algorítmicas de baixa ordem cognitiva, a atividade experimental de cunho investigativo fomentou o interesse dos alunos pela atividade, assim como a manifestação de habilidades cognitivas de ordem alta, por exemplo, elaboração de hipóteses, confirmadas ou refutadas considerando-se a análise de dados e as variáveis envolvidas. Isto foi possível pelo grau de liberdade da atividade, pois foi permitido que os alunos participassem de todas as etapas da investigação, desde a elaboração do procedimento até a comunicação dos resultados para os pares. Outro resultado importante refere-se ao tipo de resposta (o nível cognitivo) dos estudantes, que depende do tipo de pergunta que o professor propõe, ou seja, o nível cognitivo de certas questões dos estudantes foi determinado pelo tipo de questão do professor.

Em outra pesquisa, Suart e Marcondes (2018) investigaram como um licenciando em Química elabora, ministra e analisa uma sequência de aulas baseadas em uma perspectiva de ensino por investigação e para a promoção da alfabetização científica no Ensino Médio. Para tanto, realizaram encontros para promover uma reflexão orientada. Esse processo teve duração de aproximadamente um ano e meio e se desenvolveu em momentos extraclasse de um curso de licenciatura em Química de uma IES do Sudeste brasileiro, sendo que o licenciando investigado participou de nove encontros para a elaboração de sua sequência. Os resultados mostram que o licenciando evoluiu com relação às concepções apresentadas ao iniciar sua participação no processo reflexivo, utilizando referenciais teóricos sobre ensino por investigação, alfabetização científica e exigência cognitiva das questões para avaliar sua prática docente. Esse trabalho também evidencia que o desenvolvimento de 
atividades experimentais investigativas, por licenciandos, demanda considerável quantidade de tempo e de discussão mediada.

Colagrande, Martorano e Arroio (2017) investigaram as visões de 19 licenciandos sobre o papel das atividades experimentais no Ensino de Ciências. Para tanto, solicitou-se que os licenciandos respondessem a perguntas sobre como usariam as atividades experimentais no futuro. A atividade ocorreu em duas etapas: a primeira foi antes de estudar e discutir textos sobre a NdC, com ênfase no papel da experimentação na formulação de hipóteses; a segunda etapa ocorreu posteriormente a essas atividades. Os resultados mostram que as discussões sobre a $\mathrm{NdC}$ influenciaram as visões dos licenciandos sobre o papel das atividades experimentais para o Ensino de Ciências, no sentido de conduzir à reformulação dessas visões, o que resultou em uma compreensão mais ampla desses sujeitos. Antes das atividades de estudo dos textos e das discussões, a visão dos estudantes sobre as atividades centrava-se na observação e na comprovação de teorias, estando mais preocupados com a execução do experimento do que com o aprendizado dos conceitos científicos; após as atividades, os estudantes inseriram características relacionadas às atividades experimentais baseadas em investigação, preocupando-se em favorecer atitudes que fazem com que a atividade tenha caráter ativo e participativo, desenvolvendo habilidades de observação, registro, comparação, teste de hipóteses e de argumentação. Ainda, os resultados mostram que os licenciandos atribuem forte aspecto motivacional às atividades experimentais.

Abrahams e Millar (2008) investigaram a eficiência das atividades experimentais de 25 professores de Ciências do Ensino Médio em dois aspectos: (i) a relação entre o que o professor pretende que os estudantes façam e o realmente executado pelos estudantes e (ii) a relação entre o que o professor pretende que o aluno aprenda com o que é realmente aprendido. Os resultados dessa pesquisa mostram que os professores concentram seus esforços em garantir que os estudantes compreendam o procedimento que devem executar em detrimento da compreensão acerca dos fenômenos estudados, ou seja, prioriza-se a execução do experimento. Ainda, os professores tendiam a considerar que os objetivos educacionais foram bem-sucedidos se os estudantes conseguissem executar o experimento e realizar as observações necessárias. Dessa constatação, infere-se que muitos professores esperam que os alunos aprendam os fenômenos como uma consequência da manipulação de equipamentos, vidrarias e reagentes. Por fim, verificou-se a predominância de atividades experimentais do tipo "receita" propostas pelos professores. Essa tendência era intensificada quando o conteúdo que envolvia a atividade experimental não era associado à formação específica do professor. Esses professores, quando desenvolviam atividades 
práticas que envolvessem assuntos que não dominavam, tendiam a confiar mais em atividades fechadas e com grande controle, por reduzirem a probabilidade de eventos ou questões inesperadas. Portanto, a formação do professor é uma característica que apresenta grande influência na forma como as atividades experimentais serão desenvolvidas.

Buscando investigar as percepções de professores de Ciências sobre as atividades experimentais no contexto escolar, Wei e Li (2017) entrevistaram 87 professores de Ciências da Educação Básica, solicitando a eles que comparassem os experimentos realizados pelos estudantes àqueles desenvolvidos na pesquisa científica. Identificaram-se oito dimensões ao se analisar o discurso dos professores: i) pedagógica; ii) epistemológica; iii) conceitual; iv) procedimental; v) material; vi) social; vii) de tempo; e viii) de segurança. Dentre essas dimensões, três foram mais frequentes entre os professores ao se referirem aos experimentos de nível escolar: a dimensão pedagógica, a procedimental e a epistemológica. Já ao se referirem aos experimentos científicos, foram mais frequentes as dimensões procedimental, epistemológica e material. Embora amplamente discutidas na literatura, as dimensões conceitual e social quase não foram mencionadas pelos professores, assim como as dimensões de tempo e de segurança. Em síntese, os resultados dessa pesquisa mostram que a compreensão dos professores sobre as atividades experimentais desenvolvidas no contexto escolar apresenta diferenças sutis em termos da composição de suas dimensões em relação aos experimentos na pesquisa científica, embora a dimensão pedagógica seja exclusiva dos experimentos realizados na escola. Essa dimensão reflete as preocupações dos professores com relação aos objetivos, propósitos, metas e recursos das atividades experimentais para o aprendizado dos estudantes no Ensino de Ciências, preocupações também identificadas em outras pesquisas (GALIAZZI; GONÇALVES, 2004; CORRALO, 2017; SUART; MARCONDES, 2018).

Outra característica é a demanda material, que abrange desde a infraestrutura até os equipamentos e reagentes. No âmbito nacional, esse problema é uma preocupação recorrentemente citada nas pesquisas (ARAÚJO; ABIB; 2003; GONÇALVES; MARQUES, 2006, 2012; MATIELLO, 2017). Enfrentando essa problemática, professores e pesquisadores buscaram formas alternativas que minimizassem os problemas materiais, sendo as atividades experimentais que utilizam materiais alternativos, de baixo custo e fácil acesso um expressivo recorte das pesquisas sobre experimentação no Ensino de Ciências. Outras justificativas para o uso de materiais alternativos são: i) a aproximação do fenômeno estudado com o contexto do aluno, tornando a aprendizagem mais relevante para o estudante, o que fomenta a curiosidade e motivação; ii) a questão da segurança, já que um 
dos motivos usualmente citados na escolha de materiais alternativos é sua baixa periculosidade para os estudantes; e iii) a preocupação com o meio ambiente.

Embora nem todas as atividades experimentais sejam vistas de forma positiva por todos os alunos (HODSON, 1994), a motivação é uma questão de grande preocupação para licenciandos, professores e pesquisadores do campo do ensino (GONÇALVES; MARQUES, 2006, 2012; GALIAZZI; GONÇALVES, 2004; COLAGRANDE; MARTORANO; ARROIO; 2017; SILVA et al., 2018).

Corrallo (2017) investigou a RS sobre "atividades experimentais para o Ensino de Física" de 444 sujeitos, professores do Ensino Superior e da Educação Básica e estudantes universitários. Os resultados apontam para uma persistência quanto ao aspecto motivacional na representação sobre atividades experimentais. Por um lado, estudantes e professores atribuem às atividades experimentais um forte caráter motivacional, como um aspecto inerente à observação dos fenômenos, ver algo diferente do cotidiano, ou pela surpresa através da descoberta de um fenômeno ou da compreensão de um conceito (GALIAZZI; GONÇALVES, 2004; COLAGRANDE; MARTORANO; ARROIO, 2017; CORRALLO, 2017). Por outro, a motivação relaciona-se à curiosidade científica, sendo um importante estímulo para o engajamento cognitivo dos estudantes nas tarefas escolares, o que auxilia no desenvolvimento de diferentes atitudes, como pesquisar e comunicar (SILVA et al., 2018).

\subsection{Objetivos das atividades experimentais no Ensino de Ciências}

\subsubsection{Objetivos das atividades experimentais no Ensino de Ciências}

Há cinco principais objetivos comumente citados na literatura sobre o papel da experimentação no Ensino de Ciências (HOFSTEIN; LUNETTA, 1982; HODSON, 1985; HODSON, 1994; ARAÚJO; ABIB; 2003; HOFSTEIN; LUNETTA, 2003; ABD-EL-KHALICK et al., 2004; HOFSTEIN, 2004; OLIVEIRA, 2010; DUIT; TESCH, 2010; GYLLENPALM; WICKMAN, 2011). O primeiro refere-se à dimensão afetiva, pois mostrou-se que as atividades experimentais auxiliam a despertar o interesse e a motivação dos alunos pelo aprendizado de Ciências e, devido ao estímulo e à diversão envolvidos em sua prática, facilitam a apropriação, pelos alunos, de atitudes, valores e da curiosidade científica.

O segundo objetivo refere-se à dimensão cognitiva. Para tanto, as atividades experimentais devem facilitar o aprendizado de conceitos científico-escolares, esses são os conceitos e conteúdos referentes às Ciências Naturais. O terceiro objetivo refere-se ao desenvolvimento de habilidades práticas, pois os estudantes aprendem a manusear 
equipamentos, vidrarias e reagentes, a montar e executar experimentos. Essas características são fundamentais para uma melhor compreensão da $\mathrm{NdC}$, que se referem ao quarto objetivo, no qual os estudantes devem saber formular hipóteses e testá-las, prever fenômenos por meio de teorias, saber projetar e executar investigações e formular explicações fundamentadas sobre os resultados obtidos.

O quinto objetivo se refere à dimensão valorativa. Os autores entendem que, ao se trabalharem esses objetivos, os estudantes terão uma imagem mais positiva das Ciências, da atividade científica e de sua relação com a sociedade, características enfatizadas pelo movimento Ciência, Tecnologia e Sociedade.

No entanto, a forma como os objetivos propostos para as atividades experimentais foram implementados no Ensino de Ciências e a sua avaliação têm sido os mesmos de outros métodos de ensino, o que fez com que alguns professores e pesquisadores do campo do ensino questionassem a eficiência e o papel das atividades experimentais no Ensino de Ciências (TOBIN, 1990; HOFSTEIN; LUNETTA, 2003).

\subsubsection{As atividades experimentais são realmente eficientes?}

Diversas pesquisas compararam a eficiência das atividades experimentais com outros métodos de ensino, tendo-se como variável o desenvolvimento de conceitos científicoescolares, de habilidades de cunho manipulativo e investigativo e de concepções sobre $\mathrm{NdC}$, buscando verificar se as atividades experimentais, realizadas em laboratório, desenvolvem aspectos semelhantes àqueles atingidos por alternativas de ensino menos custosas e demoradas.

Hofstein e Lunetta (1982) verificaram que não havia dados suficientes para confirmar ou rejeitar de maneira convincente a hipótese de que as atividades experimentais estimulam o aprendizado dos estudantes. Segundo a literatura, são quatro os principais motivos para a insuficiência de dados que indiquem o real papel das atividades experimentais no ensino.

Primeiro, tradicionalmente as atividades experimentais voltam-se ao aprendizado de um dos três objetivos de ensino: i); conceitos científicos ii); Natureza das Ciências e iii) práticas das Ciências. Porém, não é possível aprender essas questões de forma separada. Embora seja necessário conhecer os conceitos e compreender os procedimentos da Ciência, eles são insuficientes para permitir que o aluno participe com sucesso de atividades investigativas laboratoriais, que se aproximem das características de uma pesquisa científica. Essa capacidade seria desenvolvida através da vivência, em outras palavras, a prática da Ciência seria a única maneira de se aprender Ciência (HODSON, 1994). Outros pesquisadores defendem que a multiplicidade de objetivos educacionais relacionados às 
atividades experimentais dificulta o alcance de resultados mais específicos do processo de ensino e aprendizado. Por exemplo, a mesma atividade é utilizada para auxiliar estudantes a compreenderem um conceito científico-escolar e adquirir habilidades de investigação que integrem o aprendizado sobre a NdC (ABD-EL-KHALICK et al. 2004). Seria de se perguntar se essas metas são realmente mais relevantes quando se pensa sobre o ensino na Escola Básica, onde o mais relevante é que os alunos se apropriem de uma forma de pensar sobre o mundo, não sendo significativo que sejam imersos nos valores e práticas da Ciência institucionalizada, praticada por profissionais.

Segundo, não há unanimidade entre os filósofos da Ciência quanto à relação entre as concepções de Ciência e método científico, (HODSON, 1985). Esse dissenso dificulta a caracterização e aplicação das atividades experimentais no Ensino de Ciências, como apontado por Abrahams e Millar (2008). Além disso, o que os professores pensam sobre as atividades experimentais no Ensino de Ciências nem sempre se reflete em seu planejamento e desenvolvimento na sala de aula.

Terceiro, o tipo de avaliação influencia as atividades experimentais (TOBIN, 1990; HOFSTEIN; LUNETTA, 2003). A forma como os alunos são avaliados influencia o processo de ensino e aprendizado. A avaliação geralmente é objetiva, escrita, organizada em perguntas e respostas, e enfatiza o aprendizado rotineiro de fatos científicos e a memorização de conceitos, o que não é coerente com a gama de objetivos que as atividades experimentais apresentam para o Ensino de Ciências.

Quarto, várias pesquisas mostram que, tanto o professor como os alunos, estão mais preocupados com detalhes técnicos do procedimento e da manipulação das atividades experimentais do que com os objetivos educacionais. Essa preocupação excessiva com o andamento do experimento acaba consumindo a maior parte do tempo e energia despendidos nas atividades, o que limita seriamente a parte de construção de conceitos (HOFSTEIN; LUNETTA, 2003; ABRAHAMS; MILLAR, 2008; COLAGRANDE; MARTORANO; ARROIO, 2017).

Apesar de identificarem essa aparente contradição quanto ao papel da experimentação no Ensino de Química e de outras áreas das Ciências Naturais, essas pesquisas sugerem que as atividades experimentais contribuem para o aprendizado dos estudantes, principalmente se planejadas e desenvolvidas adequadamente. Nessa condição, elas apresentam o potencial de contribuir para o aprendizado dos conceitos científico-escolares e a compreensão sobre a NdC. 


\section{TEORIA DAS REPRESENTAÇÕES SOCIAIS}

Neste Capítulo serão apresentados os fundamentos teórico-metodológicos que norteiam o desenvolvimento desta pesquisa. Primeiramente, serão abordados a gênese e os pressupostos da Teoria das Representações Sociais (MOSCOVICl, 2007), centrando em uma de suas abordagens, a abordagem estrutural (ABRIC, 2001) para, posteriormente, descrever o modelo que subjaz à alocação dos termos do Núcleo Central das Representações Sociais.

\subsection{Teoria das Representações Sociais}

\subsubsection{Gênese e princípios epistemológicos}

A Teoria das Representações Sociais (TRS) foi proposta por Serge Moscovici em sua Tese de Doutorado, intitulada "La psychanalyse: son image et son publique", defendida na França, em 1961 (MOSCOVICl, 2007). Essa investigação buscou compreender como o conhecimento restrito é transformado para que seja apropriado pelas pessoas comuns. Por exemplo, esse processo se dá quando o conhecimento científico circula em segmentos sociais externos àquele de sua origem. Para compreender esse processo, Moscovici investigou os conhecimentos, opiniões e atitudes de sujeitos de diferentes estratos sociais, como também os meios de comunicação de massa, com respeito ao objeto de estudo, a "psicanálise", tema emergente e com vasta circulação social naquela época.

Antes de Moscovici, a maioria dos teóricos distinguiam os fenômenos em dois níveis: os que ocorriam em uma esfera individual, denominada psicologia fisiológica, e os que ocorriam em uma esfera coletiva, denominada cultura ou Representação Coletiva (FARR, 2013). Acreditava-se que os fenômenos coletivos apresentavam características distintas daquelas dos fenômenos individuais, sendo o intrapessoal distinto do interpessoal.

Moscovici iniciou o processo de construção da teoria com base na perspectiva sociológica de Representação Coletiva proposta por Émile Durkheim, considerado o fundador da Sociologia como campo de estudo. O conceito de Representação Coletiva é central na obra de Durkheim, sendo suas principais características expostas por Oliveira (2004)

[...] Empiricamente, as representações podem representar qualquer coisa, ou seja, qualquer objeto pode ser mentalmente representado. As representações são assim funções mentais. Representando, fazemos viver o mundo [...] as representações coletivas sintetizam o que os homens pensam sobre si mesmos e sobre a realidade que os cerca. É, portanto, inicialmente, uma forma de conhecimento socialmente produzida. Resultado de esforço coletivo, elas emancipam-se das representações individuais, 
pautam novas ações e demonstram a existência da sociedade. As representações são coletivas e, portanto, não podem ser simplesmente reduzidas aos indivíduos. Sendo fruto da interação e dos laços sociais que os homens estabelecem entre si, elas os ultrapassam, adquirindo realidade e autonomia próprias [...], alcançam o terreno das práticas sociais, às quais se ligam [...]. Em resumo, o conceito de representações coletivas é, ao mesmo tempo, forma de conhecimento e guia para as ações sociais [...] ( $p$. 71).

Durkheim (2000) foi um defensor da separação entre Psicologia e Sociologia. Para ele, os estudos psicológicos deveriam voltar-se às Representações Individuais, enquanto os estudos sociológicos deveriam voltar-se às Representações Coletivas. As Representações Coletivas não poderiam ser reduzidas ao somatório das Representações Individuais, por serem mais complexas do que a mera soma delas.

Durkheim estava interessado em investigar como as sociedades se mantêm estáveis e os fatores que favorecem sua manutenção, sobretudo o caráter coletivo, sua força material e o poder de ambientes simbólicos na resistência à mudança, sendo os objetos de seus estudos a religião, os costumes, os mitos e fenômenos semelhantes (FARR, 2013). A observação se assentou nas abordagens comportamentais que interpretam os sujeitos e os objetos em lados diametralmente opostos. Durkheim afirma que a representação é algo externo ao sujeito, sendo apresentada a ele como acabada, como cópia fiel do real, sem possibilidade de transfiguração, tendo, portanto, caráter estático (MOSCOVICl, 2007). Por serem impostas ao indivíduo, as Representações Coletivas não permitem reelaborações decorrentes de interações entre os indivíduos pertencentes aos grupos sociais, o que as torna pouco operacionais para a compreensão da dinâmica das sociedades modernas.

No entanto, as sociedades modernas são caracterizadas por seu pluralismo e pela rapidez das mudanças econômicas, políticas e culturais. A Ciência, nesse cenário, é uma fonte fecunda de novas representações, sendo a TRS um instrumento adequado para a investigação empírica das concepções leigas sobre as Ciências, suas atividades e seus produtos, não se atendo às concepções do mundo reificado dos cientistas. Como exemplo, Moscovici estudou a RS sobre o objeto "psicanálise", não sua teoria, entendendo que a teoria psicanalítica originou-se em uma cultura diferente daquela de sua difusão, através dos meios de comunicação de massa.

Portanto, a TRS possibilita a compreensão de como o conhecimento de senso comum é produzido e permite analisar seu impacto nas práticas sociais através da investigação de como o tripé grupos/atos/ideias constitui e transforma a sociedade (OLIVEIRA, 2004). 


\subsubsection{Delimitação}

As RS desempenham um papel fundamental nas práticas e na dinâmica das relações sociais e exercem a função de tornar a comunicação, dentro de um grupo, relativamente não-problemática, devido ao certo grau de consenso entre seus membros. Abric (2001) propõe quatro funções para as RS, as quais estão sumariadas no Quadro 4.1.

\section{Quadro 4.1 - Funções das Representações Sociais.}

\begin{tabular}{|l|l|}
\hline \multicolumn{1}{|c|}{ Função } & \multicolumn{1}{|c|}{ Característica } \\
\hline Conhecimento & $\begin{array}{l}\text { Permite entender e explicar a realidade. Permite que os sujeitos adquiram } \\
\text { conhecimento em um quadro orientado e compreensível de acordo com o seu } \\
\text { funcionamento psicológico e com os valores a que aderem. }\end{array}$ \\
\hline Identidade & $\begin{array}{l}\text { Permite preservar a especificidade dos grupos. Desempenha um papel importante } \\
\text { no controle social exercido pela comunidade sobre seus membros, através de } \\
\text { sistemas social e historicamente determinados de normas e valores. }\end{array}$ \\
\hline Orientação & $\begin{array}{l}\text { Orienta comportamentos e práticas, é um guia para a ação, produzindo um sistema } \\
\text { de antecipações e expectativas que definirá o que é permitido, tolerável ou } \\
\text { inaceitável em um determinado contexto social. }\end{array}$ \\
\hline Justificação & $\begin{array}{l}\text { As RS também intervêm após a ação, através da justificativa de um comportamento } \\
\text { em uma situação. Perpetua e justifica diferenças entre grupos sociais e, através dos } \\
\text { estereótipos, reforçam a posição social do grupo envolvido. }\end{array}$ \\
\hline
\end{tabular}

Fonte: Abric (2001, p. 17-18), adaptado.

As funções das RS explicam a dinâmica das relações sociais e dos indivíduos com seu entorno social, sendo um elemento essencial para a compreensão dos aspectos determinantes dos comportamentos e das práticas sociais. São fruto do processo de construção das RS, que, em sua constituição, entrelaça aspectos psicológicos ${ }^{4}$ e sociais do pensamento, dependentes da linguagem e dos saberes práticos permeados na inter-relação entre grupos, atos e ideias.

Ao entrar em contato com uma palavra nova, a rede de conceitos do indivíduo é estimulada. Essa palavra (conceito) desconhecida pelo sujeito causa um estranhamento, uma perturbação, o que o motiva a atribuir-Ihe um significado, estabelecendo uma relação precisa com sua linguagem corrente, ou seja, ele liga a palavra a uma significação ${ }^{5}$. A esse

\footnotetext{
${ }^{4} \mathrm{O}$ aspecto psicológico das RS deve ser aqui entendido como formas de representar e ordenar um conteúdo, sendo marcadas pela divisão entre dois universos: o consensual e o reificado. Elas são construídas nas práticas sociais através das comunicações interpessoais, estruturadas nos universos consensuais de pensamento (MOSCOVICl, 2007). Resulta de dois movimentos: uma generalização de imagens e uma expressão direta dos fenômenos concretos. Esses movimentos registram e transformam as noções abstratas em imagens concretas carregadas de elementos metafóricos (JODELET, 2016).

${ }^{5}$ No trabalho seminal sobre a Psicanálise, Moscovici identificou quatro termos-chave (inconsciente, consciente, recalcamento e complexo) que compõem o modelo ilustrativo da representação. Esses termos tinham valor informativo, sem ter um significado preciso. Por exemplo, ao solicitar que as pessoas justificassem sobre o que eles queriam dizer por "complexo", Moscovici se deparou com o fato que elas não sabiam explicar o termo, concluindo que o modelo figurativo parece estar esvaziado de significado próprio. Para Moscovici, é precisamente essa característica que permite que um termo
} 
mecanismo, Moscovici (2007) denominou ancoragem, um dos dois mecanismos principais do processo de desenvolvimento das $\mathrm{RS}^{6}$.

O outro mecanismo proposto por Moscovici foi o da objetivação, operação em que se materializa as ideias e se forma o conhecimento. Esse mecanismo funciona por meio de esquemas conceituais, através da formação de imagens mentais. Quando há a apropriação das novas características, forma-se uma significação coerente, que reproduz o objeto de uma maneira seletiva e concreta, muitas vezes de forma icônica ou estereotipada. As novas características passam a formar os conhecimentos basilares que são utilizados, com outros saberes e informações, em uma variedade de situações. As características reificadas do objeto formam um núcleo figurativo ${ }^{7}$ (MOSCOVICl, 2007) que estabelece os parâmetros que balizam as condutas desejadas ou admitidas.

Nesse sentido, as formulações simbólicas não podem ser separadas do pensamento e do comportamento. A linguagem, por meio dos signos, é a forma com que um grupo representa a realidade, é a mola propulsora da relação entre o mundo dos objetos exteriores ao sujeito e o mundo do objeto pessoal.

É importante destacar que nem todo objeto gera uma RS para um grupo. Para que se tenha uma representação compartilhada, o objeto deve ser relevante para o contexto social específico. Mesmo que um objeto tenha uma representação para um grupo social, ele pode ter significações diferentes em outros contextos sociais, porque o "conteúdo semântico de cada ideia e cada crença depende de suas conexões com outras crenças e ideias" (MOSCOVICl, 2007, p. 181). Expressando de outra forma, não existe realidade objetiva, pois toda realidade é representada, apropriada por um indivíduo, reconstruída em seu sistema psicológico e integrada em seu sistema de valores, que depende de sua história e do contexto social e ideológico do qual ele faz parte (ABRIC, 2001).

As RS apresentam características aparentemente contraditórias, sendo, ao mesmo tempo: estáveis e dinâmicas; consensuais e marcadas pela individualidade do grupo. Essas

se associe a uma série de outras palavras e sua consequente simbolização do objeto de representação.

6 Outro processo descrito por Moscovici, por exemplo é o da formação da linguagem. Esse processo é governado por dois mecanismos: i) normalização e ii) motivação. A normalização é o mecanismo em que "os conceitos científicos passam para a linguagem corrente e são empregados sem que se estabeleça uma relação precisa com os demais termos do vocabulário" (MOSCOVICl, 1987, 242). A nova palavra não tem conexão com a rede de conceitos constituída pelo vocábulo do sujeito, não possui qualquer conteúdo ou classificação particular, mas uma simples função de indicação simbólica de algo. A motivação ocorre quando há recombinação de uma palavra por uma nova significação.

7 O núcleo figurativo é uma estrutura imagética em que se articulam os elementos do objeto de representação do indivíduo, que foram selecionados segundo critérios culturais ou normativos dos grupos. Na seleção, os elementos do objeto representado são descontextualizados, retendo apenas certas qualidades icônicas, que passam a ter maior autonomia em relação ao objeto representado. 
características podem ser explicadas pela Abordagem Estrutural das TRS, denominada Teoria do Núcleo Central.

\subsection{Teoria do Núcleo Central}

\subsubsection{Princípios epistemológicos, Sistema Central e Sistema Periférico}

A Teoria do Núcleo Central (TNC) foi proposta por Jean-Claude Abric em sua Tese de Doutorado, intitulada "Jeux, conflits et représentations sociales", defendida em 1976, na Universidade da Provença (SÁ, 2002). Em sua investigação, ele buscou um modelo que permitisse explicar as características e a organização das RS. Assim, Abric (2001) sugeriu que a organização das RS tem uma característica particular: seus termos são hierarquizados e essa hierarquia se estrutura em torno de um núcleo central que, por sua vez, atribui significado à representação.

Para a formulação da TNC Abric (2001) se embasou nos estudos dos fenômenos de atribuição de Fritz Heider, no trabalho acerca de percepção social de Solomon Asch e no processo de objetivação de Serge Moscovici (ABRIC, 2001; RATEAU et al., 2012).

A ideia de centralidade não é nova; desde 1927, em estudos sobre os fenômenos de atribuição, Fritz Heider defende que as pessoas tendem a atribuir núcleos unitários de significado aos eventos que a cercam, dando um sentido à diversidade dos estímulos imediatos, o que permite ordenar e compreender a realidade vivenciada pelo indivíduo e pelos grupos (ABRIC, 2001). Esse processo de percepção social aparece como termos centrais, constitutivos do pensamento social.

Asch $(1946)^{8}$ reforça as ideias de organização centralizada e vai além, propondo uma estrutura. Investigando como várias características atuam conjuntamente para produzir a percepção sobre uma pessoa, e que princípios regulam esse processo, verifica que na constituição da percepção, certos traços desempenham papéis determinantes na imagem que fazemos de uma pessoa. Esses traços moderam o significado de todas as outras características atribuídas a essa pessoa. Por exemplo, atribuir a alguém o traço "frio" ou "quente", termos centrais, nos leva a estabelecer um significado específico para todos os outros traços que lhe podemos atribuir, os termos periféricos, os quais se organizam em

\footnotetext{
${ }^{8}$ Dentre sete traços de personalidade sugeridos para os sujeitos como critério para classificar um indivíduo, um deles (quente/frio) desempenhou um papel determinante, gerando a natureza da representação, impressão na nomenclatura de Asch. Este elemento desempenhou um papel central, sendo mais importante do que todos os outros elementos. A alteração do elemento central ocasionou a transformação radical da representação, enquanto que a mudança de um elemento periférico teve um efeito muito mais brando, estando esses elementos hierarquicamente organizados pelo elemento central.
} 
uma hierarquia. A transformação dos termos centrais causa uma mudança na percepção que se tem pessoa.

Ao relacionar essas ideias com a de objetivação de Moscovici (2007), processo em que os indivíduos retêm seletivamente parte das informações que os circundam, levando a um arranjo particular de conhecimento, Abric transcende a estrutura puramente genética da ideia de núcleo figurativo, propondo uma estrutura interna para as representações, que se organizariam em um sistema central e um sistema periférico, com características e funções distintas.

Os termos que constituem o sistema central são marcados pela memória coletiva e pelo sistema de normas do grupo, refletindo condições sócio-históricas e valorativas. Eles têm valor simbólico para o grupo e constituem a base comum, coletivamente partilhada, das representações, expressando a homogeneidade do grupo. O Sistema Central é relativamente pouco sensível ao contexto social e material imediato, assegurando a continuidade e a permanência da representação. Tem como funções gerar o significado da representação, determinar a organização de seus demais termos e prover estabilidade, assegurando a permanência da representação do grupo no que se refere ao objeto social.

Foi a partir do entendimento dessas características que as pesquisas sobre a estrutura das RS se ocuparam, quase exclusivamente, da natureza do sistema central, negligenciando a composição global das representações e as funções cumpridas pelo sistema periférico (SÁ, 2002).

Características aparentemente contraditórias fazem parte da estrutura e do modo de funcionamento das representações. Atribui-se essa característica à lógica dupla que as rege: a lógica psicológica (funcionamento cognitivo e psíquico) e a lógica social (funcionamento do sistema social). Esse modelo possibilita explicar porque as representações integram, ao mesmo tempo, o racional e o irracional: por serem construções sociocognitivas toleram contradições aparentes e sustentam raciocínios ilógicos ou incoerentes (Quadro 4.2).

Ao contrário do sistema central, o sistema periférico é mais sensível ao contexto social e imediato, o que possibilita mobilidade dos termos da representação. É mais flexível do que o sistema central, permitindo a atualização e contextualização dos termos. Através das sucessivas modificações das circunstâncias externas, das práticas sociais, podem-se ocasionar modificações dos termos que constituem o sistema periférico e, posteriormente, modificam os termos do NC, modificando-se, assim, a representação. Nesse sentido, o sistema periférico funciona como uma "almofada" que protege os termos do sistema central 
das contingências vivenciadas pelo indivíduo e, por consequência, da modificação da RS de um indivíduo sobre um objeto.

Quadro 4.2 - Síntese das características dos Sistemas Central e Periférico das RS.

\begin{tabular}{|l|l|}
\hline \multicolumn{1}{|c|}{ Sistema Central } & \multicolumn{1}{c|}{ Sistema Periférico } \\
\hline $\begin{array}{l}\text { Ligado à memória coletiva e ao processo de } \\
\text { construção histórica do grupo }\end{array}$ & $\begin{array}{l}\text { Proporciona a integração entre o que é comum } \\
\text { e as experiências individuais }\end{array}$ \\
\hline Consensual - define a homogeneidade do grupo & Suporta a heterogeneidade do grupo \\
\hline Estável, coerente e rígido & Flexível, suporta as contradições \\
\hline Pouco sensível ao contexto imediato & Sensível ao contexto imediato \\
\hline Funções: & $\begin{array}{l}\text { Funções: } \\
\text { - gera a significação da representação }\end{array}$ \\
- determina sua organização & $\begin{array}{l}\text { - permite a diferençãa à realidade cononcreta } \\
\text { - protege o sistema central }\end{array}$ \\
\hline
\end{tabular}

Fonte: Abric (1993), adaptado.

As características de sensibilidade e flexibilidade levam a uma terceira, adaptabilidade, o que permite modulação individual da representação devida às experiências singulares do indivíduo. A personalização desses termos (RATEAU et al., 2012) deve-se à heterogeneidade de opiniões no âmbito de um mesmo grupo social, que permanecem compatíveis com os termos do sistema central, o que mantém a característica do grupo.

Os aspectos mencionados acerca dos fenômenos de representação, atrelados à contínua reelaboração teórica e refinamento metodológico, fez que os estudos sobre o NC trouxessem uma importante contribuição quanto à explicitação dos conceitos, proposições teóricas e abordagens metodológicas da TRS, desembocando em uma nova abordagem, a abordagem estrutural. Abric (2001) compreende a TRS como a grande teoria e apresenta a abordagem estrutural como uma teoria que aprofunda aspectos específicos para a compreensão da TRS, contribuindo para o processo de seu estudo através de proposições metodológicas específicas.

\subsubsection{Alocação dos termos no Núcleo Central de uma Representação Social}

O NC é constituído de um ou mais termos que ocupam uma posição privilegiada na estrutura da representação, sendo importante identificá-los e determinar sua relação com os outros termos da RS, para que se possa verificar a existência da RS sobre um objeto (SÁ, 2002).

Para isso, utiliza-se uma abordagem multimetodológica, organizada em três etapas, visando apreender o valor simbólico dos termos componentes da RS (Quadro 4.3), propriedade qualitativa que se reflete no poder associativo e na saliência do termo na RS do grupo sobre um objeto social. 
Quadro 4.3 - Propriedades dos termos do Núcleo Central da RS.

\begin{tabular}{|c|c|c|}
\hline \multicolumn{2}{|r|}{ Propriedades } & Características das propriedades do NC \\
\hline \multirow{3}{*}{ 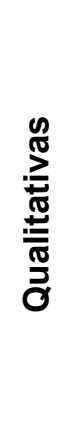 } & Valor Simbólico & $\begin{array}{l}\text { Expressa o significado dos termos centrais para o grupo, trata-se de uma } \\
\text { propriedade qualitativa associada à RS, indica a inegociabilidade do } \\
\text { termo, a importância do termo em relação ao objeto social. }\end{array}$ \\
\hline & $\begin{array}{l}\text { Poder } \\
\text { Associativo }\end{array}$ & $\begin{array}{l}\text { Capacidade polissêmica dos termos centrais. Relaciona-se com a } \\
\text { capacidade de ligação que desses termos a outros termos da RS. }\end{array}$ \\
\hline & Saliência & $\begin{array}{l}\text { Consequência do valor simbólico das representações. A saliência é } \\
\text { expressada pela hierarquia, ordem de evocação dos termos; e pela } \\
\text { frequência, repetição dos termos por diferentes sujeitos. }\end{array}$ \\
\hline \multirow{2}{*}{ 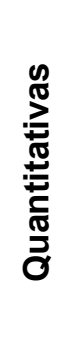 } & Conectividade & $\begin{array}{l}\text { Associada ao valor simbólico, expressa a relação que alguns termos } \\
\text { estabelecem com outros termos, destacando o processo de co- } \\
\text { ocorrência das evocações de sujeitos pertencentes ao mesmo grupo } \\
\text { social. }\end{array}$ \\
\hline & $\begin{array}{l}\text { Ordem Média de } \\
\text { Evocação }\end{array}$ & $\begin{array}{l}\text { Reflexo do valor simbólico. É expressa pela hierarquia e frequência com } \\
\text { que um termo é evocado. Expressa a ordem de um termo específico em } \\
\text { relação ao conjunto de termos evocados. }\end{array}$ \\
\hline
\end{tabular}

Fonte: Abric (2001); Sá (2002); Wachelke (2009); Vogel (2016).

A primeira etapa refere-se à identificação do conteúdo da RS. Para isso, utiliza-se a metodologia proposta para a identificação do valor simbólico, a Análise Prototípica, proposta por Vergès (1992) para a identificação dos termos componentes do NC. Nessa abordagem, admite-se que os termos de maior relevância para o grupo seriam evocados com maior frequência e com prioridade pelos indivíduos em tarefas de livre associação de palavras a um termo indutor. Portanto, os termos mais salientes podem ser identificados considerandose essas duas variáveis, que definem uma propriedade quantitativa, a Ordem Média de Evocação (OME), como expresso pela Equação 3 (Quadro 4.4).

Quadro 4.4 - Equações para determinar os valores de corte.

\begin{tabular}{|c|c|}
\hline$O M E=\sum_{i-1}^{z} h_{i} \sum_{j=1}^{k} n_{j} / f_{i} \quad$ (onde $\left.i ; j \in N\right)$ & (Equação 1) \\
\hline$\tilde{f}=\operatorname{MED}\left(f_{i}\right) \quad($ onde $i \in N)$ & (Equação 2) \\
\hline$O G O E=\sum_{i=1}^{n} \frac{O M E_{i}}{m_{i}} \quad$ (onde $\left.i \in N\right)$ & (Equação 3) \\
\hline
\end{tabular}

OME, Ordem Média de Evocação; $h$, hierarquia de evocação; $\mathrm{n}$, quantidade de vezes com que o termo foi evocado; $f$, frequência; OGOE, Ordem Geral de Ordenamento das Evocações; $m$, frequência total de evocações dos termos, após a definição do valor de corte.

Fonte: Schaffer (2007), Vogel (2016). 
No Quadro 12, apresentam-se as equações usadas para distribuir os termos no quadrante de Vergès (Figura 4.1), conforme os valores de corte de suas coordenadas cartesianas; no eixo X, o valor de corte para a OME é estabelecido pela OGOE (Equação 3), enquanto no eixo $\mathrm{Y}$, o valor de corte para as frequências é dado pela frequência média (Equação 2).

Figura 4.1 - Quadrante de quatro casas proposto por Vergès.

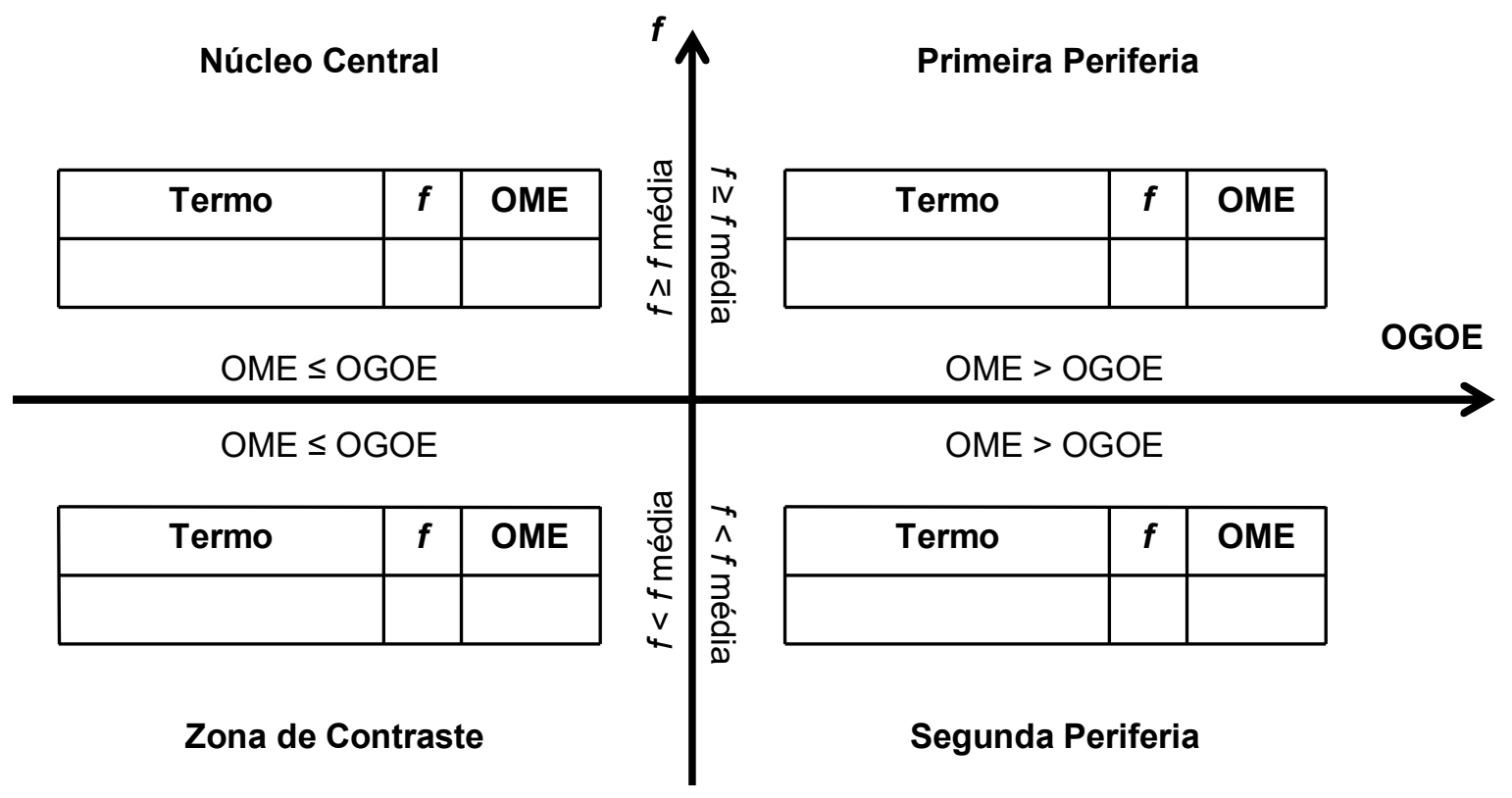

OME - Ordem Média de Evocação; OGOE - Ordem Geral dos Ordenamentos de Evocação.

Os termos com frequências $(f)$ maiores ou iguais à frequência média $\left(f_{\text {med }}\right)$ e valores para OME menores do que o determinado para a OGOE são alocados no quadrante superior à esquerda e são os possíveis termos do NC. No quadrante superior à direita estão alocados os termos da primeira periferia, termos com frequências $(f)$ maiores ou iguais à frequência média $\left(f_{\text {med }}\right)$ e valores para OME maiores do que o determinado para a OGOE. Os termos com frequências $(f)$ menores do que a frequência média $\left(f_{\text {med }}\right)$ e valores para OME maiores do que o determinado para a OGOE ficam alocados na segunda periferia, quadrante inferior à direita. Esses termos apresentam baixa saliência, o que permite inferir que seu valor simbólico é baixo para a representação do grupo social sobre o objeto; os termos alocados nesse quadrante expressam as opiniões dos indivíduos componentes do grupo. No quadrante inferior à esquerda, com frequências $(f)$ menores do que a frequência média $\left(f_{\text {med }}\right)$ e valores para OME menores do que o determinado para a OGOE, estão alocados da zona de contraste, termos que podem ser complementares aos termos da primeira zona periférica 
ou indicar a existência de um subgrupo que atribui grande valor a termos distintos daqueles valorizados pela maioria do grupo.

$\mathrm{Na}$ segunda etapa, investigam-se as relações entre os termos da representação e seu poder associativo, realizando-se a Análise de Similitude, proposta por Flament (SÁ, 2002). Para identificar o poder associativo dos termos, identifica-se a quantidade de conexões que os termos mantêm com outros termos da representação. Nessa abordagem, admite-se que quanto maior for o número de sujeitos que aceite ou rejeite simultaneamente dois termos, mais próximos eles estão e, portanto, mais conectados eles são (BOURICHE, 2003). Portanto, os termos com maior poder associativo podem ser identificados considerando-se sua conectividade. Para isso, consideram-se os valores de co-ocorrência dos termos evocados, a partir de uma relação entre frequência (f) e co-ocorrência das palavras. Podese expressar a co-ocorrência entre termos através de um grafo denominado árvore de similitude máxima, como exemplificado na Figura 4.2.

Figura 4.2 - Recorte da árvore de similitude máxima para os termos mais representativos sobre o objeto social ser "professor de Química": sub-grupo dos licenciandos não/PIBID.

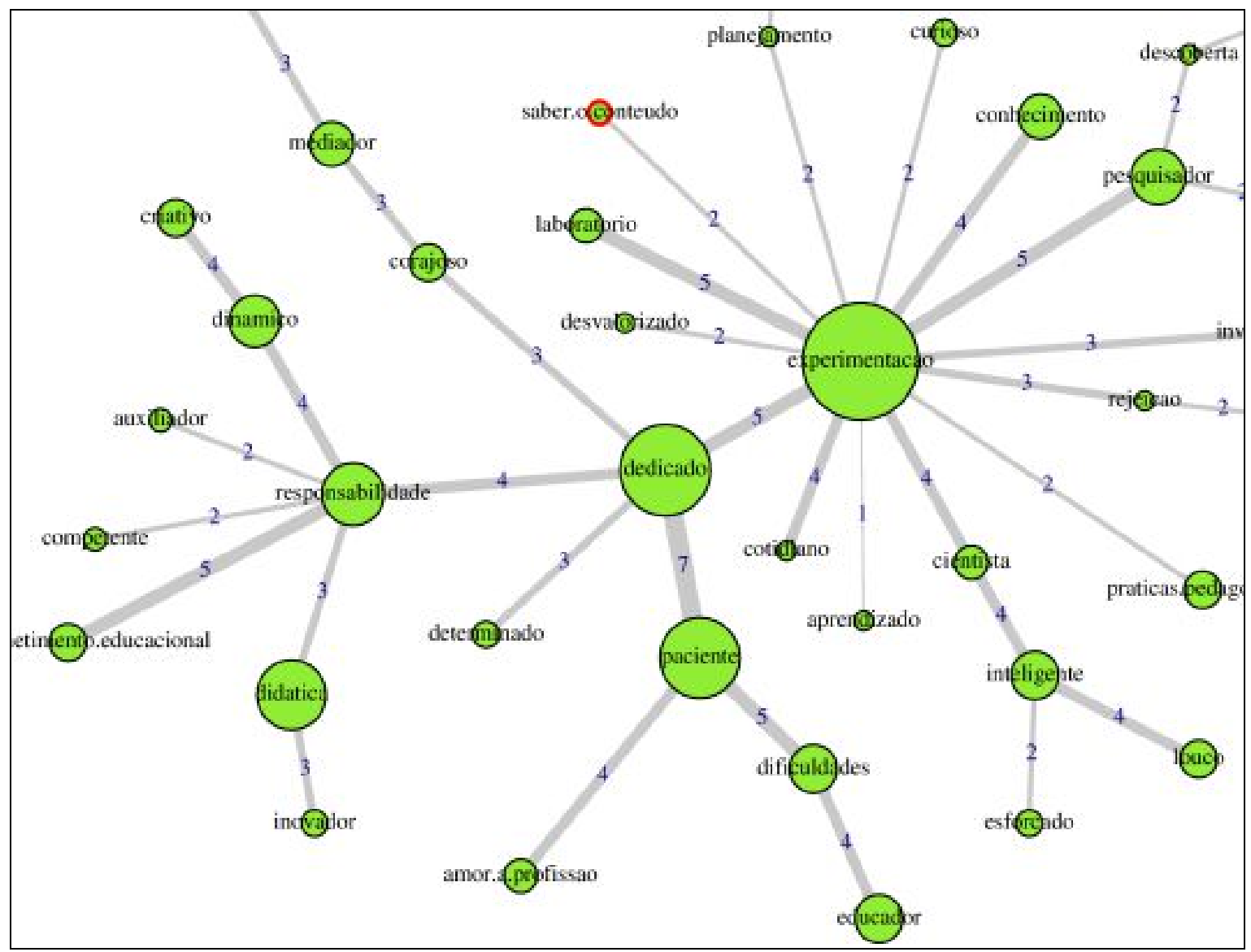

Fonte: Vogel (2016). 
A árvore de similitude máxima é constituída por vértices e arestas ligando os termos em pares em que uma frequência ( $f$ ) mais alta é evidenciada pelo maior valor do vértice. As arestas, por sua vez, ligam dois termos e o número expresso sobre a aresta indica o valor de co-ocorrência deles (no exemplo da Figura 4.2, experimentação e dedicado co-ocorrem 5 vezes), ou seja, a quantidade de vezes que esses dois termos foram citados conjuntamente no corpus analisado. Os vértices que apresentam maior somatório de co-ocorrência são os de maior conectividade (no exemplo, experimentação apresenta $\Sigma c o=40$; vide Figura 4.2).

Por último, na terceira etapa, analisa-se o significado dos termos da representação. Para isso, realiza-se uma análise de conteúdo para captar o sentido das justificativas que os sujeitos apresentaram em relação aos termos evocados. Essa análise amplia a compreensão da análise lexicográfica, considerando-se os termos evocados, a hierarquia e as associações produzidas, para uma análise temático-categorial, agrupando-se os termos em categorias temáticas, o que facilita a atribuição de significado aos termos componentes da RS (VOGEL, 2016). 


\section{PERCURSO METODOLÓGICO}

O desenvolvimento da metodologia desta pesquisa baseou-se nos pressupostos da TRS, caracterizando-se por ser um estudo qualitativo. O ramo das pesquisas orientadas pela TRS tem se caracterizado

[...] por uma utilização bastante criativa e diversificada de métodos e pelo desenvolvimento contínuo de novas técnicas, tanto no que se refere à coleta quanto ao tratamento de dados [...]. A rigor, desde a escolha, combinação ou adaptação de métodos, bem como a elaboração de instrumentos de coleta de dados e a definição ou criação de técnicas para seu tratamento, a pesquisa das representações sociais é explicitamente orientada pela conceituação e pela construção teórica específica que o pesquisador tenha adotado (SÁ, 2002, p. 99-100).

Decorrente da organização dos saberes práticos que estão ligados aos sujeitos e aos objetos em determinadas contextos sócio-histórico-culturais, a manifestação dos fenômenos apresenta complexidade e diversidade. Por isso, as pesquisas em RS devem ser planejadas de forma rigorosa e explícita, desde a "construção do objeto" (processo de transformação de uma apreensão intuitiva sobre um fenômeno para a prática de sua investigação), passando pela escolha e combinação de métodos até a elaboração de instrumentos de obtenção e análise de informações (SÁ, 2002).

O objeto de pesquisa não constitui uma réplica do fenômeno social a ser investigado, mas uma aproximação ditada pelas possibilidades e limitações da prática da pesquisa científica, devidos aos recursos disponíveis, como a viabilidade metodológica, a disponibilidade de técnicas de estudo, orçamento e tempo. Ou seja, esses "fenômenos simplesmente não podem ser captados pela pesquisa científica de um modo direto e completo" (SÁ, 2002, p. 21), como aliás é característico de qualquer estudo empírico.

A seguir, elucidar-se-á o caminho metodológico traçado para o desenvolvimento desta investigação. Inicia-se pela descrição do público-alvo, em seguida descreve-se o instrumento de obtenção de informações, o método de evocações livres associadas a um termo indutor e, por último, os métodos de análise que conduzem à construção dos dados a partir das informações obtidas.

\subsection{Público-Alvo}

O processo de obtenção e análise de informações foi planejado com o intuito de se fazer a comparação dos dados construídos a partir das informações obtidas de duas fontes, a saber: (i) professores de Licenciaturas em Química Coordenadores do PIBID e; (ii) professores de Licenciaturas em Química não-Coordenadores do PIBID. O objetivo foi 
investigar as RS sobre o objeto social "experimentação" desses grupos, tendo-se como ideia norteadora que a diversidade de ações desses grupos pode colaborar para que suas RS sejam diferentes. A seleção do público-alvo obedeceu aos critérios descritos no Quadro 5.1. Em relação ao critério de inclusão para a participação na pesquisa, para os Coordenadores foi o de coordenar o programa, independente de área de titulação; o critério de exclusão foi o de não coordenar esse programa. Já para os não-Coordenadores do PIBID, o critério de inclusão foi o docente lecionar para a Licenciatura em Química e o critério de exclusão foi o docente de Química não lecionar para a Licenciatura em Química.

Quadro 5.1 - Critérios para seleção dos Participantes da Pesquisa.

\begin{tabular}{|l|l|}
\hline \multicolumn{1}{|c|}{ Colaboradores } & \multicolumn{1}{c|}{ Critérios de seleção } \\
\hline $\begin{array}{l}\text { Coordenadores de } \\
\text { Área do PIBID }\end{array}$ & $\begin{array}{l}\text { i) Instituições de Ensino Superior que participam, ou participaram, de } \\
\text { atividades do PIBID, com subprojetos em Química; } \\
\text { ii) coordenar ou já ter coordenado o subprojeto PIBID-Química; } \\
\text { iii) disposição do sujeito em cooperar com a obtenção de informações para a } \\
\text { pesquisa. }\end{array}$ \\
\hline Não- & $\begin{array}{l}\text { i) professores que lecionam em cursos de Licenciatura em Química onde há } \\
\text { a realização de atividade do subprojeto PIBID-Química; } \\
\text { PIBID }\end{array}$ \\
& $\begin{array}{l}\text { ii) ter obtido resposta do coordenador do subprojeto PIBID-Química da } \\
\text { Instituição de Ensino Superior ao qual o sujeito está vinculado; } \\
\text { iii) disposição do sujeito em cooperar com a obtenção de informações para a } \\
\text { pesquisa. }\end{array}$ \\
\hline
\end{tabular}

A delimitação do campo de obtenção de informações apoiou-se nos relatórios de geração de pagamento de bolsas da CAPES dos anos 2013 a $2017^{9}$, sendo consultado o mês de novembro. A partir do levantamento realizado no final do ano de 2017, identificaram-se 570 coordenadores de área dos subprojetos PIBID-Química, em uma média de 226 subprojetos por ano. Essas informações são estimativas, pois as folhas de pagamento flutuam de ano para ano, pois novos subprojetos são iniciados ou encerrados.

Como o instrumento de obtenção de informações foi um questionário e a abordagem da TRS é a estrutural, optou-se por entrar em contato com todos os possíveis sujeitos de pesquisa, para que se obtivesse um número de participantes adequado à análise das informações que seria adotada. O contato com os participantes da pesquisa se deu através

${ }^{9}$ O Relatório de geração de pagamento de bolsas da CAPES é disponibilizado de forma online na página da plataforma CAPES. Neste consta as informações: nome e sigla da Instituição de Ensino Superior, o projeto PIBID e o Campus em que é sediado, as modalidades dos subprojetos, o nível e o nome dos participantes. Disponível em:

<http://www.capes.gov.br/educacao-basica/capespibid/relatorios-e-dados>. Acessado em: 15 de Agosto de 2017. 
de correio eletrônico, no qual havia um texto explicativo sobre o convite e um link que encaminhava o sujeito para o questionário sediado na plataforma do Google Docs. Os emails foram obtidos através das plataformas online das IES, de cada Campus, utilizando como instrumento de busca o Google. O contato se deu entre os meses de março e julho de 2018 sendo, também, solicitado o encaminhamento do convite para outros professores que se encaixassem no perfil da pesquisa. Ao final do processo, encaminhou-se o convite por meio eletrônico para 538 coordenadores, tendo havido retorno de 172 coordenadores.

Após a resposta dos coordenadores dos subprojetos PIBID-Química, iniciou-se o contato com os professores não-Coordenadores, de forma análoga à descrita acima. Porém, o contato com esses sujeitos foi realizado entre os meses de maio e agosto de 2018. Dos 643 professores contatados obteve-se resposta de 154, sendo que 103 sujeitos lecionam nos cursos de Licenciatura em Química onde há subprojetos PIBID-Química fazendo parte dos desta pesquisa. Os outros 51 sujeitos eram professores de Química que não lecionavam para cursos de Licenciatura em Química não sendo, portanto, considerados nesta pesquisa.

\subsection{Instrumento de obtenção de informações}

A obtenção de informações foi realizada através de um questionário semiestruturado planejado com base na abordagem estrutural das RS (ABRIC, 2001). Essa abordagem leva em consideração dois componentes: o conteúdo das RS e sua organização. Faz-se necessário empregar um instrumento que possibilite, por um lado, identificar e gerar termos constitutivos da RS e, por outro, conhecer a organização desses termos para a possível identificação de seu NC pela frequência e hierarquia dos termos manifestados. questionário é um importante instrumento para desvelar temas de representação por testes de associação livre de palavras a um termo indutor, pois

O caráter espontâneo, portanto menos controlado, e a dimensão projetiva
dessa produção deveriam permitir o acesso, muito mais fácil e rápido do
que uma entrevista, aos elementos que constituem o universo semântico do
termo ou do objeto estudado. A associação livre permite a atualização de
elementos implícitos ou latentes que seriam perdidos ou mascarados nas
produções discursivas (ABRIC, 2001p.59).

Embora esta pesquisa tenha caráter qualitativo, a identificação dos possíveis termos pertencentes ao NC ou ao sistema periférico da RS de um determinado grupo sobre um objeto é facilitada quando o número de sujeitos é maior, quando se faz a análise prototípica, baseada na frequência e hierarquia dos termos evocados (WACHELKE, 2016). Nesse sentido, o questionário é um instrumento que possibilita aumentar o número de sujeitos de pesquisa, ao mesmo tempo em que padroniza as perguntas, diminuindo a interferência do pesquisador no momento da obtenção das informações (ABRIC, 2001). 
Assim, a técnica utilizada para identificar os possíveis termos pertencentes ao NC da RS dos grupos de investigados será de tipo associativo, a evocação livre de palavras associada a um termo indutor, respaldada por questões em que os sujeitos justificam suas escolhas. questionário empregado teve como modelo o questionário aplicado e validado em pesquisas anteriores desenvolvidas pelo grupo LiEQui ${ }^{10}$ (VOGEL, 2016; PEREIRA, 2012).

O questionário (Apêndice A, p. 111) apresenta três seções. Na primeira seção, apresenta-se um texto explicativo ao colaborador e, logo após, solicita-se que ele assine o termo de consentimento de utilização das informações. O termo de livre consentimento (Apêndice $A$ ) assegura total sigilo das informações pessoais e avisa-o de que as demais informações serão usadas somente para a construção da Dissertação e de possíveis publicações.

A segunda seção (questões 1 - 9) objetiva caracterizar o grupo investigado. Assim, o colaborador foi convidado a responder se coordena ou não o PIBID e por quanto tempo; caso coordene, quais funções exerceu no subprojeto; título de graduação; última titulação; área da última titulação; os interesses atuais de pesquisa; se lecionou no Ensino Básico e por quanto tempo; tempo de atuação no Ensino Superior; e as disciplinas que leciona mais frequentemente (Apêndice A).

A terceira seção (questões 10 - 13) do questionário versa sobre as questões de associação livre de palavras ao termo indutor "experimentação", que foram a base para a construção dos dados necessários para se compreender as RS desse grupo sobre o objeto investigado, fundamentada na abordagem estrutural da TRS (ABRIC, 2001). As questões 10 e 11 visavam obter informações sobre as RS desse grupo sobre o objeto social estudado; as questões 12 e 13 foram utilizadas para compreender o significado dos termos evocados.

\subsection{Procedimento de Construção dos Dados}

A análise das informações obtidas com a técnica de associação livre de palavras envolveu três momentos sucessivos, sumariados no Quadro 5.2.

\footnotetext{
${ }^{10}$ Grupo de Pesquisa em Linguagem no Ensino de Química (LiEQui), sob coordenação da Prof. ${ }^{a}$ Dr. ${ }^{a}$ Daisy de Brito Rezende. O grupo tem desenvolvido suas pesquisas no âmbito do Programa Interunidades em Ensino de Ciências da Universidade de São Paulo.
} 
Quadro 5.2 - Momentos da abordagem estrutural.

\begin{tabular}{|c|c|c|c|}
\hline \multicolumn{2}{|c|}{ Momento } & Procedimento & Objetivo \\
\hline $1^{\circ}$ & $\begin{array}{c}\text { Análise } \\
\text { Prototípica }\end{array}$ & $\begin{array}{c}\text { Identificam-se os termos do NC e do sistema central e } \\
\text { do sistema periférico da RS. }\end{array}$ & $\begin{array}{c}\text { Conteúdo e } \\
\text { Estrutura da RS }\end{array}$ \\
\hline Similitude \\
$3^{\circ}$ & $\begin{array}{c}\text { Análise de } \\
\text { Conteúdo }\end{array}$ & $\begin{array}{c}\text { Estudam-se as relações entre os termos dos sistemas } \\
\text { central e periférico e sua importância relativa e sua } \\
\text { hierarquia. }\end{array}$ & Estrutura da RS \\
\hline
\end{tabular}

Fonte: Abric (2001), adaptado.

\subsubsection{Análise Prototípica}

A Análise Prototípica baseia-se no método associativo ou de associação livre de palavras. Esse método busca reduzir a dificuldade de expressão de termos ou a dispersão proveniente do discurso. O caráter espontâneo e diretivo do método auxilia no acesso aos termos mais importantes que constituem o universo semântico do objeto social estudado podendo, inclusive, permitir o acesso a termos que poderiam ser mascarados nas técnicas de entrevista (ABRIC, 2001; SÁ, 2002).

Para tanto, solicita-se aos sujeitos, a partir de um termo indutor, que expressem uma quantidade de palavras ou termos que the venham à mente de forma mais imediata. No caso desta pesquisa o instrumento utilizado foi o questionário semiestruturado, a forma de registro é a escrita, o termo indutor é "experimentação" e o número de termos solicitados aos respondentes, seis.

A Análise Prototípica é facilitada empregando-se o programa EVOCATION $2005^{\circledR}$ (Ensemble de Programmes Permettant l'Analyse de Évocations; VERGÈS et al., 2003; REIS et al., 2013), que é um conjunto de subprogramas organizados, visando, dentre outras coisas, processar as análises matemáticas das evocações necessárias para a construção do quadrante de Vergès (vide Equações 1, 2 e 3, Capítulo 4.4).

Para se utilizar o EVOCATION $2005^{\circledR}$, é necessário construir um banco de dados após a obtenção das informações, tendo o cuidado de não cometer quaisquer erros, como o de digitação, para evitar alterações dos resultados. O programa admite que o banco de dados seja construído tanto no Office Word como no Excel, (sendo possível a utilização de programas Open Source: BrOffice e Libre Office; REIS et al., 2013). Nesta pesquisa, optouse por organizar os termos evocados em uma planilha do programa Microsoft Office Excel (com extensão .csv), como proposto por Vogel (2016), por diminuir a complexidade e a possibilidade de erros. 
Após a submissão da planilha ao programa EVOCATION $2005^{\circledR}$, realiza-se a análise através dos subprogramas LEXIQUE, TRIEVOC, NETTOIE, RANGMOT, LISTVOC, AIDECAT e RANGFRG, cujas funções estão sumariadas no Quadro 5.3.

Quadro 5.3 - Programas do EVOCATION 2005® utilizados e suas respectivas funções.

\begin{tabular}{|c|l|}
\hline Subprograma & \multicolumn{1}{c|}{ Função } \\
\hline LEXIQUE & $\begin{array}{l}\text { Cria um vocabulário de evocações (léxico), identifica a quantidade de indivíduos } \\
\text { e de termos presentes no arquivo de entrada. }\end{array}$ \\
\hline TRIEVOC & $\begin{array}{l}\text { Cria um vocabulário de evocações identificando os termos que serão utilizados } \\
\text { nas análises posteriores. }\end{array}$ \\
\hline NETTOIE & $\begin{array}{l}\text { Possibilita a modificação dos termos do banco de dados, visando por um lado, } \\
\text { auxiliar na erradicação dos erros ortográficos, e por outro, a homogeneização } \\
\text { dos termos, tornando o banco de dados mais robusto. }\end{array}$ \\
\hline RANGMOT & $\begin{array}{l}\text { Gera uma lista informando a Ordem Média de Evocação (OME), o total de } \\
\text { vezes que cada termo foi evocado (frequência) e o número de vezes que cada } \\
\text { evocação aparece em uma determinada evocação (rang). As informações } \\
\text { apresentadas por esse subprograma são fundamentais para a construção do } \\
\text { quadrante de Vergès. }\end{array}$ \\
\hline RANGFRG & $\begin{array}{l}\text { Gera o quadrante de Vergès a partir do tratamento dos dados relacionando } \\
\text { hierarquia em função da frequência, e apresentando como saída uma } \\
\text { sequência das evocações, das mais frequentes para as menos frequentes, e a } \\
\text { OME. }\end{array}$ \\
\hline SELIDENT & $\begin{array}{l}\text { Cria novos arquivos a partir de varáveis que se deseja investigar a partir do } \\
\text { arquivo inicial. }\end{array}$ \\
\hline COMPLEX & $\begin{array}{l}\text { Compara os dados gerados inicialmente pelo programa com os novos dados } \\
\text { gerados pelo subprograma SELIDENT. }\end{array}$ \\
\hline
\end{tabular}

Fonte: Reis et al. (2013); Pereira (2016); Vogel, (2017).

\subsubsection{Análise de Similitude}

A Análise de Similitude possibilita caracterizar as relações de conectividade entre os termos, partindo-se do princípio de que os termos que são mencionados pelos sujeitos de pesquisa (termos que ocorrem juntos), possuem relações entre si. Esta análise baseia-se em uma matriz de co-ocorrências dos termos evocados e seu resultado pode ser expresso na forma de um grafo, árvore de similitude máxima, contendo vértices (os termos) interligados por arestas, cujos valores são os índices de co-ocorrência (Sá, 2002).

Essa análise é facilitada empregando-se o programa IRAMUTEQ $0.7^{\circledR}$ (Interface de $R$ pour les Analyses Multidimensionnelles de Textes et de Questionnaires) desenvolvido por Pierre Ratinaud (RATINAUD; DEJEAN, 2008).

Neste estudo, o banco de dados utilizado para a construção do quadrante de Vergès, uma planilha do Microsoft Excel, foi submetido ao IRAMUTEQ $0.7^{\circledR}$, seguindo o procedimento proposto por Vogel (2016), de calcular os índices de similitude entre os termos de maior valor simbólico para o grupo estudado, e não entre categorias construídas a posteriori a partir das evocações (OLIVEIRA et al., 2001). 
Para este estudo, considerou-se como critério de seleção os termos de maior saliência, conjunto de termos que abrangem cerca de $50 \%$ do total acumulado de termos evocados, admitindo-se o mesmo valor de corte para a frequência mínima adotado na Análise Prototípica.

\subsubsection{Análise de Conteúdo}

A análise de conteúdo é muito utilizada no campo das pesquisas sobre RS, por permitir a construção de categorias ou dimensões que auxiliam no processo de interpretação dos resultados alcançados de forma sistemática e flexível (CARMO et al., 2017).

A análise de conteúdo é "um conjunto de técnicas de análise das comunicações que utiliza procedimentos sistemáticos e objetivos de descrição do conteúdo das mensagens" (BARDIN, 2011, p. 44), consistindo, basicamente, em três fases.

A primeira fase, pré-análise, é caracterizada pelo aspecto organizacional, pela organização e preparação do material e visa sistematizar as ideias iniciais, estabelecendose um esquema de desenvolvimento das operações futuras.

A segunda fase, exploração do material, é caracterizada pela administração sistemática das decisões tomadas, ou seja, da análise propriamente dita, através das operações de codificação. Nesta etapa, realizou-se a construção de:

- unidades de registro, através da leitura e releitura das evocações;

- unidades de significação, através da análise das respostas às questões de número 12 (explique as razões de suas escolhas) e 13 (organize os termos em pares) em relação às evocações expressas na questão de número 11 do questionário;

- unidades de contexto, através da análise dos termos do NC para a posterior construção das dimensões temáticas que orientarão a classificação dos termos constituintes dos demais elementos das RS;

- unidades temáticas e alocação dos termos presentes nos outros elementos da RS nas dimensões, tendo como orientação as justificativas apresentadas pelos sujeitos.

A terceira fase, tratamento dos resultados, inferência e interpretação, é o momento em que o pesquisador realiza interpretações a partir dos objetivos traçados. É a etapa em que se atribui sentido aos termos componentes da representação social. Nesta etapa realizaramse:

- a captação do sentido emergente, em que a saturação das unidades básicas de análise leva à compreensão do todo;

- a escrita de um metatexto apresentando as inferências do pesquisador. 


\subsubsection{Adequação dos termos para análise}

Para a construção do quadro de quatro casas de Vergès e da árvore de similitude máxima, utilizaram-se CAQDAS (Computer Aided Qualitative Data Analysis Software). Estes programas trazem vantagens por sua capacidade de construção, codificação, recuperação e apresentação dos dados, porém não substituem o pesquisador (LAGE e GODOY, 2008; REIS et al., 2013).

Um dos aspectos inerentes ao processo de utilização dos CAQDAS é a adequação das informações que serão fornecidas aos programas no processo de construção do banco de dados, o input. Por exemplo, os programas utilizados nesta pesquisa, EVOCATION $2005^{\circledR} \mathrm{e}$ IRAMUTEQ $0.7^{\circledR}$, permitem a inserção tanto de arquivos de texto (extensão .txt) como arquivos de planilha (extensão .csv), porém há necessidade da adequação dos termos para que se evitem erros de leitura. Enquanto o programa EVOCATION $2005^{\circledR}$ aceita acentos nas palavras, o IRAMUTEQ $0.7^{\circledR}$ não o faz. Em ambos os programas, os termos evocados devem ser digitados com letras minúsculas e os termos que apresentarem mais de uma palavra devem ser tratados como uma ideia única, ligando-os através de um hífen. No Quadro 5.4, apresentam-se algumas das modificações realizadas para a construção do banco de dados.

Quadro 5.4 - Modificação dos termos para a construção do banco de dados.

\begin{tabular}{|c|c|}
\hline Termo evocado & Termo modificado \\
\hline Investigação & investigacao \\
EPls & epis \\
Método científico & metodo-cientifico \\
\hline
\end{tabular}

Para a construção de um banco de dados mais robusto também é interessante realizar a padronização dos termos, realizado de duas formas: lematização e categorização semântica.

A lematização é o processo de agrupamento das palavras que compartilham o mesmo radical e classe. Nesse caso, agrupam-se os termos que possuem variações entre masculino e feminino, singular e plural, em uma só forma, segundo a resposta mais freqüente. É possível realizar esse procedimento com o IRAMUTEQ $0.7^{\circledR}$, apresentando boa confiabilidade (SARRICA et al., 2016). No caso de frequências iguais, convenciona-se a forma que seja mais representativa para os sujeitos estudados. Para isso, é necessário voltar à questão 12 do questionário para verificar o significado atribuído aos termos pelos sujeitos. 
De forma análoga, ocorre com a categorização semântica, que utiliza critérios semânticos para realizar o agrupamento dos termos que compartilham significados em comum para os sujeitos estudados (WACHELKE; WOLTER, 2011). Para esta análise, utilizaram-se três estratégias sequenciadas: primeiramente, realizou-se a leitura das justificativas dos termos evocados (questão 12, Apêndice A, p.111), para, posteriormente, realizar-se a leitura do pareamento dos termos evocados, referentes à questão $13 \mathrm{e}$, por último, caso ainda houvesse dúvidas, realizou-se a leitura dos termos posteriores e anteriores, e as respectivas justificativas para o termo evocado, referentes as questões 11 e 12 (Apêndice A). No Quadro 5.5, apresentam-se alguns exemplos de homogeneização dos termos.

No Quadro 5.5 apresenta-se alguns exemplos de homogeneização dos termos.

Quadro 5.5 - Homogeneização e Categorização Semântica dos termos evocados.

\begin{tabular}{|c|c|c|}
\hline Forma de Homogeneização & Termo Evocado & Termo Modificado \\
\hline Homogeneização & $\begin{array}{c}\text { laboratórios } \\
\text { demonstrativo } \\
\text { material-alternativo }\end{array}$ & $\begin{array}{c}\text { laboratorio } \\
\text { demonstrativa } \\
\text { materiais-alternativos }\end{array}$ \\
\hline Categorização Semântica & $\begin{array}{c}\text { pesquisar } \\
\text { apresquisa } \\
\text { investigadora }\end{array}$ & $\begin{array}{c}\text { aprendizagem } \\
\text { inverimentizacao-investigativa }\end{array}$ \\
\hline
\end{tabular}

Nesta pesquisa, realizou-se, primeiramente, a homogeneização dos termos e, posteriormente, a categorização semântica. A listagem original dos termos está disponível no Apêndice B (p. 116) e a lista da modificação dos termos evocados está disponível no Apêndice C (p. 129). 


\section{RESULTADOS E DISCUSSÃO}

Neste Capítulo, apresenta-se a construção dos dados e discutem-se os resultados obtidos a partir das informações coletadas dos sujeitos de pesquisa. Para tal, apresentamse a caracterização dos sujeitos da pesquisa, os quadrantes de Vergès, as árvores máximas de similitude e a análise de conteúdo dos termos evocados.

\subsection{Caracterização dos Sujeitos de Pesquisa}

As faixas de tempo de participação no subprojeto PIBID estão apresentadas na Tabela 6.1 e advêm da pergunta de número 2.2 "Qual foi seu tempo total de participação no programa PIBID? (em meses)" do Questionário (Apêndice A, p.111). Da análise da Tabela 6.1 , é possível inferir que $85 \%$ dos coordenadores permaneceram por mais de um ano no exercício deste papel e que $50 \%$ deles o exerceram por mais de três anos. Este dado é importante porque mostra que há continuidade das ações do Coordenador nos subprojetos PIBID em muitos casos, uma característica que contribui para que os projetos de Iniciação à Docência propostos possam ser repensados e melhor estruturados para o contexto em que se desenvolvem.

Tabela 6.1 - Tempo de participação dos coordenadores no subprojeto PIBID.

\begin{tabular}{ccc}
\hline $\begin{array}{c}\text { Tempo de Participação } \\
\text { em meses }\end{array}$ & $\begin{array}{c}\text { Quantidade de } \\
\text { sujeitos }\end{array}$ & Porcentagem do total \\
\hline $0-12$ & 26 & 15 \\
$13-24$ & 31 & 18 \\
$25-36$ & 29 & 17 \\
$37-48$ & 50 & 29 \\
$49-60$ & 9 & 5 \\
$61-72$ & 11 & 7 \\
$n>72$ & 16 & 9 \\
TOTAL & 172 & 100 \\
\hline
\end{tabular}

Há equidade no que se refere ao sexo dos sujeitos (Tabela 6.2) entre os Coordenadores e os não-Coordenadores do PIBID, embora para os não-Coordenadores haja uma quantidade sutilmente maior para o sexo feminino. Segundo um estudo desenvolvido pelo Instituto Nacional de Estudos e Pesquisas Educacionais Anísio Teixeira (INEP; MEC-INEP, 2018), a quantidade de ingressantes do sexo feminino na graduação é superior à daqueles do sexo masculino, embora a quantidade de concluintes de sexo masculino seja maior. Já os estudos do World Economic Forum (WEF, 2016) mostram que a quantidade de ingressantes e concluintes do sexo feminino na pós-graduação das IES brasileiras é maior do que a pessoas do sexo masculino, tanto no Mestrado como no Doutorado. Essa 
característica também se mantém para os docentes de Pós-graduação na área de Ensino, na qual a quantidade de docentes do sexo feminino corresponde a $55 \%$ do quadro docente (CAPES-MEC, 2018). Entretanto, pode-se perceber (Tabela 6.2) que essa superioridade de docentes do sexo feminino não se manifesta inteiramente no caso dos Coordenadores do PIBID que participaram desta pesquisa.

Tabela 6.2 - Distribuição dos sujeitos de pesquisa em função do sexoa.

\begin{tabular}{ccccc}
\hline & \multicolumn{2}{c}{ Coordenadores do PIBID } & \multicolumn{2}{c}{ Não-Coordenadores do PIBID } \\
\hline \multicolumn{1}{c}{ Sexo } & Sujeitos & \% do total & Sujeitos & \% do total \\
\hline Masculino & 87 & 51 & 46 & 45 \\
\hline Feminino & 85 & 49 & 57 & 55 \\
\hline TOTAL & 172 & 100 & 103 & 100
\end{tabular}

a. o sexo dos sujeitos foi inferido a partir de seus nomes e da leitura da biografia constante de seus currículos Lattes.

$\mathrm{Na}$ Tabela 6.3, estão informados a área e o nível de titulação dos sujeitos da pesquisa. Quanto ao título obtido na graduação, percebe-se que há uma quantidade maior de licenciados $(110 ; 63,9 \%)$ no grupo de Coordenadores do PIBID, enquanto para os nãoCoordenadores predomina a dupla titulação no bacharelado e na licenciatura (43; $41,7 \%)$. A titulação bacharel + licenciado se refere ao modelo de formação $3+1$ (ou $4+1$ ), predominante no período de 1971 a 1996 (SAVIANI, 2009), período de conclusão da graduação da maior parte dos não-Coordenadores do $\mathrm{PIBID}^{11}$.

Tabela 6.3 - Área e nível da titulação dos sujeitos.

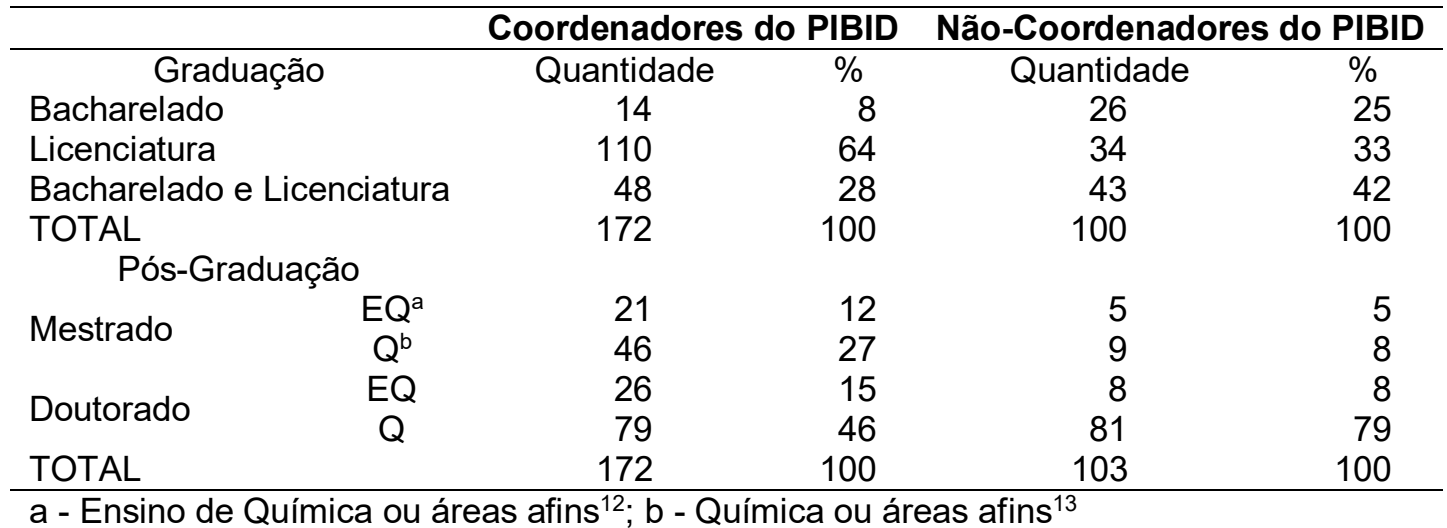

Quanto ao nível de titulação na pós-graduação, percebe-se que o grupo com maior porcentagem de doutores é o dos não-Coordenadores do PIBID (89; 87,3\%), em relação

\footnotetext{
${ }^{11}$ informação obtida na questão 3 "Em que ano você concluiu o curso de graduação?"

${ }^{12}$ Mestrado ou Doutorado em Educação ou Ensino de Ciências, por exemplo.

${ }^{13}$ Mestrado ou Doutorado em Farmácia (Farmacoquímica) ou Ciências Biológicas (Bioquímica), por exemplo.
} 
aos Coordenadores $(105 ; 61 \%)$. Porém, para ambos os casos o número de docentes com doutorado é superior à média nacional de docentes doutores em cursos de licenciatura, que corresponde a 59,2\% (MEC-INEP, 2018). Estes resultados mostram que a implementação de vários programas de pós-graduação em Ensino de Ciências vem contribuindo para a formação de pesquisadores nesse campo de conhecimento (vide Figura 6.1).

Figura 1.1 - Crescimento do número de programas de Pós-Graduação na Área de Ensino de Ciências (2000-2017).

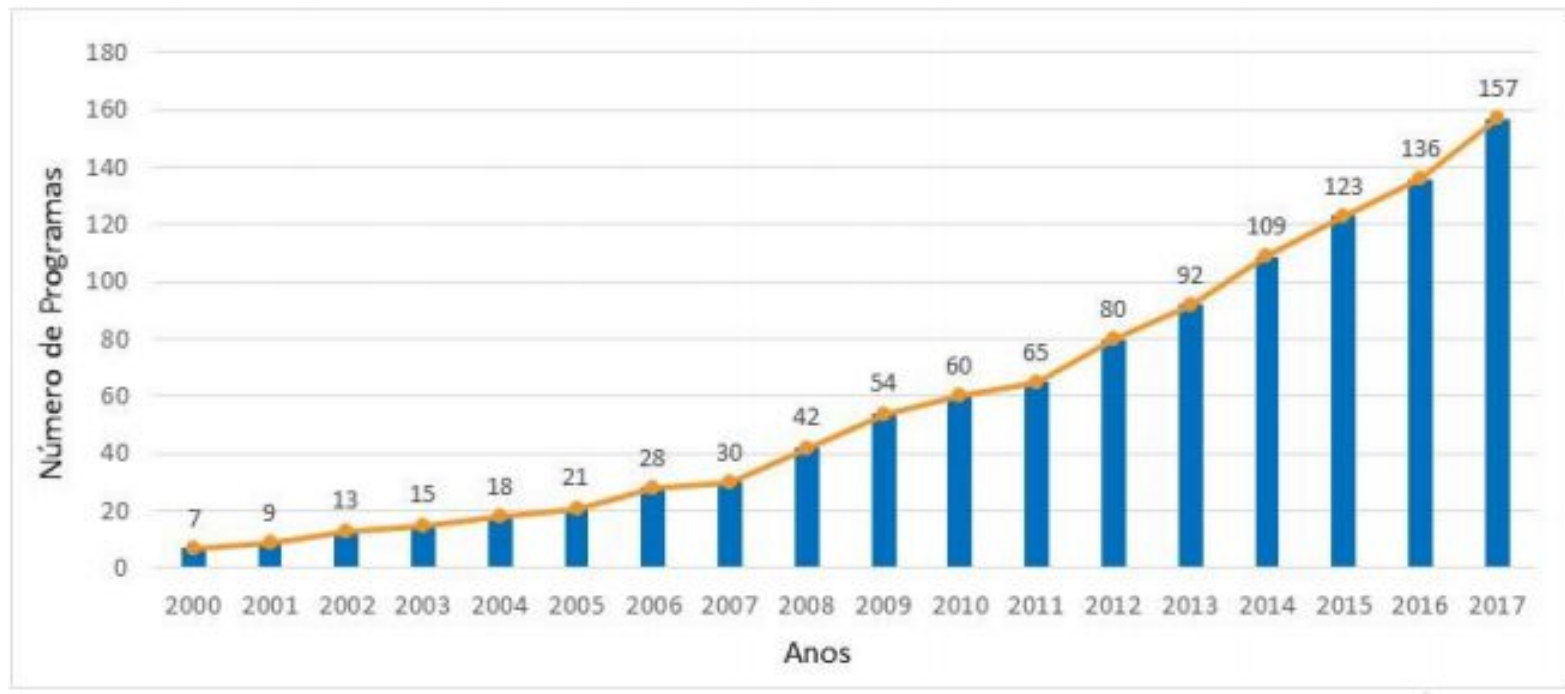

Fonte: CAPES - Plataforma Sucupira apud CAPES-MEC (2018).

O primeiro programa de Pós-graduação na área de Ensino foi implementado na década de 1970, porém no ano 2000 só havia sete programas. Esse quadro foi sendo alterado com um contínuo crescimento de programas de Pós-graduação na área de Ensino, tanto acadêmicos como profissionais, sendo que, no ano de 2017, já havia 157 programas. Esse crescimento se reflete no número de mestres e doutores formados, sendo que, entre 2000 e 2003, haviam sido titulados 327 Mestres, mas nenhum Doutor na área de Ensino; entre 2007 e 2009, 1.053 Mestres e 142 Doutores obtiveram seus títulos e, entre 2013 e 2016, esse número subiu para 2.046 Mestres e 908 Doutores titulados. No total, entre 2000 e 2017 foram titulados 10.375 Mestres e de 1.355 Doutores na área de Ensino de Ciências (CAPES-MEC, 2018).

Analisando-se a Tabela 6.4, percebe-se que a maior parte do grupo dos nãoCoordenadores nunca lecionou na Educação Básica ou o fez por pouco tempo, diferentemente do que ocorre com o grupo dos Coordenadores do PIBID, em que a maior parte dos sujeitos leciona ou lecionou na Educação Básica. É importante mencionar que alguns dos sujeitos da pesquisa atuam tanto no Ensino Superior como no Ensino Básico. Esta situação refere-se tanto a docentes contratados em tempo parcial nas Universidades 
como àqueles que atuam nos Institutos Federais de Educação, Ciência e Tecnologia, onde o Ensino Médio é ofertado concomitantemente às licenciaturas. Percebe-se, também, que ao aumentar o número de anos de permanência no Ensino Básico, diminui, proporcionalmente, o número de sujeitos.

Tabela 6.4 - Tempo de experiência docente no Ensino Básico.

\begin{tabular}{ccccc}
\hline & \multicolumn{2}{c}{ Coordenadores do PIBID } & Não-Coordenadores do PIBID \\
\hline Tempo (anos) & Quantidade & $\%$ & Quantidade & $\%$ \\
$\mathrm{n}=0$ & 32 & 19 & 43 & 42 \\
$1-3$ & 37 & 21 & 25 & 24 \\
$4-6$ & 28 & 16 & 15 & 14 \\
$7-9$ & 19 & 11 & 7 & 7 \\
$10-12$ & 22 & 13 & 5 & 5 \\
$13-15$ & 13 & 8 & 1 & 1 \\
$16-18$ & 6 & 3 & 1 & 1 \\
$\mathrm{n}>18$ & 15 & 9 & 6 & 6 \\
TOTAL & 172 & 100 & 103 & 100 \\
\hline
\end{tabular}

Quanto ao tempo de atuação no Ensino Superior, a análise da Tabela 6.5 possibilita inferir que há uma concentração tanto de Coordenadores como de não-Coordenadores do PIBID que apresentam experiência de 4 a 12 anos como docentes do Ensino Superior. No caso dos não-Coordenadores do PIBID há também sujeitos que apresentam um tempo de experiência considerável no Ensino Superior (28 sujeitos, correspondendo a 27\%), lecionando há mais de 18 anos.

Tabela 6.5 - Tempo de experiência docente no Ensino Superior.

\begin{tabular}{ccccc}
\hline & \multicolumn{2}{c}{ Coordenadores do PIBID } & Não-Coordenadores do PIBID \\
\hline Tempo (anos) & Quantidade & $\%$ & Quantidade & $\%$ \\
$1-3$ & 8 & 5 & 5 & 5 \\
$4-6$ & 29 & 17 & 21 & 20 \\
$7-9$ & 41 & 23 & 19 & 18 \\
$10-12$ & 38 & 22 & 17 & 17 \\
$13-15$ & 24 & 14 & 7 & 7 \\
$16-18$ & 8 & 5 & 6 & 6 \\
$\mathrm{n}>18$ & 24 & 14 & 28 & 27 \\
TOTAL & 172 & 100 & 103 & 100 \\
\hline
\end{tabular}

$\mathrm{Na}$ Tabela 6.6, está sumariada a área das disciplinas ministradas pelos sujeitos de pesquisa (foi solicitado aos participantes que informassem as disciplinas que lecionam com maior frequência no Ensino Superior, em ordem decrescente de frequência). Realizou-se o agrupamento das disciplinas em duas áreas, Educação e Ensino de Química (E/EQ) e Química (Q). A área de Educação e Ensino de Química abrange as disciplinas teóricas ou práticas de cunho pedagógico ou de interface química/educação. Já a área de Química abrange as disciplinas teóricas ou práticas de conteúdo químico. A categoria ambos refere- 
se àqueles sujeitos que ministram tanto disciplinas da área de Educação e Ensino de Química, como da área de Química.

Tabela 6.6 - Área das disciplinas que os sujeitos da pesquisa ministram no Ensino Superior.

\begin{tabular}{ccccc}
\hline & \multicolumn{2}{c}{ Coordenadores do PIBID } & Não-Coordenadores do PIBID \\
\hline Área & Quantidade & $\%$ & Quantidade & $\%$ \\
E/EQ $^{a}$ & 38 & 22 & 7 & 7 \\
$\mathrm{Q}^{\mathrm{b}}$ & 59 & 34 & 78 & 76 \\
Ambos & 75 & 44 & 18 & 17 \\
TOTAL & 172 & 100 & 103 & 100 \\
\hline
\end{tabular}

a - Educação e Ensino de Química; b - Química

Analisando-se a Tabela 6.6, é possível verificar que, enquanto os Coordenadores geralmente ministram disciplinas tanto da área de Educação como do Ensino de Química e da Química, os não-Coordenadores do PIBID ministram, majoritariamente, disciplinas da área de Química. Este dado não é surpreendente porque seria de se esperar que esses docentes dedicassem a maior parte de seus esforços ao ensino e pesquisa aos conteúdos de Química próximos de sua área de pesquisa durante a pós-graduação. Esta suposição é confirmada pelos dados sobre os interesses atuais de pesquisa (Tabela 6.7), dos quais verifica-se que os Coordenadores do PIBID preferem realizar pesquisas no campo da Educação e Ensino de Química, diferentemente do que ocorre com os não-Coordenadores, que dedicam-se para a pesquisa nas demais áreas da Química.

Tabela 6.7 - Área do interesse atual de pesquisa.

\begin{tabular}{ccccc}
\hline \multicolumn{4}{c}{ Coordenadores do PIBID } & Não-Coordenadores do PIBID \\
\hline Área & Quantidade & $\%$ & Quantidade & $\%$ \\
${\mathrm{E} / E Q^{a}}^{\mathrm{b}}$ & 112 & 65 & 22 & 21 \\
$\mathrm{Q}^{\mathrm{b}}$ & 26 & 15 & 60 & 58 \\
$\mathrm{Ambos}$ & 34 & 20 & 21 & 21 \\
TOTAL & 172 & 100 & 103 & 100 \\
\hline a - Educação e Ensino de Química; b - Química
\end{tabular}

No Apêndice D (p. 132), há uma lista dos sujeitos em função das IES, Estado e região brasileiros. O número total de IES é de 89, localizadas em 26 Estados, das 5 regiões brasileiras. A partir da comparação destes dados com a Figura 6.2, na qual se apresenta a distribuição geográfica dos Coordenadores do PIBID, identifica-se que estes sujeitos situamse em 26 Estados, principalmente, nas regiões Nordeste (56 sujeitos; representando $33 \%$ do total) e Sudeste $(54 ; 31 \%)$, nos estados da Bahia e São Paulo, respectivamente. Essa característica provém da distribuição regional dos projetos PIBID, com maior concentração nas regiões Sudeste, Sul e Nordeste, embora o maior número de bolsistas e de IES participantes sejam do Nordeste (CAPES-DEB, 2013; CAPES-MEC, 2017). 
Figura 6.2 - Distribuição geográfica dos Coordenadores do PIBID.

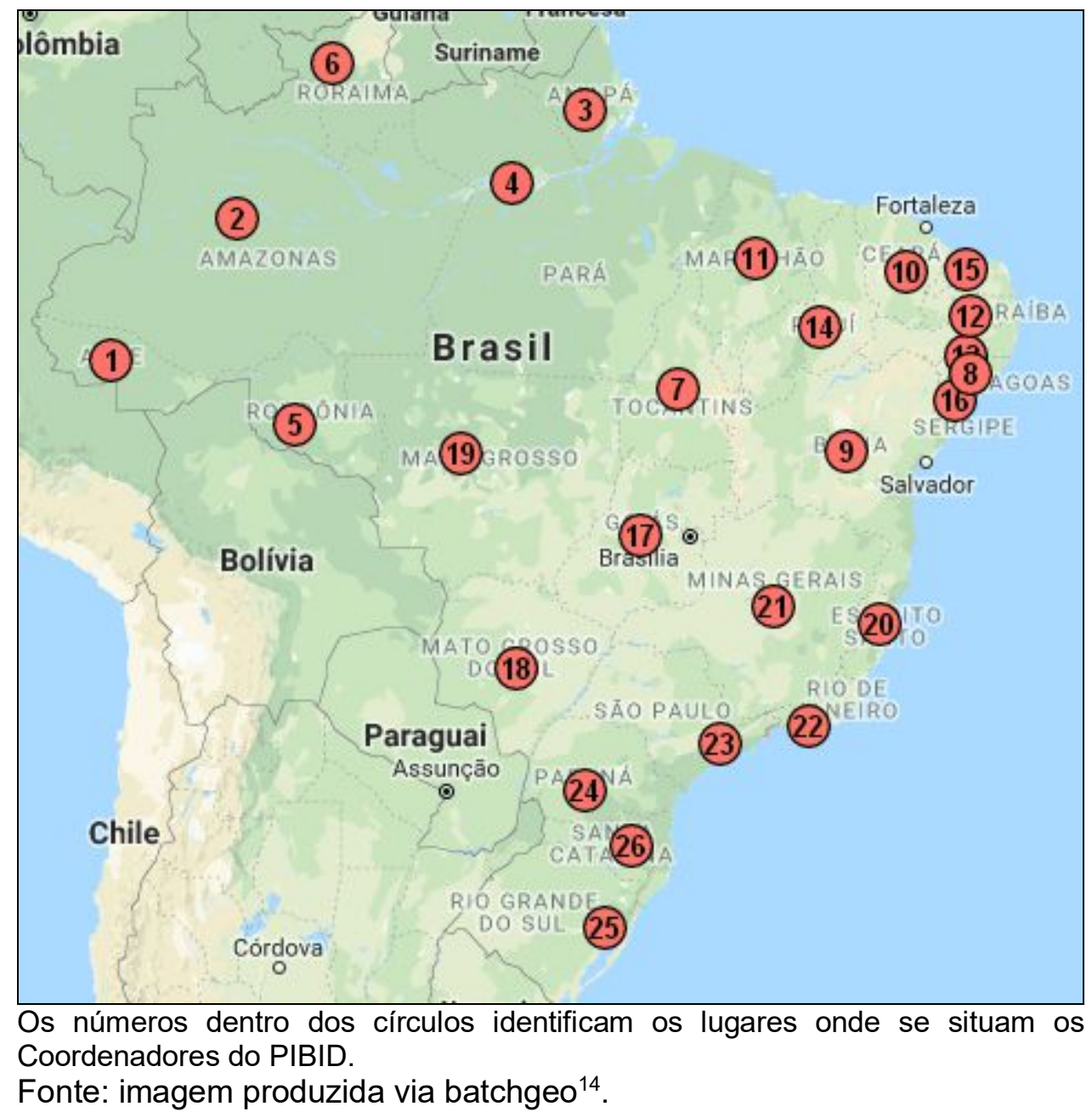

Já os não-Coordenadores estão situados em 16 Estados brasileiros (vide Figura 6.3), mas há uma grande concentração na região Sudeste (60; 58,3\%), no Estado de São Paulo. Essa característica é consequência da distribuição regional que historicamente se têm dos cursos de graduação e dos programas de Pós-graduação brasileiros, tendo grande concentração nas regiões Sudeste e Sul; isso está associado tanto com a concentração de Universidades e Institutos de Pesquisa historicamente consolidados nessas regiões, como à disparidades na distribuição de recursos que essas regiões apresentam em relação às demais regiões brasileiras (SIDONE et al., 2016). Porém, há um movimento de descentralização dos Programas de Pós-Graduação em Ensino, por exemplo, que tem aumentado o número de cursos de graduação e programas de Pós-graduação nas regiões Norte, Nordeste e Centro-Oeste (CAPES-MEC, 2017; CAPES-MEC, 2018).

${ }^{14} \mathrm{O}$ BatchGeo é uma ferramenta online gratuita que realiza o processamento de endereços por coordenadas geográficas (geocodificação). Disponível em: <https://pt.batchgeo.com/>. Acesso em 25 março de 2019. 
Figura 6.3 - Distribuição geográfica dos não-Coordenadores do PIBID.

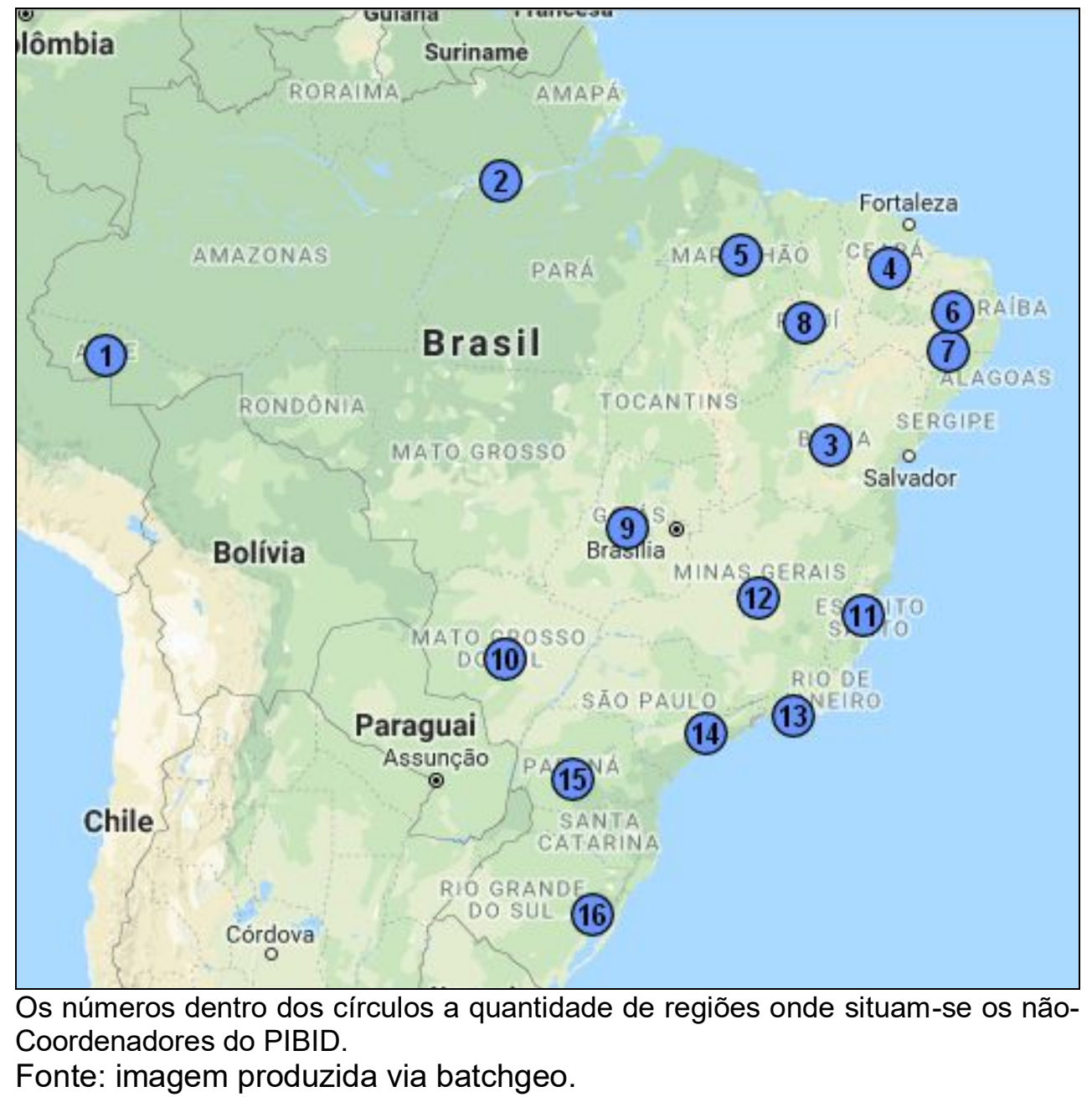

As IES são, majoritariamente, da esfera pública (80; 89,9\%; Instituições Públicas de Ensino Superior, IPES) sendo as demais da esfera privada ${ }^{15}$. A maioria das IPES é mantida pelo Governo Federal $(61 ; 73,3 \%)$, enquanto $19(26,7 \%)$ são da responsabilidade de governos estaduais.

\footnotetext{
${ }^{15}$ As IES da esfera privada, sem fins lucrativos, tiveram a possibilidade de submissão de propostas a partir do edital no 061/2013 da CAPES: "O objeto deste edital é a seleção de projetos institucionais de iniciação à docência que visem ao aperfeiçoamento da formação inicial de professores por meio da inserção de estudantes de licenciatura em escolas públicas de educação básica. Para o desenvolvimento dos projetos, serão concedidas 72.000 (setenta e duas mil) bolsas a alunos dos cursos de licenciatura e a professores das Instituições de Ensino Superior e das escolas da rede pública de ensino. Dessas bolsas, 10.000 (dez mil) serão destinadas a alunos de licenciatura do Programa Universidade para Todos (ProUni) e aos professores envolvidos na sua orientação e supervisão. Concessões não preenchidas na modalidade do Pibid-ProUni poderão ser remanejadas para as instituições públicas e privadas sem fins lucrativos". Disponível em https://www.capes.gov.br/images/stories/download/editais/Edital 0612013 PIBID RETIFICADO.pdf. Acessado em 30 de setembro de 2018.
} 
Outro ponto a se comentar é que, em duas das 89 IES (UFPI e UNICAMP), há somente sujeitos não-Coordenadores do PIBID. Este fato se deve ao conteúdo do e-mail enviado pelo correio eletrônico, em que se solicitava que os contatados encaminhassem o e-mail para outros professores que considerassem se encaixar no perfil da pesquisa. 0 encaminhamento do e-mail resultou na resposta de dois docentes que lecionam em cursos de Licenciatura, caracterizados como não-Coordenadores, mas sem haver respostas de sujeitos que se encaixassem nos grupos dos Coordenadores do PIBID.

A partir da descrição das características dos sujeitos da pesquisa, pode-se inferir que eles apresentam diferenças nas seguintes variáveis (i) experiência de coordenação em subprojetos PIBID; (ii) área e nível de titulação; (iii) tempo de experiência docente na Educação Básica; (iv) tempo de experiência docente no Ensino Superior; (v) áreas das disciplinas que ministram no Ensino Superior; e (vi) área dos interesses atuais de pesquisa.

\subsection{Construção de dados considerando o total de sujeitos investigados}

Neste tópico, a construção e análise dos dados será feita admitindo-se que os professores das diferentes Licenciaturas possam constituir um único grupo social.

\subsubsection{Análise Prototípica das Evocações}

Ao analisar as informações com o auxílio dos subprogramas LEXIQUE e RANGMOT do EVOCATION $2005^{\circledR}$ gera-se um arquivo que apresenta a relação do número de sujeitos e termos evocados (VOCAB1.LIST) e identificam-se os termos diferentes. Verificou-se que os 275 sujeitos evocaram 1621 termos dos 1650 possíveis (6 termos x 275 sujeitos), correspondendo a $98,2 \%$ das possibilidades, sendo 757 termos diferentes, o que indica o amplo espectro de concepções sobre destes sujeitos com relação ao objeto social investigado. Após a inserção dos dados, realizou-se sua homogeneização e categorização semântica, com o auxílio do subprograma NETTOIE (vide Apêndice C, p. 129). Em seguida, usando-se novamente o subprograma RANGMOT, verificou-se que os termos diferentes foram reduzidos de 757 para 654 (Quadro 6.1).

Quadro 6.1 - Sujeitos e termos evocados.

\begin{tabular}{|c|c|c|}
\hline Número de sujeitos & Número de termos & Número de termos diferentes \\
\hline 275 & 1621 & 654 \\
\hline
\end{tabular}

O subprograma RANGMOT também gera uma lista de palavras organizadas hierarquicamente segundo a ordem crescente de frequências de evocação (RANGMOT.Ist, 
vide Apêndice D, p. 132 e Tabelas 6.8 e 6.9). Na Tabela 6.8, a primeira coluna lista a frequência de evocação dos termos, a segunda, lista a quantidade de termos diferentes para cada frequência e, na terceira coluna, encontra-se a quantidade total de evocações para cada caso. Por exemplo, considerando-se a segunda linha, tem-se que 74 termos foram evocados com frequência 2, correspondendo a um total de 148 evocações.

Tabela 6.8 - Distribuição dos termos em função das frequências de evocação.

\begin{tabular}{|c|c|c|}
\hline Frequência & $\begin{array}{l}\text { № de termos } \\
\text { diferentes/ } \\
\text { frequência }\end{array}$ & $\begin{array}{l}\text { Quantidade total } \\
\text { de evocações }\end{array}$ \\
\hline 1 & 473 & 473 \\
\hline 2 & 74 & 148 \\
\hline 3 & 31 & 93 \\
\hline 4 & 14 & 56 \\
\hline 5 & 14 & 70 \\
\hline $6^{a}$ & 5 & 30 \\
\hline 7 & 9 & 63 \\
\hline 8 & 3 & 24 \\
\hline 9 & 2 & 18 \\
\hline 10 & 3 & 30 \\
\hline 11 & 2 & 22 \\
\hline 12 & 3 & 36 \\
\hline 13 & 2 & 26 \\
\hline 14 & 2 & 28 \\
\hline $16^{\mathrm{b}}$ & 3 & 48 \\
\hline 18 & 1 & 18 \\
\hline 19 & 1 & 19 \\
\hline 20 & 1 & 20 \\
\hline 22 & 1 & 22 \\
\hline 23 & 1 & 23 \\
\hline 26 & 1 & 26 \\
\hline 27 & 2 & 54 \\
\hline 28 & 1 & 28 \\
\hline 36 & 1 & 36 \\
\hline 44 & 1 & 44 \\
\hline 52 & 1 & 52 \\
\hline 54 & 1 & 54 \\
\hline 60 & 1 & 60 \\
\hline
\end{tabular}

Número de termos diferentes: 654 ;

Total de termos: 1621;

a. frequência mínima de corte;

b. frequência média.
Tabela 6.9 - Quantidade de termos em função das frequências acumuladas.

$\begin{array}{cc}\begin{array}{c}\text { № total de } \\ \text { termos }\end{array} & \% \\ 1621 & 100,0 \\ 1148 & 70,8 \\ 1000 & 61,7 \\ 907 & 56,0 \\ 851 & 52,5 \\ 781 & 48,2 \\ 751 & 46,3 \\ 688 & 42,4 \\ 664 & 41,0 \\ 646 & 39,9 \\ 616 & 38,0 \\ 594 & 36,6 \\ 558 & 34,4 \\ 532 & 32,8 \\ 504 & 31,1 \\ 456 & 28,1 \\ 438 & 27,0 \\ 419 & 25,8 \\ 399 & 24,6 \\ 377 & 23,3 \\ 354 & 21,8 \\ 328 & 20,2 \\ 274 & 16,9 \\ 246 & 15,2 \\ 210 & 13,0 \\ 166 & 10,2 \\ 114 & 7,0 \\ 60 & 3,7\end{array}$

O total de termos evocados para cada somatório de frequências encontra-se ordenado em ordem decrescente na primeira coluna da Tabela 6.9: por exemplo, a primeira linha mostra que foi evocado um total de 1621 termos, valor encontrado ao somarem-se os valores da terceira coluna da Tabela 6.8. Descontando-se deste total os termos que foram evocados somente uma vez $\left(473 ; 1^{\text {a }}\right.$ linha Tabela 6.8$)$, tem-se o total de termos que foram evocados pelo menos duas vezes (1148) e assim por diante. A segunda coluna da Tabela 6.9 apresenta a porcentagem desses termos em função do total de termos evocados. Assim, 
por exemplo, 1621 termos correspondem a 100\% de termos evocados e 1148 termos correspondem a $70,8 \%$ de termos evocados, aqueles que o foram com pelo menos frequência 2.

Para a construção do quadrante de Vergès, um gráfico em coordenadas cartesianas, é necessário definir a frequência mínima de corte, visando à exclusão dos termos cujas frequências são baixas, por serem estes termos mais individuais do que coletivos, para o grupo social investigado. Para tanto, indica-se a realização do corte segundo a Lei de Zipf ${ }^{16}$, que se aplica melhor a conjuntos grandes de valores (WACHELKE e WOLTER, 2011). Para conjuntos mais restritos, como o desta pesquisa, pode-se considerar a frequência mínima de corte como o conjunto de termos que abrangem cerca de $50 \%$ do total acumulado de termos evocados (REIS et al., 2013). Neste caso, escolheu-se o valor de frequência igual a 6 , o que irá abranger 48,2\% dos termos evocados (vide Tabela 6.9, $6^{\mathrm{a}}$ linha), ou seja aqueles que foram expressos por pelo menos seis indivíduos (frequência $=6$ ) do grupo social em foco. Ao se adotar esse valor de corte, selecionam-se os termos de maior significação para o grupo estudado. Isso significa que, dos 1621 termos evocados, 781 foram citados 6 ou mais vezes, como se pode observar na Tabela 6.9, em que o total de termos evocados está organizado em função do somatório das frequências de evocação, em ordem decrescente. Destes, 48 são distintos (Tabela 6.8). Assim, o valor da frequência média para cada um dos termos distintos $\left(f_{\mathrm{med}}\right)$ seria igual a $16(781 / 48)$. Este é o valor de corte para a ordenada (eixo y) do gráfico em coordenadas cartesianas que relaciona as variáveis frequência e OME, chamado na literatura da área de quadrante de Vergès. $\mathrm{Na}$ abscissa estão os valores de OME, cujo valor de corte é a OGOE (Figura 6.4).

O subprograma RANGMOT também fornece um valor para a OGOE (Ordem Geral de Ordenamento das Evocações) que se aproxima do obtido ao se utilizar a Equação 3 (vide Metodologia, p. 49), embora seja calculado de forma diferente (VOGEL, 2016). Este subprograma calcula a média dos pesos atribuídos às evocações, sendo 1 o mais importante e 6 o menos importante, quando se solicitam seis palavras na tarefa de livre associação a um termo indutor, como foi feito neste trabalho (Apêndice A, p.111). Nesta pesquisa, considerou-se como valor para a OGOE o valor 3 , que resulta da média (ou mediana) dos pesos atribuídos às palavras evocadas considerando-se, também o valor zero, de modo que se pudesse ter um valor central na sequência de números que evitasse a interpolação de valores. Assim, obtiveram-se grafos menos dispersos no que se refere à co-

\footnotetext{
${ }^{16}$ A lei de Zipf foi proposta na década de 40 por George Kingsley Zipf ao notar uma relação de potência para a distribuição da frequência das palavras em um texto. Utilizando-se a lei de Zipf $\left(f_{(\mathrm{x})}=\mathrm{bx}^{\mathrm{a}}\right)$ é possível analisar a frequência de ocorrência em função da distribuição dos termos que, por sua relação de potência, geralmente originam um segmento de parábola.
} 
ocorrência de termos e uma distribuição de termos nos quadrantes de Vergès mais adequada.

Na sequência, realiza-se o tratamento com o subprograma RANGFRQ, que relaciona as frequências de evocação dos termos com a $f_{\text {med }}$ (neste trabalho $=16$ ) e as OME dos termos com a OGOE calculada para distribuir os termos constituintes da RS nos quadrantes, separando-os nos sistemas central e periférico, como apresentado na Figura 6.4.

Os termos são organizados no quadrante de Vergès segundo seus valores de frequência $(f)$ e OME. Os termos com frequências $(f)$ maiores ou iguais à frequência média $\left(f_{\text {med }}=16\right)$ e valores para OME menores do que o determinado para a OGOE são alocados no quadrante superior à esquerda e constituem os prováveis termos do NC. Esses termos refletem a homogeneidade do grupo, são termos que estão ligados à memória coletiva, sendo consensuais e estáveis. Os termos aprendizagem, investigação e prática destacam-se dos demais pelos valores de frequência e valores de OME mais baixos, que refletem seu valor simbólico para o grupo investigado (Figura 6.4). Por exemplo, na última linha da coluna referente ao total de termos, observa-se que há um termo que foi evocado 60 vezes.

No quadrante superior à direita, estão alocados os termos da primeira periferia, termos com frequências $(f)$ maiores ou iguais à frequência média $\left(f_{\text {med }}\right)$ e valores para OME maiores ou iguais do que o determinado para a OGOE. Neste quadrante, os termos laboratório e observação merecem destaque devido à sua frequência, embora os valores para as OME sejam mais altos do que o referente à OGOE.

Os termos com frequências $(f)$ menores do que a frequência média $\left(f_{\text {med }}\right)$ e valores para OME maiores ou iguais do que aquele determinado para a OGOE estão alocados na segunda periferia, quadrante inferior à direita. Esses termos apresentam baixa saliência, o que permite inferir que seu valor simbólico para a representação social não é alto, mostrando que se relacionam mais à expressão individual do que à coletiva, quanto ao objeto social investigado.

No quadrante inferior à esquerda estão os termos da zona de contraste, com frequências $(f)$ menores ou iguais à frequência média $\left(f_{\text {med }}\right)$ e valores para OME menores do que o determinado para a OGOE. Estes termos indicam a existência de um subgrupo que valoriza alguns termos além daqueles evocados pela maioria do grupo. 
Figura 6.4 - Quadrante de Vergès para os termos evocados para "experimentação".

\begin{tabular}{|c|c|c|}
\hline \multicolumn{3}{|c|}{ Núcleo Central } \\
\hline Termo & $f$ & OME \\
\hline Investigação & 60 & 2,2 \\
\hline Prática & 52 & 2,9 \\
\hline Aprendizagem & 44 & 2,7 \\
\hline Contextualização & 28 & 2,7 \\
\hline Relação Teoria e Prática & 26 & 2,3 \\
\hline Problematização & 22 & 2,4 \\
\hline $\begin{array}{l}\text { Experimentação } \\
\text { Investigativa }\end{array}$ & 16 & 2,1 \\
\hline Pesquisa & 16 & 2,5 \\
\hline \multicolumn{3}{|c|}{$\mathrm{OME}<3,0$} \\
\hline \multicolumn{3}{|c|}{$\mathrm{OME}<3,0$} \\
\hline Termo & $f$ & OME \\
\hline $\begin{array}{l}\text { Construção do } \\
\text { Conhecimento }\end{array}$ & 14 & 2,7 \\
\hline Conhecimento & 14 & 2,6 \\
\hline Experimento & 13 & 2,4 \\
\hline Lúdico & 09 & 2,8 \\
\hline
\end{tabular}

Zona de Contraste

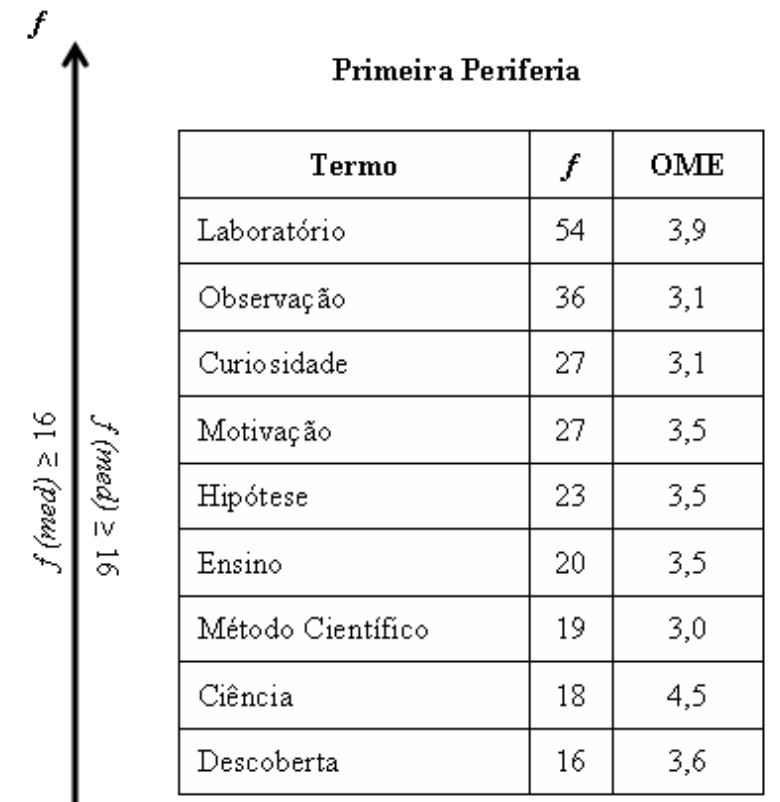

$O M E \geq 3,0$

$\mathrm{OME} \geq 3,0$

\begin{tabular}{|l|c|c|}
\hline \multicolumn{1}{|c|}{ Termo } & $f$ & OME \\
\hline Metodologia & 13 & 3,0 \\
\hline Cotidiano & 12 & 4,0 \\
\hline Materiais Alternativos & 12 & 3,7 \\
\hline Química & 12 & 3,1 \\
\hline Criatividade & 11 & 3,8 \\
\hline Visualização & 11 & 3,7 \\
\hline Análise & 10 & 3,6 \\
\hline Estímulo & 10 & 3,5 \\
\hline Fenômeno & 10 & 3,3 \\
\hline Habilidade & 09 & 4,4 \\
\hline Planejamento & 08 & 3,7 \\
\hline Reflexão & 08 & 3,5 \\
\hline Segurança & 08 & 3,5 \\
\hline
\end{tabular}

Segunda Periferia

$(n=275)$.

\subsubsection{Análise de Similitude das evocações para o total de sujeitos da pesquisa}

Prosseguindo a análise, construiu-se a árvore de similitude máxima empregando-se o mesmo banco de dados utilizado para a construção do quadrante de Vergès pelo 
EVOCATION $2005^{\circledR}$, empregando-se a mesma frequência mínima de corte, $(f)=6$, adotada anteriormente, para que a análise do poder associativo dos termos contemplasse o mesmo universo de termos utilizado para a elaboração do quadro de quatro casas, que remete à identificação dos termos mais salientes na representação. Esta análise foi feita com o auxílio do programa IRAMUTEQ $0.7^{\circledR}$.

Como já mencionado, este grafo é constituído por vértices e linhas ligando os termos em pares; os termos de frequência ( $f$ ) mais alta são evidenciados pelo maior valor do vértice. As arestas (Ar), por sua vez, ligam dois termos e seu número indica o valor de co-ocorrência, ou seja, a quantidade de vezes em que dois termos foram citados conjuntamente (Figura $6.5)$.

Figura 6.5 - Árvore de similitude máxima para os termos mais representativos sobre o objeto social "experimentação" para os sujeitos de pesquisa.

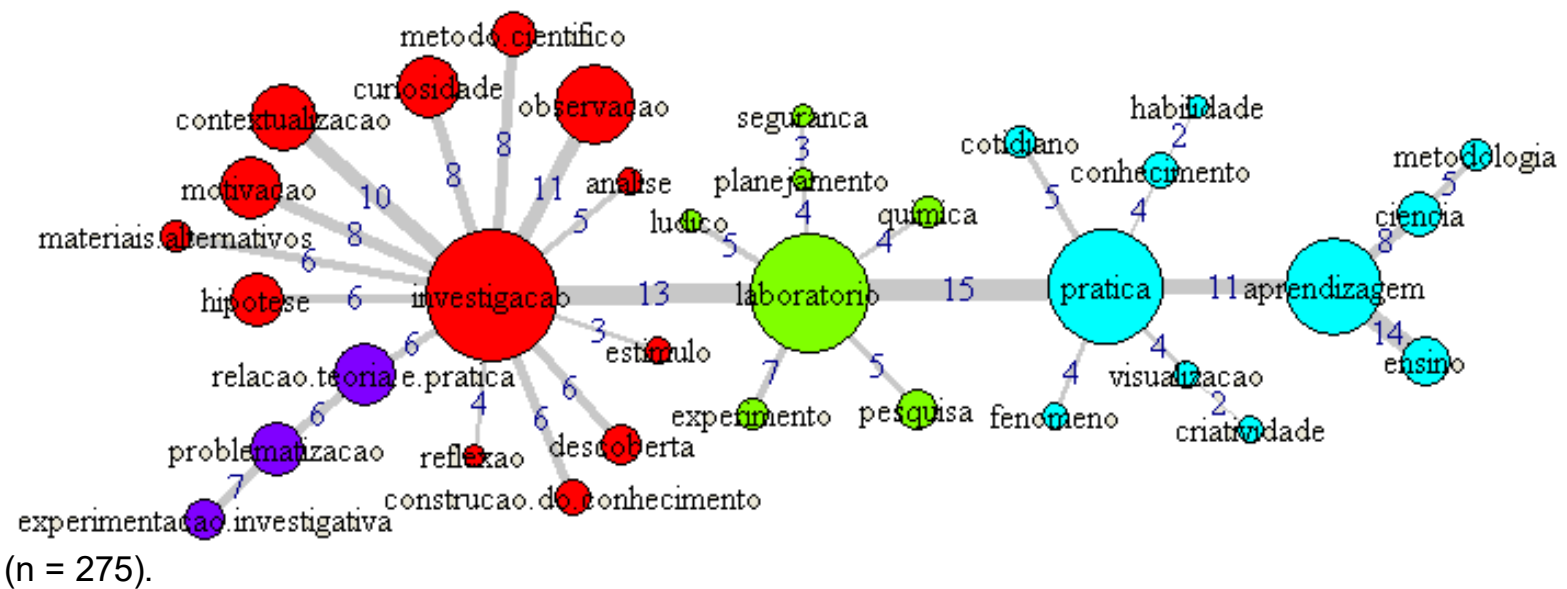
$(n=275)$.

Analisando-se a Figura 6.5, é possível identificar os termos de maior conectividade pelo maior número de conexões (arestas), cada uma das quais com indicação de várias ocorrências, mostrando um índice de co-ocorrência maior do que aqueles verificados para os demais termos evocados. Estes termos são investigação $(\mathrm{Ar}=15 ; \Sigma \mathrm{co}=101)$, laboratório $(A r=11 ; \Sigma c o=84)$, prática $(A r=13 ; \Sigma c o=74)$ e aprendizagem $(\operatorname{Ar}=9 ; \Sigma c o=59)$, sumariados na Tabela 6.10. Os termos de maior saliência e poder associativo são os componentes do NC da RS.

Portanto, para este grupo social, os termos do NC da RS sobre experimentação são os apresentados na Tabela 6.10. Para compreender melhor o significado destes termos, procedeu-se à verificação da influência de diferentes variáveis para os resultados obtidos. 
Tabela 6.10 - Termos de maior saliência e conectividade para os sujeitos de pesquisa $(n=275)$.

\begin{tabular}{ccccc}
\hline \multirow{2}{*}{ Evocação } & \multicolumn{2}{c}{ Saliência } & \multicolumn{2}{c}{ Poder Associativo } \\
\cline { 2 - 5 } & Frequência & OME $^{\mathrm{a}}$ & Arestas & Conectividade \\
\hline Investigação & 60 & 2,2 & 17 & 107 \\
Laboratório & 54 & 3,9 & 8 & 54 \\
Prática & 52 & 2,9 & 8 & 49 \\
Aprendizagem & 44 & 2,7 & 9 & 56 \\
\hline
\end{tabular}

a. Ordem Média de Evocação.

Iniciou-se pela verificação das frequências absoluta e relativa dos termos evocados pelos Coordenadores e não-Coordenadores do PIBID procedendo-se à Análise de frequências múltiplas com auxílio do programa IRAMUTEQ $0.7^{\circledR}$ e de dois subprogramas do EVOCATION $2005^{\circledR}$, o SELIDENT e o COMPLEX ${ }^{17}$. Esta análise auxilia a identificar os termos de maior frequência comuns aos dois grupos, como apresentado na Tabela 6.11.

Tabela 6.11 - Relação dos termos de maior frequência comuns para os Coordenadores e nãoCoordenadores do PIBID.

\begin{tabular}{|c|c|c|c|c|c|}
\hline \multirow[b]{2}{*}{ Termo } & \multicolumn{2}{|c|}{ Coordenadores } & \multicolumn{2}{|c|}{ Não-Coordenadores } & \multirow[b]{2}{*}{ Total } \\
\hline & $\begin{array}{c}\text { Quantidade } \\
\text { (172) }\end{array}$ & $\begin{array}{c}\text { Total } \\
(\%)\end{array}$ & $\begin{array}{c}\text { Quantidade } \\
\text { (103) }\end{array}$ & $\begin{array}{c}\text { Total } \\
(\%)\end{array}$ & \\
\hline Investigação & 46 & 27 & 14 & 14 & 60 \\
\hline Laboratório & 32 & 19 & 22 & 21 & 54 \\
\hline Pratica & 33 & 19 & 19 & 17 & 52 \\
\hline Aprendizagem & 25 & 15 & 19 & 18 & 44 \\
\hline Curiosidade & 22 & 13 & 5 & 5 & 27 \\
\hline Observação & 20 & 12 & 16 & 16 & 36 \\
\hline Motivação & 18 & 10 & 9 & 9 & 27 \\
\hline Problematização & 17 & 10 & 5 & 5 & 22 \\
\hline Ensino & 15 & 9 & 5 & 5 & 20 \\
\hline Descoberta & 7 & 4 & 9 & 9 & 16 \\
\hline Total & 235 & & 123 & & 358 \\
\hline
\end{tabular}

Analisando-se os dados da Tabela 6.11 observa-se que considerando-se as porcentagens com relação ao número de indivíduos de cada grupo, os termos mais evocados pelos Coordenadores do PIBID foram investigação, prática, curiosidade, motivação, problematização e ensino, enquanto os não-Coordenadores do PIBID evocaram mais frequentemente os termos laboratório, aprendizagem, observação e descoberta. As porcentagens em que os demais termos foram evocados podem ser consideradas semelhantes. Destaca-se que, para os Coordenadores do PIBID, os termos investigação, curiosidade e problematização apresentam, em porcentagem de frequência, o dobro de evocações em relação aos não-Coordenadres, o que permite inferir a importância que esses

17 Com o subprograma SELIDENT geram-se novos arquivos com as variáveis "Coordenadores" e "não-Coordenadores" e os termos evocados por eles. Já com o subprograma COMPLEX realizou-se a comparação com os novos dados gerados pelo subprograma SELIDENT. 
termos apresentam para este grupo. Já para os não-Coordenadores, o termo que apresenta um maior valor de porcentagem é descoberta.

É possível observar que, embora alguns termos apresentem a mesma importância para os dois grupos, outros termos têm maior importância para rede de significações sobre o termo "experimentação" para determinados sujeitos. Este resultado aponta que as representações dos Coordenadores e não-Coordenadores do PIBID, apresentam diferenças, o que sugere ser mais apropriado tratar os dois sub-grupos como grupos sociais diferentes. Assim, embora se tenha determinado um aparente NC para o conjunto dos sujeitos, isso provavelmente deva-se às importâncias simbólicas de diferentes termos para cada um dos sub-grupos, compostos por um número equivalente de sujeitos.

Posteriormente, considerou-se a variável tempo de participação no subprojeto PIBID para os sujeitos de pesquisa. Para tanto, os sujeitos foram divididos em três grupos: os que não coordenaram o subprojeto PIBID, totalizando 103 sujeitos, os que coordenaram esse projeto por até 36 meses, 86 sujeitos no total, e os que o coordenaram por mais de 36 meses, totalizando 86 sujeitos (Figura 6.6). Para tanto, manteve-se o valor de 16 para a frequência média $\left(f_{\text {mef }}\right)$, englobando os termos do sistema central e primeira periferia, que são os de maior valor simbólico para os sujeitos investigados. O resultado desta análise está apresentado na Figura 6.6.

Analisando-se a Figura 6.6, é possível observar que os termos de maior conectividade para os não-Coordenadores do PIBID são laboratório, aprendizagem e prática. Para os sujeitos que coordenaram o subprojeto PIBID por até 36 meses verifica-se maior coocorrência dos termos investigação, prática e curiosidade. Percebe-se também que, para os Coordenadores do PIBID com tempo de coordenação superior a 36 meses, os termos de maior conectividade são investigação, problematização e relação teoria e prática. Outra característica que pode ser observada é a maior proximidade dos sujeitos que coordenaram o PIBID por até 36 meses em relação ao termo prática (refletida no número de coocorrências), se comparada à daqueles docentes da Licenciatura que não o coordenaram. Adicionalmente, observa-se que o termo investigação está mais próximo dos sujeitos que coordenaram o PIBID por mais de 36 meses do que daqueles que o coordenaram por até 36 meses. A partir desses resultados é possível inferir que à medida que o sujeito vivencia a coordenação do PIBID, os termos relacionados à "experimentação" vão sendo modificados, o que sugere que a participação como coordenador de área do subprojeto PIBID-Química recontextualiza as representações dos sujeitos quanto ao objeto social "experimentação". 
Figura 6.6 - Árvore de similitude máxima para a variável tempo de coordenação do subprojeto PIBID, para os sujeitos de pesquisa.

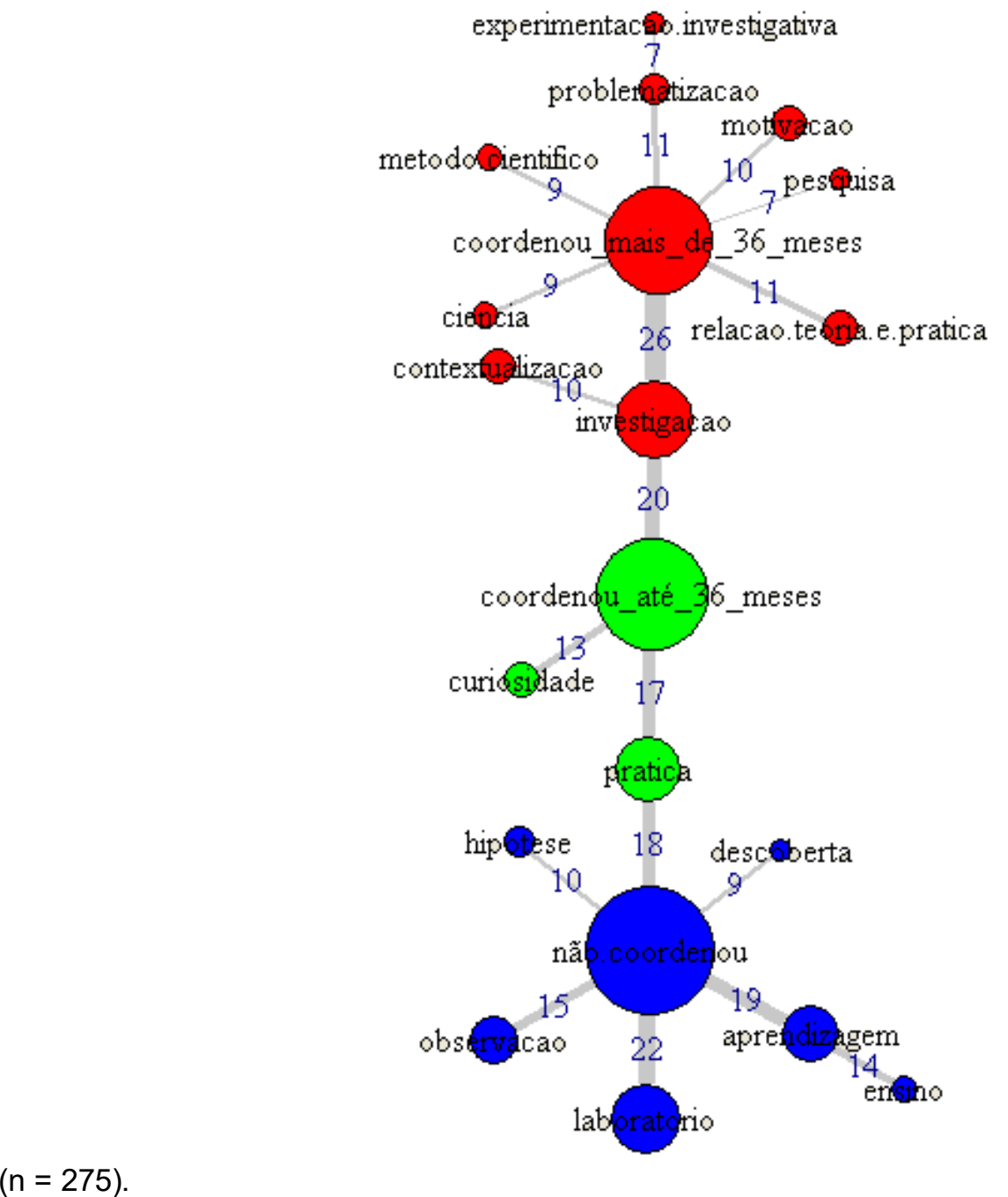

Considerando este conjunto de resultados, percebe-se a necessidade de proceder à análise dos dados considerando que os sujeitos possam constituir dois grupos sociais distintos. Posteriormente, procedeu-se à análise das justificativas das evocações com o objetivo de verificar se há diferença entre as RS sobre "experimentação" dos professores Coordenadores e não-Coordenadores do PIBID. Para tanto, a análise das informações foi realizada para os dois subgrupos individualmente, como será apresentado a seguir. 


\subsection{Representação Social sobre "experimentação" dos não- Coordenadores do PIBID}

\subsubsection{Análise Prototípica das evocações dos não-Coordenadores do PIBID}

Os Não-Coordenadores do PIBID são professores de Química que não coordenam ou coordenaram o subprojeto PIBID, mas ministram disciplinas para os cursos de Licenciatura em Química. Os 103 não-Coordenadores evocaram 602 termos, dos 876 possíveis, correspondendo a $97,4 \%$ das possibilidades, sendo que 340 termos são diferentes (Quadro $6.2)$.

Quadro 6.2 - Relação não-Coordenadores do PIBID e termos evocados.

\begin{tabular}{|c|c|c|}
\hline Número de sujeitos & Número de termos & Número de termos diferentes \\
\hline 103 & 602 & 340 \\
\hline
\end{tabular}

O valor de corte para a OGOE foi definido como 3,0, como discutido na seção 6.2.1. A análise da Tabela 6.12 dá subsídio para definir a frequência mínima $(f)$ de corte como 3 (corresponde a 43,7\% dos termos evocados), abrangendo as 263 evocações mais expressivas para este grupo, isto é, aqueles termos que são mais frequentes; a frequência média $\left(f_{\text {med }}\right)$ é igual a 9, acumulando 137 termos. Estes resultados refletem um menor número de termos diferentes, 39 das 340 palavras evocadas (referentes à segunda coluna da Tabela 6.12), termos de maior saliência para esses sujeitos.

Tabela 6.12 - Distribuição das frequências de evocações para os não-Coordenadores do PIBID.

\begin{tabular}{ccc}
\hline Frequência & $\begin{array}{c}\text { No de termos } \\
\text { diferentel } \\
\text { frequência }\end{array}$ & $\begin{array}{c}\text { Quantidade total } \\
\text { de evocações }\end{array}$ \\
01 & 263 & 263 \\
02 & 38 & 76 \\
$03^{a}$ & 10 & 30 \\
04 & 7 & 28 \\
05 & 7 & 35 \\
06 & 3 & 18 \\
07 & 1 & 7 \\
08 & 1 & 8 \\
$09^{b}$ & 3 & 27 \\
10 & 2 & 20 \\
14 & 1 & 14 \\
16 & 1 & 16 \\
19 & 2 & 38 \\
22 & 1 & 22 \\
\hline Número de termos diferentes: $402 ;$ & \\
Total de termos: $602 ;$ & \\
a. frequência mínima de corte; & \\
b. frequência média. &
\end{tabular}

Tabela 6.13 - Número de termos porcentagem.

\begin{tabular}{cr}
\hline $\begin{array}{c}\text { № total de } \\
\text { termos }\end{array}$ & $\%$ \\
602 & 100,0 \\
339 & 56,3 \\
263 & 43,7 \\
233 & 38,7 \\
205 & 34,1 \\
170 & 28,2 \\
152 & 25,2 \\
145 & 24,1 \\
137 & 22,8 \\
110 & 18,3 \\
90 & 15,0 \\
76 & 12,6 \\
60 & 10,0 \\
22 & 3,7 \\
\hline
\end{tabular}


Posteriormente, realizou-se a construção do quadrante de Vergès (Figura 6.7). Analisando-se a Figura 6.7, observa-se que, na zona de centralidade da representação deste grupo, há quatro termos, merecendo destaque os temos aprendizagem ( $f=19$; OME = $2,6)$ e investigação ( $f=14$; OME $=2,7$ ) por apresentarem altos valores de frequências e baixos valores de OME. Na primeira periferia do quadrante de Vergès, há 5 termos, destacando-se laboratório ( $f=22$; OME $=3,5)$, prática $(f=19$; OME $=3,0)$ e observação $(f=$ 16; OME $=3,1)$ que, embora apresentem valor para a OME igual ou mais alto do que a OGOE, têm frequência elevada, refletindo a saliência desses termos. 
Figura 6.7 - Quadrante de Vergès dos termos de representação sobre "experimentação" para os não-Coordenadores do PIBID.

Núcleo Central

\begin{tabular}{|l|c|c|}
\hline \multicolumn{1}{|c|}{ Termo } & $f$ & OME \\
\hline Aprendizagem & 19 & 2,6 \\
\hline Investigação & 14 & 2,7 \\
\hline Contextualização & 10 & 2,3 \\
\hline Experimento & 9 & 2,2 \\
\hline
\end{tabular}

$\mathrm{OME}<3,0$

$\mathrm{OME}<3,0$

\begin{tabular}{|l|c|c|}
\hline \multicolumn{1}{|c|}{ Termo } & \multicolumn{1}{c|}{$f$} & OME \\
\hline Método Científico & 8 & 2,5 \\
\hline Relação Teoria e Prática & 7 & 2,1 \\
\hline Conhecimento & 6 & 2,8 \\
\hline Pesquisa & 6 & 1,8 \\
\hline Química & 6 & 2,8 \\
\hline Curiosidade & 5 & 2,4 \\
\hline $\begin{array}{l}\text { Experimentação } \\
\text { Investigativa }\end{array}$ & 5 & 2,8 \\
\hline Problematização & 5 & 2,6 \\
\hline Desenvolvimento & 3 & 1,6 \\
\hline Segurança & 3 & 2,3 \\
\hline
\end{tabular}

Zona de Contraste

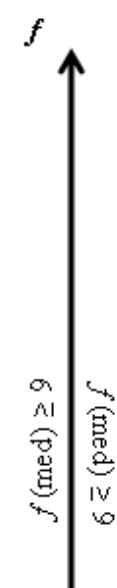

Primeira Periferia

\begin{tabular}{|l|c|c|}
\hline \multicolumn{1}{|c|}{ Termo } & \multicolumn{1}{c|}{$\boldsymbol{f}$} & OME \\
\hline Laboratório & 22 & 3,5 \\
\hline Prática & 19 & 3,0 \\
\hline Observação & 16 & 3,1 \\
\hline Hipótese & 10 & 4,0 \\
\hline Descoberta & 9 & 3,8 \\
\hline Motivação & 9 & 3,1 \\
\hline
\end{tabular}

$\mathrm{OME} \geq 3,0$

OGOE

$\mathrm{OME} \geq 3,0$

\begin{tabular}{|l|c|c|}
\hline \multicolumn{1}{|c|}{ Termo } & $f$ & OME \\
\hline Criatividade & 5 & 3,6 \\
\hline Ensino & 5 & 3,2 \\
\hline Planejamento & 5 & 4,2 \\
\hline Visualização & 5 & 3,0 \\
\hline Análise & 4 & 4,2 \\
\hline Ciência & 4 & 4,2 \\
\hline Cotidiano & 4 & 4,2 \\
\hline Ensaio & 4 & 3,2 \\
\hline Experiência & 4 & 3,0 \\
\hline Habilidade & 4 & 5,0 \\
\hline Questionamento & 4 & 3,2 \\
\hline Aplicação & 3 & 3,6 \\
\hline Desafio & 3 & 3,3 \\
\hline Dinâmica & 3 & 4,3 \\
\hline Interação & 3 & 3,0 \\
\hline Manipulação & 3 & 6,0 \\
\hline Metodologia & 4,0 \\
\hline Relatório & 5,0 \\
\hline Resultados & 3,3 \\
\hline
\end{tabular}

Segunda Periferia

$(n=103)$ 
Ao se realizar a comparação entre os termos componentes da representação do grupo total (Figura 6.4) com aqueles do grupo dos não-Coordenadores do PIBID, percebe-se que a maioria dos termos coincide, exceto ensaio, experiência, questionamento, aplicação, desafio, dinâmica, interação, manipulação, relatório e resultados. Esses termos que não constituem o rol de termos alocados no quadrante de Vergès para o grupo total, constitui o rol de termos evocados pelos não-coordenadores do PIBID.

Outra alteração que pode ser percebida é em relação ao termo prática, que estava alocado na zona de centralidade do grupo total e passou a fazer parte dos termos da primeira periferia para os não-coordenadores do PIBID. Os termos relação teoria e prática, problematização, experimentação e pesquisa que, para o grupo total de sujeitos estavam alocados no sistema central, passaram a constituir a zona de contraste para os nãocoordenadores do PIBID. Já os termos curiosidade e método científico passaram da primeira periferia do grupo total para a zona de contraste. Por fim, o termo experimento que, para o grupo total, estava alocado na zona de contraste passou a fazer parte do sistema central dos não-Coordenadores do PIBID.

Destacam-se, nessa primeira análise, os termos que apresentam alto valor de frequência e baixo valor de OME como os mais salientes alocados no sistema central, aprendizagem e investigação e, na primeira periferia, laboratório, prática e observação, os quais apresentam as características dos termos pertencentes ao NC da RS.

\subsubsection{Análise de Similitude das evocações dos não-Coordenadores do PIBID}

Apresenta-se, na Figura 6.8, a árvore de similitude máxima para o grupo de docentes não-Coordenadores do PIBID, para cuja construção adotou-se o valor 3 para a frequência mínima de corte $(f)$.

Analisando-se a Figura 6.8, pode-se inferir que os termos que apresentam maior número de arestas e co-ocorrências são laboratório, prática, aprendizagem, observação, investigação e descoberta, sumariados na Tabela 6.14. Relacionando-se a saliência com o poder associativo (Tabela 6.14), infere-se que os termos da primeira periferia (Figura 6.7) que possuem a saliência e o poder associativo adequados para pertencer ao NC da RS dos não-coordenadores do PIBID é laboratório. 
Figura 6.8 - Árvore de similitude máxima para os termos mais representativos sobre o objeto social "experimentação" para os não-Coordenadores do PIBID.

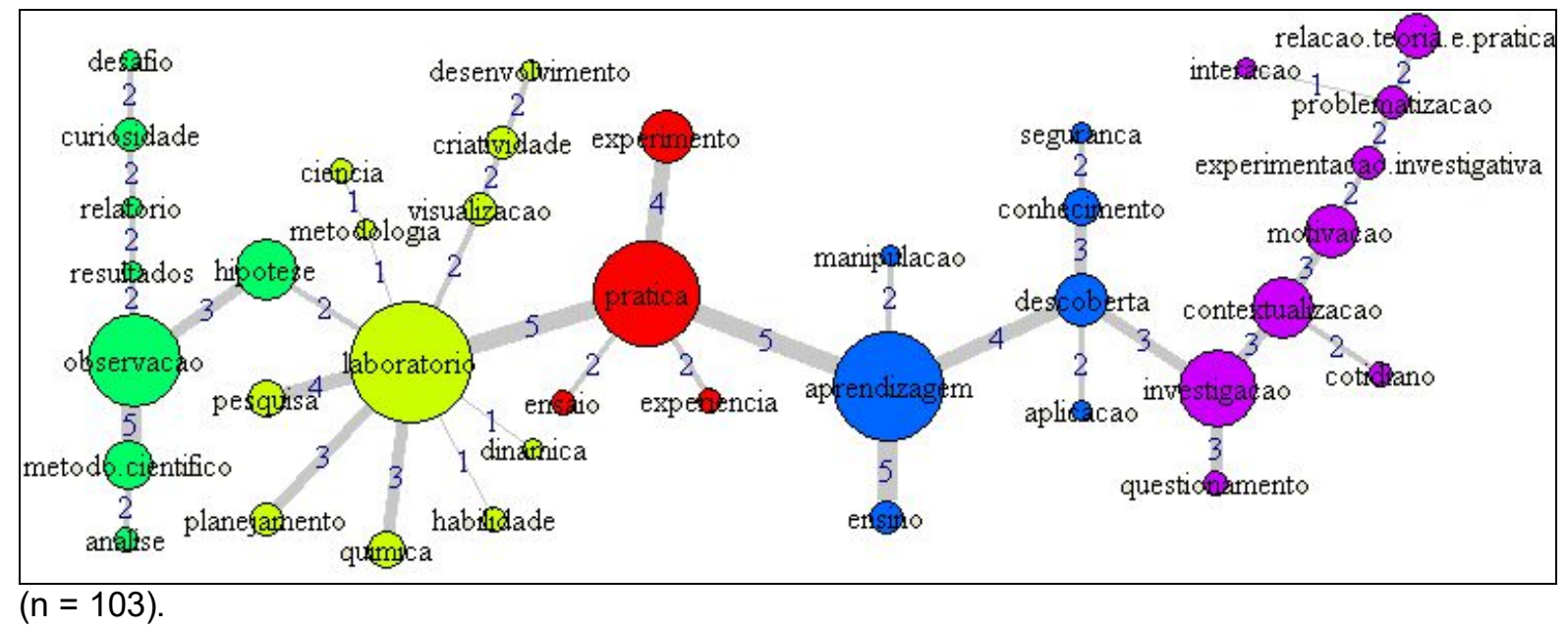

Tabela 6.14 - Termos de maior saliência e conectividade para os não-Coordenadores do PIBID.

\begin{tabular}{ccccc}
\hline \multirow{2}{*}{ Evocação } & \multicolumn{2}{c}{ Saliência } & \multicolumn{2}{c}{ Poder Associativo } \\
\cline { 2 - 5 } & Frequência & OME $^{\mathrm{a}}$ & Arestas & Conectividade \\
\hline Laboratório & 22 & 3,5 & 9 & 22 \\
Prática & 19 & 3,0 & 4 & 12 \\
Aprendizagem & 19 & 2,6 & 3 & 14 \\
Observação & 16 & 3,1 & 4 & 12 \\
Investigação & 14 & 2,7 & 3 & 9 \\
Contextualização & 10 & 2,3 & 3 & 8 \\
Descoberta & 9 & 3,8 & 4 & 12 \\
\hline
\end{tabular}

a. Ordem Média de Evocação.

Em síntese, pode-se sugerir que o NC da RS sobre experimentação para os nãocoordenadores do PIBID seja constituído do termo laboratório.

\subsection{Representações Sociais sobre "experimentação" dos Coordenadores do PIBID}

\subsubsection{Análise Prototípica das evocações dos Coordenadores do PIBID}

Os Coordenadores do PIBID são professores que, atualmente, coordenam ou já coordenaram subprojetos PIBID-Química. Os 172 Coordenadores do PIBID evocaram 1019 termos, dos 1032 possíveis, correspondendo a 98,7\% das possibilidades, sendo que 437 termos são diferentes, informações sintetizadas no Quadro 6.3. O valor de corte para a OGOE, no caso desses sujeitos também foi definido como 3,0 (vide 6.2.1. p. 69). A análise da Tabela 6.15 mostra que pode-se admitir o valor da frequência mínima $(f)$ de corte como sendo igual a 5 , pois assim abrangem-se as 495 evocações $(50,3 \%)$ mais frequentes; o 
valor da frequência média $\left(f_{\text {med }}\right)$ é igual a 12 , que é o adotado para identificar os termos evocados de maiores frequências.

Quadro 6.3 - Relação dos Coordenadores do PIBID e termos evocados.

\begin{tabular}{|c|c|c|}
\hline Número de sujeitos & Número de termos & Número de termos diferentes \\
\hline 172 & 1019 & 437 \\
\hline
\end{tabular}

Analisando-se a Tabela 6.16, observa-se que são acumulados 495 termos ( $5^{\mathrm{a}}$ linha) para 20 valores de frequência (da $5^{a}$ à $24^{a}$ linhas da Tabela 6.15), mostrando que um número menor de palavras diferentes, 41 das 437 evocadas, acumulam metade do número total de termos evocados, o que mostra a importância destes termos para o grupo.

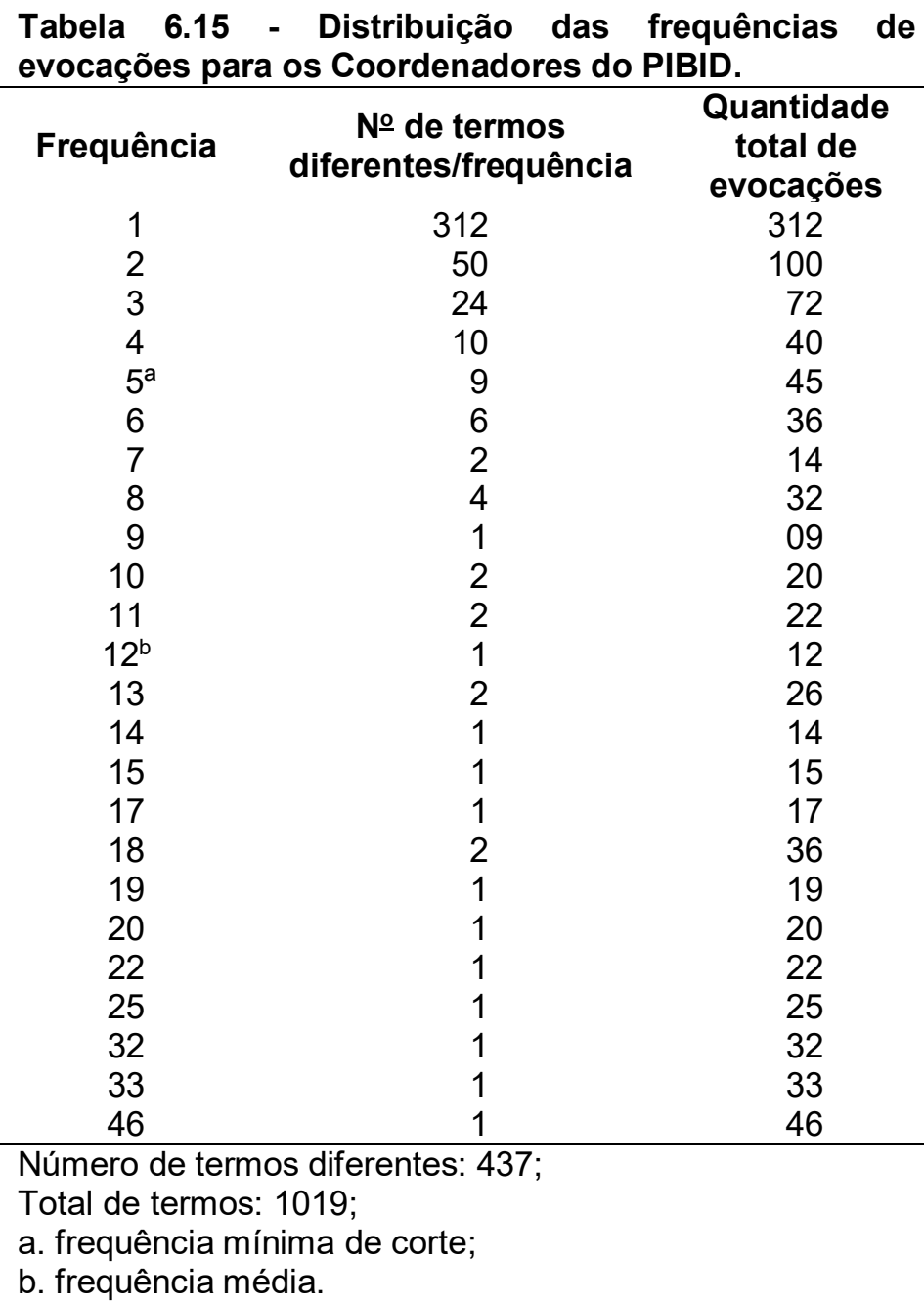

Tabela 6.16 - Número de termos porcentagem.

\begin{tabular}{cr}
\hline $\begin{array}{c}\text { No total de } \\
\text { termos }\end{array}$ & $\%$ \\
1019 & 100,0 \\
707 & 69,4 \\
607 & 59,6 \\
535 & 52,5 \\
495 & 48,6 \\
450 & 44,2 \\
414 & 40,6 \\
400 & 39,3 \\
368 & 36,1 \\
359 & 35,2 \\
339 & 33,3 \\
317 & 31,1 \\
305 & 29,9 \\
279 & 27,4 \\
265 & 26,0 \\
250 & 24,5 \\
233 & 22,9 \\
197 & 19,3 \\
178 & 17,5 \\
158 & 15,5 \\
136 & 13,3 \\
111 & 10,9 \\
79 & 7,8 \\
46 & 4,5 \\
\hline
\end{tabular}

Ao realizar a comparação entre os termos de representação para o total de sujeitos (Figura 6.4) e aqueles para o grupo dos Coordenadores do PIBID, é possível identificar que a maioria dos termos são coincidentes, exceto experimento e planejamento que, embora presentes para o total de sujeitos, não aparecem no quadrante de Vergès para os 
Coordenadores do PIBID. Há, também, o surgimento de novos termos para os Coordenadores do PIBID: didática, vivência, demonstração, interesse, autonomia, baixo custo, materiais, procedimentos e teste.

O termo construção do conhecimento que, para o total de sujeitos, estava alocado na zona de contraste passou a constituir o sistema central dos Coordenadores do PIBID. Já o termo pesquisa que, para o total de sujeitos, estava alocado no sistema central, passou a constituir a zona de contraste para este grupo.

Analisando-se a Figura 6.9, observa-se que, na zona de centralidade da representação deste grupo, há seis termos, destacando-se os temos investigação, prática, problematização e aprendizagem, por apresentarem altos valores de frequência e baixos valores de OME. Estas características indicam a saliência desses termos para o grupo.

Voltando para a Figura 6.9, percebe-se que, na primeira periferia do quadrante de Vergès, há 7 termos. Os termos laboratório e curiosidade, embora apresentem um valor mais alto de OME, foram evocados frequentemente pelo grupo, o que indica sua saliência na representação social deste grupo sobre experimentação. Estes termos, portanto, são possíveis termos constituintes da zona de centralidade da RS, dependendo de sua conectividade.

Destacam-se, nesta primeira análise, os termos que apresentam alto valor de frequência e baixo valor de OME como os mais salientes (investigação, prática, laboratório, problematização, aprendizagem, curiosidade e observação), termos esses que apresentam as características dos termos pertencentes ao NC da RS. Outros dois procedimentos de análise, para identificar as demais características dos termos, estão apresentados nas seções 6.4.2 e 6.4.3. 
Figura 6.9 - Quadrante de Vergès dos termos de representação sobre "experimentação" para os Coordenadores do PIBID.

\begin{tabular}{|c|c|c|}
\hline Termo & $f$ & OME \\
\hline Inve stigação & 46 & 2,1 \\
\hline Prática & 33 & 2,9 \\
\hline Aprendizagem & 25 & 2,8 \\
\hline Relação teoria e prática & 19 & 2,4 \\
\hline Problematização & 17 & 2,4 \\
\hline $\begin{array}{l}\text { Construção do } \\
\text { conhecimento }\end{array}$ & 13 & 2,6 \\
\hline
\end{tabular}

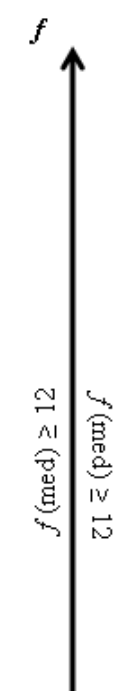

\begin{tabular}{|c|c|c|}
\hline \multicolumn{3}{|c|}{ Primeira Periferia } \\
\hline Termo & $f$ & OME \\
\hline Laboratório & 32 & 4,1 \\
\hline Curiosidade & 22 & 3,2 \\
\hline Observação & 20 & 3,2 \\
\hline Contextualização & 18 & 3,0 \\
\hline Motivação & 18 & 3,7 \\
\hline Ensino & 15 & 3,5 \\
\hline Ciência & 14 & 4,6 \\
\hline Hipótese & 13 & 3,1 \\
\hline Materiais Alternativos & 12 & 3,7 \\
\hline
\end{tabular}

\begin{tabular}{|l|c|c|}
\hline \multicolumn{1}{|c|}{ Termo } & $f$ & OME \\
\hline $\begin{array}{l}\text { Experimentação } \\
\text { Investigativa }\end{array}$ & 11 & 1,9 \\
\hline Metodologia & 10 & 2,1 \\
\hline Pesquisa & 10 & 2,9 \\
\hline Conhecimento & 8 & 2,7 \\
\hline Lúdico & 8 & 2,6 \\
\hline Didática & 5 & 2,8 \\
\hline Vivência & 5 & 2,8 \\
\hline
\end{tabular}

\begin{tabular}{|l|c|c|}
\hline \multicolumn{1}{|c|}{ Termo } & $f$ & OME \\
\hline Método Científico & 11 & 3,4 \\
\hline Estímulo & 9 & 3,5 \\
\hline Cotidiano & 8 & 3,8 \\
\hline Fenômeno & 8 & 3,1 \\
\hline Descoberta & 7 & 3,2 \\
\hline Reflexão & 7 & 3,1 \\
\hline Análise & 6 & 3,1 \\
\hline Criatividade & 6 & 4,0 \\
\hline Demonstração & 6 & 5,5 \\
\hline Interesse & 6 & 5,0 \\
\hline Química & 6 & 3,5 \\
\hline Visualização & 5 & 4,3 \\
\hline Autonomia & 5 & 3,4 \\
\hline Baixo Custo & 5 & 3,0 \\
\hline Habilidade & 5,8 \\
\hline Materiais & 5 & 4,0 \\
\hline Procedimentos & 5 & \\
\hline Segurança & 5 & 3,6 \\
\hline Teste & 5 & 5 \\
\hline
\end{tabular}

Segunda Periferia

$(n=172)$. 


\subsubsection{Análise de Similitude das Evocações dos Coordenadores do PIBID}

Buscando evidenciar o poder associativo dos termos alocados no quadrante de Vergès, para identificar os termos do NC da RS sobre experimentação deste grupo, empregou-se o programa IRAMUTEQ $0.7^{\circledR}$ para obter a árvore de similitude máxima referente aos termos presentes no quadrante de Vergès (vide Figura 6.10) mantendo-se a frequência de corte ( $f=$ 5) empregada na análise prototípica, de forma a obterem-se dados comparáveis.

\section{Figura 6.10 - Árvore de similitude máxima para os termos mais representativos sobre o objeto} social "experimentação" para os Coordenadores do PIBID.

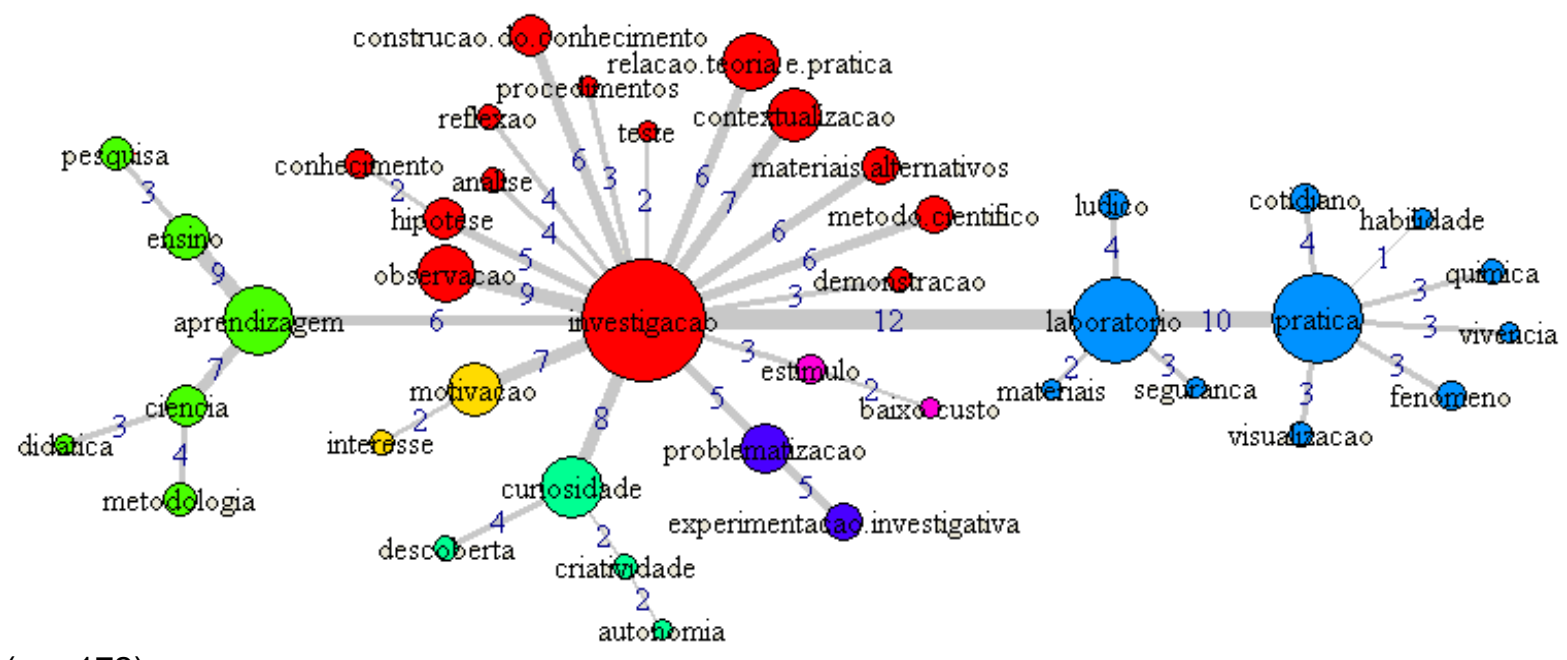

$(n=172)$.

A análise da Figura 6.10 mostra que o termo de maior conectividade é investigação $(\mathrm{Ar}=$ 18; $\Sigma c o=102$ ), por apresentar maior número de arestas e co-ocorrências em relação aos demais termos evocados. Este termo parece ser o organizador da estrutura da representação para o grupo de Coordenadores do PIBID. Esta característica é reforçada por sua maior saliência em relação aos demais termos evocados (vide Tabela 6.17).

Os termos laboratório $(\mathrm{Ar}=5 ; \Sigma \mathrm{co}=31)$, prática $(\mathrm{Ar}=7 ; \Sigma \mathrm{co}=27)$ e aprendizagem $(\mathrm{Ar}=$ 3; $\Sigma \mathrm{co}=26$ ) também apresentam relevância em relação aos demais termos presentes na árvore de similitude máxima, porém com uma conectividade consideravelmente menor do que o termo investigação.

Os termos curiosidade $(\mathrm{Ar}=3 ; \Sigma \mathrm{co}=14)$ e observação $(\mathrm{Ar}=1 ; \Sigma \mathrm{co}=9)$ apresentam baixa conectividade por apresentar menor número de arestas e co-ocorrências em relação aos demais termos evocados. 
Tabela 6.17 - Termos de maior saliência e conectividade para os Coordenadores do PIBID.

\begin{tabular}{ccccc}
\hline \multirow{2}{*}{ Evocação } & \multicolumn{2}{c}{ Saliência } & \multicolumn{2}{c}{ Poder Associativo } \\
\cline { 2 - 5 } & Frequência & OME $^{\text {a }}$ & Arestas & Conectividade \\
\hline Investigação & 46 & 2,1 & 18 & 102 \\
Prática & 33 & 2,9 & 7 & 27 \\
Laboratório & 33 & 4,1 & 5 & 31 \\
Problematização & 28 & 2,8 & 2 & 10 \\
Aprendizagem & 25 & 2,8 & 3 & 26 \\
Curiosidade & 22 & 3,2 & 3 & 14
\end{tabular}

a. Ordem Média de Evocação.

Analisando-se a Tabela 6.17, infere-se que o termo que constitui o NC da RS sobre "experimentação" para os Coordenadores do PIBID é investigação. Os dados obtidos mostram que este termo é saliente, como indicam sua frequência de evocação e baixa OME (Figura 6.9). O termo também tem um poder associativo que o destaca dos demais termos, o que se reflete na conectividade observada na Figura 6.10. Estes resultados mostram que este termo tem valor simbólico para este grupo com relação ao objeto social investigado (experimentação).

\subsection{Análise de Conteúdo das evocações}

A análise de conteúdo sobre as explicações apresentadas pelos sujeitos quanto aos termos evocados foi inspirada nas proposições de Bardin (2011). O procedimento iniciou-se com a leitura exaustiva das justificativas para as evocações (Questão 12; Apêndice A) dos Coordenadores e não-Coordenadores do PIBID até a saturação das unidades de significado; posteriormente, as justificativas foram agrupadas, levando à construção de cinco dimensões (Quadro 6.4). As dimensões foram baseadas na literatura (GALIAZZI; GONÇALVES, 2004; GONÇALVES; MARQUES, 2006; 2012; WEI; LI, 2017; BEZERRA; AMARAL, 2019), com posterior adequação para o contexto desta pesquisa. As dimensões agrupam os termos identificados na RS sobre "experimentação" dos sujeitos desta pesquisa (vide Figura 6.4). 
Quadro 6.4 - Dimensões de análise para os termos do NC da RS sobre "experimentação" dos Coordenadores do PIBID.

\begin{tabular}{|c|l|}
\hline Dimensão & \multicolumn{1}{|c|}{ Definição das dimensões } \\
\hline $\begin{array}{c}\text { Atividade } \\
\text { Científica }\end{array}$ & $\begin{array}{l}\text { Nesta dimensão, foram agrupados os termos relacionados a aspectos da atividade } \\
\text { experimental e a sua relação com a Natureza das Ciências. Por exemplo, o papel } \\
\text { desempenhado pelo experimento pode assumir um caráter confirmatório, visando } \\
\text { validar as teorias estabelecidas, ou assume caráter investigativo, referindo-se à } \\
\text { construção do conhecimento científico. }\end{array}$ \\
\hline Material & $\begin{array}{l}\text { Esta dimensão refere-se aos materiais necessários para a atividade experimental, } \\
\text { por exemplo, instalações, equipamentos e reagentes. }\end{array}$ \\
\hline Pedagógica & $\begin{array}{l}\text { Esta dimensão envolve questões pedagógicas relativas às atividades } \\
\text { experimentais, ressaltando os objetivos e os propósitos das atividades } \\
\text { experimentais para o Ensino de Ciências. }\end{array}$ \\
\hline Procedimental & $\begin{array}{l}\text { Esta dimensão refere-se a questões procedimentais relacionadas ao } \\
\text { desenvolvimento das atividades experimentais, desde o que é necessário para se } \\
\text { executar o experimento até a forma de sua execução. }\end{array}$ \\
\hline Segurança & $\begin{array}{l}\text { Esta dimensão refere-se à importância da segurança para o desenvolvimento de } \\
\text { atividades experimentais. }\end{array}$ \\
\hline
\end{tabular}

\subsubsection{Análise de Conteúdo das evocações dos não-Coordenadores do PIBID}

O termo laboratório é compreendido como o local apropriado para a execução de experimentos por possuir o suporte necessário, com equipamentos capazes de controlar as condições experimentais, evidenciando a dimensão material que este termo possui para os não-Coordenadores do PIBID.

As atividades desenvolvidas nesse ambiente visam, por um lado, o desenvolvimento das pesquisas em Química, e por outro, o desenvolvimento de atividades voltadas para o Ensino de Química, como evidenciado pelas justificativas dos sujeitos com relação a este termo

A experimentação requer um local apropriado para a sua execução (S. 108).

As atividades de pesquisa que realizo são basicamente experimentais, logo são realizadas em um laboratório (S. 298).

Sem laboratório não há como controlar as condições para experimentação (S. 319).

Um dos melhores locais para o ensino e aprendizado da Química (S. 205).

Na Química a vivência laboratorial é fundamental para a formação (S. 276).

O laboratório como espaço adequado para a pesquisa em Química é evidenciado pela expressiva co-ocorrência com os termos pesquisa, planejamento e química.

[pesquisa] Durante a realização de pesquisas são feitos experimentos (S. 330). 
[planejamento] A experimentação demanda um planejamento para que seja possivel atingir os seus objetivos (S. 211).

[química] Por ser uma ciência experimental (S. 055).

Estes termos refletem a dimensão atividade científica (pesquisa e química) e procedimental (planejamento) da experimentação, ou seja, para o bom desenvolvimento de atividades experimentais deve-se ter o mínimo de conhecimento sobre o método científico, a experimentação deve seguir um procedimento que possibilite o controle dos dados e das interpretações para se obterem resultados confiáveis. Em síntese, esta relação é compreendida como uma característica intrínseca da Química.

O ambiente laboratorial também é apropriado para se desenvolverem atividades voltadas para o Ensino de Química, como evidenciado pela relação com os termos prática e aprendizagem, compreendidos em sua dimensão pedagógica.

[prática] A experimentação é a parte prática, que se alia à teoria química (S. 011).

[prática] Desenvolvimento na manipulação de equipamentos e materiais de laboratório (S. 282).

[aprendizagem] $A$ aprendizagem deve ser a principal preocupação ao se trabalhar a experimentação (S. 047).

[aprendizagem] A experimentação promove um aprendizado consistente (S. 219).

Essa dimensão é entendida como uma estratégia pedagógica que tem como objetivo o desenvolvimento dos conteúdos conceitual, procedimental e atitudinal. É uma estratégia central, pois possibilita a contextualização dos conteúdos ensinados em sala de aula, o que fomenta a motivação dos estudantes a aprenderem pela descoberta. Para tanto, as atividades experimentais devem ser planejadas e executadas fundamentando-se nos princípios do método científico, sendo fortemente relacionada às dimensões atividade científica e procedimental. Essas atividades devem envolver o treino de habilidades de investigação: por exemplo, os graduandos devem saber formular hipóteses, planejar experimentos, manipular equipamentos e vidrarias, observar os fenômenos, analisar os dados e resultados e produzir relatórios. Essas habilidades também são essenciais na pesquisa em Química.

A dimensão de segurança foi contemplada somente com um termo, segurança, alocado na zona de contraste da RS para os não-Coordenadores do PIBID.

Sensibilização do aluno com relação aos perigos que o cercam em um ambiente de laboratório - trabalhar com segurança deve ser um 'mantra' (S. 098). 
Como foram palavras que vieram em mente rapidamente, primeiro imaginei que, para que qualquer experimento (de laboratório clássico) seja feito, as medidas de segurança devem ser respeitadas. Desde o uso de trajes adequados até o correto manuseio e forma de se portar em um ambiente de laboratório. A experimentação em laboratório foi a que me veio em mente (S. 248).

Este resultado indica que, ao pensar em "experimentação", os problemas referentes a atividades laboratoriais não são uma preocupação recorrente para os não-Coordenadores do PIBID. Isto indica que a segurança não é um problema recorrente na prática destes sujeitos.

Em síntese, a RS sobre "experimentação" dos não-Coordenadores do PIBID é objetivada no laboratório e ancorada nas atividades práticas voltadas para a aprendizagem e para a pesquisa. Este termo apresenta maior co-ocorrência com os termos prática e pesquisa. Enquanto o termo laboratório é compreendido na dimensão material e o termo prática é compreendido na dimensão pedagógica, o termo pesquisa é compreendido na dimensão atividade científica. Esta relação sintetiza a RS sobre "experimentação" dos nãoCoordenadores do PIBID: o laboratório é compreendido como o local apropriado para a execução de experimentos voltados tanto para a prática da pesquisa como para a aprendizagem.

\subsubsection{Análise de Conteúdo das Evocações dos Coordenadores do PIBID}

O termo investigação apresenta características pertencentes às dimensões pedagógica, procedimental e atividade científica.

Depreende-se, da leitura da árvore de similitude máxima (Figura 6.10), que o termo investigação apresenta maior co-ocorrência com o termo laboratório. O termo laboratório refere-se à dimensão material, sendo compreendido como o local apropriado, mas não único, para se realizarem experimentos com objetivo pedagógico. Para os Coordenadores do PIBID, o laboratório apresenta o suporte adequado, com equipamentos e estrutura que fornece segurança para as atividades experimentais, principalmente para as mais elaboradas. Porém, este grupo entende que é possível realizar atividades experimentais em espaços alternativos a esse local, sendo possível, por exemplo, trabalhar com materiais alternativos e de baixo custo na sala de aula.

Oportunidade de uso do laboratório apesar de serem realizados comumente na própria sala de aula (S. 013).

Falar em experimentação é pensar também num local adequado, isto é, trazer o aluno ao laboratório transporta o aluno para um novo ambiente, dando significado à atividade experimental. Sabe-se que muitas atividades 
experimentais são realizadas nas próprias salas de aula. No entanto, evoco a palavra "laboratório", pois creio que é um espaço especial para a realização de atividades experimentais (S. 032).

Local mais adequado para experimentação, sem a necessidade de apresentar o formato tradicional de um laboratório de Química, mas um formato ou vários formatos em um único espaço (S. 073).

É importante que o laboratório seja utilizado desde que a escola tenha o espaço, reagentes e vidrarias para isso (S. 140).

A análise dos trechos possibilita outra interpretação: se, para os não-Coordenadores do PIBID, o laboratório é um ambiente indispensável para o desenvolvimento de atividades voltadas para a pesquisa e para a formação dos químicos, pois caracteriza a atividade empírica da Química, para os Coordenadores do PIBID, esse ambiente apresenta importância suplementar, pois é a atividade, e não o ambiente, que apresenta centralidade na fala desse grupo. Ainda, nas falas dos Coordenadores do PIBID, é possível identificar uma preocupação com a falta de condições materiais que as Instituições de Ensino apresentam. Em diversas falas, é possível identificar que a instituição mencionada é a escola da Educação Básica, algumas vezes mencionada de forma explícita, outras de forma implícita.

Já o termo prática, termo de maior co-ocorrência com laboratório, refere-se à dimensão pedagógica. O termo prática é compreendido como vivência, ou seja, é importante que os alunos vivenciem algumas práticas da Ciência, por exemplo, as atividades experimentais de cunho investigativo, mesmo que essas atividades sejam desenvolvidas sem o laboratório, pois auxiliam na construção do conhecimento dos conteúdos conceituais e procedimentais.

A experimentação é importante para que o aluno vivencie algumas praticas da ciência (S. 020).

As atividades práticas despertam interesse sejam elas nos laboratórios e/ou outros ambientes (S. 048).

A experimentação também favorece o desenvolvimento de conteúdos procedimentais, necessários à condução de uma atividade experimental (S. 203).

A vivência prática é fundamental para uma melhor assimilação de conceitos (S. 236).

A dimensão pedagógica é a que contempla o maior número de termos. Os termos que apresentam maior co-ocorrência com investigação são: curiosidade, motivação, contextualização, aprendizagem, construção do conhecimento, relação teoria e prática. 
Nesta dimensão, o termo investigação é compreendido como uma estratégia pedagógica que favorece a construção de conceitos e o desenvolvimento de habilidades cognitivas e de cunho investigativo, como pode ser observado nos trechos

O caráter investigativo caracteriza o ensino de ciências na escola (S. 026).

A importância do uso de investigação como atividade de experimentação para a construção do conhecimento ao invés de simplesmente realizar atividades somente para comprovar um fato (S. 037).

Em minha vivência na escola e na universidade, percebo que os experimentos quando planejados de forma investigativa, possibilitam a aquisição de novas habilidades cognitivas pelos estudantes. Além de motivá-los na busca de respostas e explicações para os problemas (S. 043).

[...] a perspectiva investigativa seja uma das mais importantes para o desenvolvimento de atividades experimentais, pois possibilita 0 desenvolvimento de várias habilidades por parte dos envolvidos, bem como uma visão mais crítica e próxima da realidade científica (S. 171).

Ainda, analisando-se os trechos, é possível perceber que os Coordenadores do PIBID atribuem às atividades de cunho investigativo um caráter afetivo, expresso pela relação do termo investigação com os termos motivação e curiosidade. O caráter lúdico dessa atividade tem grande relevância por auxiliar no engajamento dos alunos na execução das tarefas, o que resulta na melhoria do processo de ensino e aprendizado dos conteúdos conceituais e procedimentais. Já os termos contextualização e relação teoria e prática são estratégias inerentes às atividades experimentais de cunho investigativo.

[contextualização] Com a experimentação também é possível se trabalhar a Química em um determinado contexto, o que traz para o aluno um entendimento dos conceitos químicos dentro de um conjunto de ideias que estão mais próximas do seu entendimento (S. 044).

[contextualização] A contextualização, ao facilitar a construção de significados, incorpora valores que explicitam o cotidiano, facilitando os processos da descoberta envolvidos na experimentação (S. 089).

[relação teoria e prática] Entender o conceito químico nas suas diferentes dimensões: microscópico, macroscópico e simbólico (S. 038).

[relação teoria e prática] Para o professor, por meio da experimentação, é possível relacionar os conceitos e modelos da química na perspectiva da prática para dar sentido aos conceitos (S. 130)

O termo contextualização é compreendido como uma forma de aproximar a teoria a aspectos do cotidiano dos alunos, apresentando situações concretas, o que possibilita uma melhor compreensão dos conceitos científicos e facilita a construção de significados. $O$ termo relação teoria e prática é compreendido como uma estratégia que auxilia o 
entendimento do conhecimento químico em suas diferentes dimensões: macro, submicro e simbólico.

Já o termo aprendizagem, ratifica a dimensão pedagógica das atividades experimentais de cunho investigativo, qualificando o termo investigação.

A partir deste movimento de reflexão e levantamento de hipóteses que poderão ou não ser testadas, mas sempre analisadas de forma reflexiva é que será possível apreender o conhecimento e assim pode acontecer a aprendizagem, por meio da investigação, atividades mentais e experimentais que vão sendo direcionadas pelo professor para que o aprendizado aconteça (S. 157).

Com uma aula experimental bem preparada e executada é possível perceber uma melhoria na aprendizagem do aluno, já que este consegue fazer relações mais próximas entre o fenômeno observado e o conceito químico por trás deste (S. 144) /

Está relacionada à importância do processo de aprendizagem na Experimentação. Pois, por ser uma disciplina muito visual, a experimentação contribui de grande forma com a aprendizagem no ensino de ciências (S. 190).

Outro aspecto da investigação é sua relação com as dimensões procedimental e atividade científica. Enquanto parte dos Coordenadores do PIBID justificou a evocação do termo investigação no sentido de questionar as atividades experimentais pautadas por um processo rígido e sequenciado de etapas (dimensão procedimental),

A atividade experimental não pode ser conduzida de maneira automática, com o uso de um roteiro que deve ser reproduzido, mas deixando o aluno investigar e propor caminhos para a condução do experimento (S. 062).

Ao propor que estudantes desenvolvam habilidades cognitivas por meio da experimentação, será necessário que, após receberem os elementos básicos para a empreitada, descubram o caminho (S. 081).

Deve trazer desafios para o estudante e não receitas prontas (S. 129).

Outra parte dos coordenadores justificou a evocação do termo investigação relacionando-o aos objetivos das atividades experimentais (dimensão atividade científica), como se pode observar nos excertos que se seguem:

O caráter dado a experimentação (não apenas para comprovar teorias, leis, conceitos, fenômenos e/ou validar modelos), mas sim para trazer à tona questionamentos do aluno a partir da sua visão e interação com o mundo, para que posteriormente ele possa prever resultados, pedir ajuda ou entrar num consenso coletivo para determinada tomada de decisão (S. 125).

Um experimento pode ser realizado de diversas maneiras, de forma que a atividade experimental seja mais rica ou mais pobre em determinados objetivos, de acordo com o planejamento. Uma habilidade não muito explorada por professores da Educação Básica hoje, é a investigação, que pode estimular a formar alunos críticos (S. 128). 
Acredito que a perspectiva investigativa seja uma das mais importantes para o desenvolvimento de atividades experimentais, pois possibilita o desenvolvimento de várias habilidades por parte dos envolvidos, bem como uma visão mais crítica e próxima da realidade científica (S. 171).

Ainda, os termos que constituem a dimensão procedimental e que mais co-ocorrem com o termo investigação, são observação, hipótese e reflexão e análise como pode ser observado nos trechos

[hipótese] Entendo que a experimentação é um momento ímpar para que os estudantes se sintam mobilizados a levantar hipóteses sobre as observações e refletirem sobre os dados (S. 155).

[observação] Permite que se desenvolva a habilidade de observar os fenômenos e assim construir as hipóteses e teorias e não apenas receber o que já está pronto pelo professor (S. 006).

[análise] A experimentação requer muitas vezes a análise e reflexão das situações (S. 015).

[reflexão] A experimentação deve possibilitar a reflexão sobre a prática realizada (S. 102).

Esses termos referem-se tanto ao processo das atividades experimentais, como às habilidades necessárias para sua execução, mas que estão diretamente relacionadas com os princípios da atividade científica, por exemplo, dimensão atividade científica. Nesse sentido, as atividades experimentais de cunho investigativo, quando bem elaboradas, possibilitam uma aproximação mais adequada das características das Ciências, o que pode auxiliar no processo de alfabetização científica.

A dimensão segurança foi contemplada de forma mais expressiva no termo, segurança, alocado na segunda periferia dos Coordenadores do PIBID (já para os não-Coordenadores do PIBID esse termo constituiu a zona de contraste), e de forma menos expressiva ao justificarem o termo laboratório, refererindo-se que é importante realizar atividades experimentais em ambientes que possibilitem segurança para os discentes:

[segurança] A segurança embora esteja em último lugar [na hierarquização das evocações], ela estar presente em todas as atividades experimentais realizadas (S. 063).

[laboratório] Local adequado para praticar com segurança (S. 232).

Este resultado indica que, embora o aspecto de segurança não seja frequentemente mencionado explicitamente seja pelos Coordenadores ou não-Coordenadores do PIBID, ainda é alvo de maior atenção para aos não-Coordenadores, possivelmente por eles associarem a atividade experimental principalmente ao contexto escolar da Educação Superior, que envolve práticas mais elaboradas. 
Em síntese, a RS sobre "experimentação" dos Coordenadores do PIBID é objetivada no termo investigação e ancorado como uma estratégia pedagógica importante para o processo de ensino e aprendizado. Esta estratégia engloba as dimensões atividade científica e procedimental, necessárias para facilitar a construção de conceitos e o desenvolvimento de habilidades cognitivas e de cunho investigativo, o que aproxima os estudantes dos princípios da NdC. A alta co-ocorrência que o termo investigação apresenta com laboratório tem o sentido de justificar a possibilidade da realização de atividades experimentais de cunho investigativo sem envolver esse espaço, embora entenda-se a importância desse espaço para essas atividades. Este resultado indica a preocupação com o contexto escolar que os Coordenadores do PIBID apresentam ao planejarem atividades experimentais no âmbito do PIBID.

A seguir, serão apresentadas algumas considerações acerca das RS sobre "experimentação" dos Coordenadores e não-Coordenadores do PIBID, ressaltando suas semelhanças e diferenças.

\subsection{Síntese: Considerações sobre as Representações Sociais dos Coordenadores e não-Coordenadores do PIBID}

Os resultados da análise dos dados, por meio das abordagens Prototípica e de Similitude, mostram que o termo laboratório constitui NC da RS dos não-Coordenadores do PIBID enquanto, para os Coordenadores, o termo que constitui o NC da RS é investigação. A Análise de Conteúdo mostrou que os Coordenadores do PIBID ancoram as atividades experimentais no processo de ensino e aprendizado, enquanto os não-Coordenadores ancoram-na nos processos de aprendizagem e pesquisa. Estes resultados mostram que o NC da RS dos dois subgrupos quanto ao termo "experimentação" é distinto, caracterizando RS diferentes. Portanto, estes sujeitos constituem diferentes grupos sociais no que concerne ao objeto social "experimentação".

A compreensão sobre laboratório para ambos os subgrupos refere-se à dimensão material. Enquanto para os Coordenadores do PIBID laboratório é o local apropriado, mas não o único, para se realizarem atividades experimentais para o Ensino de Química, para os não-Coordenadores, o laboratório é o local ideal tanto para as atividades didáticas quanto para as atividades de pesquisa, pois este ambiente apresenta os equipamentos necessários para se controlarem as variáveis dos experimentos. Esta correlação entre a atividade experimental e o ambiente laboratorial como características das Ciências Naturais corrobora os resultados encontrados na literatura em estudos voltados a estudantes da Educação Básica, graduandos, pós-graduandos e professores (LEMES, 2013; GOLDSCHMIT; 
GOLDSCHMIT; LORETO, 2014; COLAGRANDE; MARTORANO; ARROIO, 2016; PEREIRA, 2016).

Outro termo cujo significado é diferente para os dois grupos é investigação. Tanto Coordenadores como não Coordenadores do PIBID compreendem este termo como uma característica das Ciências que pode ser utilizada como estratégia de ensino por conduzir ao questionamento sobre os fenômenos estudados e permitir uma aproximação à abordagem empregada pelos pesquisadores do campo das Ciências Naturais, embora os Coordenadores do PIBID apostem fortemente no caráter motivador desse processo. Ainda, nas explicações dos Coordenadores do PIBID, há aspectos que remetem ao desenvolvimento das atividades de cunho investigativo contextualizando-as para o ambiente escolar da Educação Básica. Este último aspecto já foi amplamente investigado, havendo vários estudos cujos resultados apontam a importância do caráter afetivo que as atividades experimentais despertam nos estudantes (HOFSTEIN; LUNETTA, 1982; ARAÚJO; ABIB, 2003; HOFSTEIN; LUNETTA, 2003; HOFSTEIN, 2004; OLIVEIRA, 2010; DUIT; TESCH, 2010; GONÇALVES; MARQUES, 2012, 2016; CORRALO, 2017; SILVA et al., 2018). Hoje, este aspecto é praticamente consensual para professores e pesquisadores, principalmente para o processo de ensino e aprendizado das Ciências da Natureza na Educação Básica.

Outro aspecto que merece destaque é que tanto Coordenadores como nãoCoordenadores do PIBID entendem que as atividades experimentais auxiliam no desenvolvimento de conteúdos conceituais (referentes à dimensão pedagógica) e procedimentais (referentes à dimensão procedimental) entendendo que esta relação auxilia na compreensão da atividade científica (referente à dimensão atividade científica). A diferença para os dois subgrupos está na ênfase quanto a estes conteúdos. Enquanto os Coordenadores do PIBID enfatizam o desenvolvimento das habilidades cognitivas e a compreensão acerca da $\mathrm{NdC}$, os não-Coordenadores enfatizam uma relação mais equilibrada entre os conceitos científicos, as habilidades procedimentais e os princípios do método científico das Ciências Naturais. Este entendimento é similar ao que Hodson (1994) propôs sobre os objetivos das atividades experimentais para o ensino; para uma atividade ser realmente efetiva deve contemplar três aspectos, os conceitos científicos, a Natureza das Ciências e as práticas das Ciências. Porém, o conteúdo atitudinal, relacionado a relações tanto interpessoais como sociais quase não foi mencionado por ambos subgrupos, embora seja recorrentemente citado na literatura. Wei e Li (2017) encontraram resultados similares ao investigar a compreensão de professores da Educação Básica sobre os experimentos escolares e científicos. 
Outra dimensão que foi escassamente mencionada refere-se à segurança, embora este tema também seja muito mencionado na literatura especializada da área (GONÇALVES; MARQUES, 2006; GALIAZZI; GONÇALVES, 2004; CORRALO, 2017; WEI; LI, 2017; SUART; MARCONDES, 2018). Enquanto na representação dos não-Coordenadores a dimensão de segurança relaciona-se apenas à segurança envolvida nas práticas de laboratório, para os Coordenadores do PIBID esta dimensão vincula-se aos termos segurança e laboratório. Isto indica que, embora esta questão não seja uma preocupação recorrente nas práticas desses sujeitos, para os Coordenadores do PIBID este aspecto está mais atrelado a suas práticas, possivelmente por se relacionarem às atividades experimentais no contexto da escola da Educação Básica.

Considerando este conjunto de resultados, são possíveis três inferências. Primeiro, participar como coordenador de área do subprojeto PIBID-Química contribui para a recontextualização sobre o objeto social "experimentação". Esta recontextualização foi observada pelas distintas RS sobre o objeto "experimentação" apresentadas pelos sujeitos da pesquisa (Tabela 6.11, p. 75), principalmente, quando se observa que o tempo de participação do professor como coordenador do subprojeto PIBID-Química (Figura 6.6, p. 77) potencializa sua recontextualização sobre este objeto social, mostrando a influência do tempo de vivência no projeto para a ressignificação do papel da experimentação no contexto educativo. Esta vivência como Coordenador de Área relaciona-se às ações desenvolvidas no PIBID devidas, principalmente, às atribuições ii, iii, $v, x$ e xi, referentes à ação do Coordenador de área na gestão do PIBID e na articulação entre universidade e escola, descritas no Quadro 2.2 (página 22) e sintetizadas na Figura 2.1 (página 23).

Segundo, coordenar subprojetos PIBID aproxima o Coordenador da realidade da escola da Educação Básica, modificando suas percepções sobre esse contexto, sobre a sua atuação e a formação dos futuros professores, o que propicia novas visões sobre o ensino e a prática docente (CAPES-DEB, 2012, 2013, 2014; GATTI et al., 2014; SILVA, 2015). Resultados similares foram identificados por Silva (2015) ao investigar o impacto da participação na coordenação de subprojetos PIBID-Física sobre o desenvolvimento profissional dos professores universitários.

A terceira inferência relaciona-se à contribuição do PIBID para a formação continuada dos Coordenadores de Área, principalmente, com relação aos itens "c" e "e" do Quadro 2.4 (p. 26), referentes à elevação da auto-estima e reconhecimento entre os pares e, principalmente, à mudança de posturas e práticas formativas no âmbito das próprias IES. Portanto, o PIBID, por se mostrar um importante programa de formação continuada para seus Coordenadores, contribuindo para as modificações tanto de suas compreensões sobre 
o processo educacional como para as reflexões sobre sua própria prática no âmbito do Ensino Superior, mostra a potencialidade de contribuir não só para a formação dos licenciandos bolsistas do PIBID, mas, também, para os licenciandos não participantes deste programa. Os resultados apresentados na Tabela 6.1 (p. 62) e 6.11 (p. 75) corroboram esta constatação, sendo possível observar que a adesão dos Coordenadores do PIBID em relação a este programa é positiva, pois mais de $50 \%$ coordenam o PIBID por mais de 36 meses. Isto possibilita a continuidade do processo de auto reflexão e aprendizado.

As diferenças quanto aos objetivos, metas e recursos necessários para o desenvolvimento das atividades experimentais apontam para diferentes concepções sobre formação de professores, identificadas por meio da Análise de Conteúdo das justificativas dos termos evocados pelos participantes da pesquisa. Tanto Coordenadores como nãoCoordenadores relacionam a experimentação com a formação de professores de Química. Porém, os Coordenadores do PIBID tendem a relacionar o desenvolvimento das atividades experimentais ao contexto escolar, levando em consideração as particularidades e problemáticas desse espaço, o que indica uma orientação quanto aos pressupostos do modelo de formação que relaciona a competência técnica com a competência prática. Já os não-Coordenadores tendem a pensar no desenvolvimento das atividades experimentais no contexto do Ensino Superior, indicando uma percepção formativa que se fundamenta nos princípios do modelo de formação da competência técnica (DINIZ-PEREIRA, 2002; ZEICHNER, 2010). Esta diferença pode ter relação com as práticas que os Coordenadores desenvolvem conjuntamente com os licenciandos bolsistas e os supervisores no âmbito do PIBID, que têm como principal objetivo o planejamento de ações que contribuam para a superação dos vários problemas enfrentados na escola (SANTOS; ARROIO, 2015).

Portanto, os resultados desta pesquisa possibilitam explicar o observado no estudo de Vogel (2016), em que se investigou a RS sobre "professor de Química" de licenciandos em Química participantes e não-participantes do PIBID. Enquanto os licenciandos participantes do PIBID, ao pensarem no objeto social "professor de Química," relacionam-no à atividade experimental voltada para os processos pedagógicos, os não-participantes relacionam este objeto ao caráter empírico da Química. Pode-se inferir que a associação entre experimentação e processos pedagógicos dos licenciandos participantes do PIBID-Química provém da formação mediada pelos professores Coordenadores e não-Coordenadores desse programa; já a associação que os licenciandos não-participantes do PIBID-Química fazem entre experimentação e o caráter empírico da Química provém da formação mediada pelos professores não-Coordenadores do PIBID. 
Em síntese, os resultados obtidos sugerem que o PIBID tem contribuído para modificar as concepções acerca da formação de professores dos Coordenadores dos subprojetos PIBID-Química, o que se reflete na maneira com que os licenciandos bolsistas são formados, como já observado em outras pesquisas (GATTI et al., 2014; SILVA, 2015) afetando, também, na formação dos licenciandos do curso, em geral, pois os docentes que coordenam o projeto ministram disciplinas para o conjunto dos graduandos. É de se supor que a ressignificação sobre o objeto social experimentação devida a sua atuação no PIBID transforme sua prática na Licenciatura onde atuam, ampliando o escopo do próprio projeto. 


\section{CONSIDERAÇÕES FINAIS}

O planejamento desta pesquisa baseou-se em estudo anterior desenvolvido em nosso grupo de pesquisa e buscou aprofundar a compreensão dos resultados que foram obtidos naquele estudo de Doutorado (VOGEL, 2016). Os resultados apresentados naquele Doutorado mostraram que os termos constituintes do NC das RS de licenciandos participantes e não participantes de subprojetos PIBID-Química sobre o objeto social "professor de Química" eram distintos; para os discentes que participaram desses subprojetos, o NC da RS era constituído pelos termos dedicado, experimentação e responsabilidade, enquanto para os discentes que não participaram, o NC da RS era constituído pelos termos dedicado, experimentação e inteligente. O termo experimentação era compreendido de forma distinta para esses subgrupos, referindo-se à melhoria do ensino de Química para os participantes do PIBID. Para os não participantes referia-se ao fazer científico.

Segundo esses resultados, e a partir da perspectiva de que as RS de licenciandos em Química, participantes ou não do PIBID, apresenta influência do seu contexto formativo, o que implica a relação desses alunos com seus professores formadores, esta pesquisa de Mestrado buscou identificar as RS de professores universitários de cursos de Licenciatura em Química que atuam/atuavam como coordenadores de área de subprojetos PIBIDQuímica e dos que não atuavam como coordenadores de PIBID. Com isso, pretendeu-se identificar se esses sujeitos se constituiam como dois grupos sociais em relação ao objeto social "experimentação", ou seja, se eles têm RS sobre esse termo e no que elas diferem.

Nesse sentido, pretendeu-se contribuir com estudos que se voltam à compreender melhor os processos formativos dos licenciandos em Química.

A caracterização dos sujeitos desta pesquisa possibilitou inferir que há diferenças sobre a formação e o contexto de atuação dos Coordenadores e dos não-Coordenadores do PIBID. Nesta pesquisa, a variável experiência na coordenação no subprojeto PIBID-Química foi o critério de distinção dos sujeitos, o que levou a seu agrupamento em dois conjuntos, a fim de se identificar se estes conjuntos de participantes, por critérios de semelhança, se constituíam em grupos sociais com relação ao objeto social estudado (experimentação). Porém, não se desconsiderou a influência das outras variáveis para a constituição das RS dos sujeitos da pesquisa, pois a ancoragem sobre o termo "experimentação" também advém da formação inicial e das práticas desenvolvidas nas IES. Entretanto, a análise dos dados mostra que coordenar subprojetos PIBID-Química, principalmente quando se considera o tempo de coordenação, tem maior expressão do que as outras variáveis. 
Foi possível identificar que o termo que constitui o NC da RS sobre "experimentação" dos Coordenadores do PIBID é investigação, enquanto laboratório constitui NC da RS dos não-Coordenadores do PIBID. Tal resultado indica RS distintas para os dois grupos; portanto, estes sujeitos constituem diferentes grupos sociais quanto a este objeto.

A Análise de Conteúdo possibilitou desvelar que a compreensão sobre o laboratório, tanto para os Coordenadores como para os não-Coordenadores do PIBID, se refere à dimensão material, relacionando o espaço ideal para se realizar atividades experimentais ao ambiente laboratorial. Para ambos os grupos esta atividade visa a formação de professores de Química, porém, os não-Coordenadores também relacionam esta atividade e o ambiente laboratorial à pesquisa em Química.

O termo investigação é compreendido por ambos os subgrupos como uma característica das Ciências da Natureza, que pode ser trabalhada no processo de ensino e aprendizado de Ciências, visando auxiliar no desenvolvimento de conceitos, habilidades procedimentais e investigativas, o que facilita a compreensão da atividade científica. A diferença para os dois subgrupos, com relação a este termo, está na ênfase desses conteúdos. Enquanto os Coordenadores do PIBID enfatizam o desenvolvimento das habilidades cognitivas e a compreensão da $\mathrm{NdC}$, os não-Coordenadores enfatizam a relação mais equivalente entre os conceitos científicos, as habilidades procedimentais e os princípios do método científico das Ciências Naturais. Ainda, os Coordenadores do PIBID apostam fortemente no caráter motivador das atividades experimentais de cunho investigativo e contextualizam-na no ambiente escolar da Educação Básica.

Em síntese, os resultados desta pesquisa mostram que coordenar subprojetos PIBIDQuímica contribui para o processo de recontextualização sobre o objeto social "experimentação" e aproxima os professores da universidade à realidade escolar da Educação Básica. Estes aspectos apresentam grande importância, pois possibilitam ao Coordenador do PIBID um processo de formação continuada, modificando seu olhar sobre o modelo de formação da IES à qual está vinculado. Assim, por exemplo, os resultados desta pesquisa indicam que enquanto os não-Coordenadores apresentam pressupostos do modelo de formação da competência técnica, os Coordenadores do PIBID apresentam pressupostos do modelo de formação que relaciona a competência técnica à competência prática. Esta diferença implica em novas práticas tanto no âmbito dos subprojetos PIBID como no âmbito da docência na própria IES, que se refletem no processo formativo inicial do futuro professor.

Os resultados desta pesquisa possibilitaram, ainda, observar uma relação entre a compreensão sobre "experimentação" dos estudantes de licenciaturas em Química, 
participantes ou não do PIBID, apontadas anteriormente por Vogel (2016), das RS sobre o termo "experimentação" dos professores formadores de professores de Química, que coordenam ou não subprojetos PIBID. Tal fato aponta para a importância de se compreender melhor as influências das RS dos professores universitários de cursos de Licenciatura em Química sobre aspectos inerentes à Química e seu ensino na compreensão dos licenciandos sobre esses aspectos. Esses estudos têm potencial de contribuir para o aperfeiçoamento da formação inicial de professores de Química.

Por fim, ressalta-se a preocupação das diversas alterações que o PIBID vem sofrendo, por exemplo, a inclusão de Instituições de Ensino Superior de direito privado, a redução de bolsas, a limitação na participação dos licenciandos no PIBID em até aos primeiros dois anos do curso de Licenciatura e por um período de no máximo 18 meses, e a possibilidade institucionalizada da participação do licenciando sem a remuneração da bolsa. Essas alterações podem impactar na formação inicial dos futuros professores, em sua atuação e, portanto, a qualidade da Educação Básica. 


\section{REFERÊNCIAS BIBLIOGRÁFICAS}

ABD-EL-KHALICK, F., BOUJAOUDE, S., DUSCHL, R., LEDERMAN, N. G., MAMLOKNAAMAN, R., HOFSTEIN, A., NIAZ, M.; TREAGUST, D.; TUAN, H. Inquiry in science education: International perspectives. Science Education, v. 88, p. 397-419, 2004.

ABRAHAMS, I.; MILLAR. R. Does Practical Work Really Work? A study of the effectiveness of practical work as a teaching and learning method in school science, International Journal of Science Education, v. 30, n.14, p. 1945-1969, 2008.

ABRIC, J-C; Las Representaciones Sociales: Aspectos Teóricos. In: ABRIC, J.-C. (Ed.). Prácticas sociales y representaciones. $1^{\mathrm{a}}$ ed. México, D.F.: Cultura Libre, 2001.

ABRIC, J-C. Central system, peripheral system: their functions and roles in the dynamics of social representations. Papers on Social Representations, v. 2, n. 2, p. 75-78, 1993.

ARAÚJO, M. S. T; ABIB, M. L. V. S. Atividades Experimentais no Ensino de Física: diferentes enfoques, diferentes finalidades. Revista Brasileira de Ensino de Física, v. 25, n. 2, p. 176-194, 2003.

ASCH, S. E. Forming impressions of personality. Journal of Abnormal and Social Psychology, v. 41, p. 258- 290. 1946.

AZEVEDO, N. H.; SCARPA, D. L. Um levantamento em larga escala das Concepções de Natureza da Ciência de graduandos de Biologia brasileiros e os possíveis elementos formativos associados. Revista Ensaio, v.19, e2794, 2017.

BAPTISTA, M. L. M.; FREIRE, S.; FREIRE, A. M. Tarefas de Investigação em aulas de Física: um estudo com alunos do $8^{\circ}$ ano. Caderno pedagógico, v. 10, n. 1, p. 137-151, 2013.

BARDIN, L. Análise de conteúdo. Lisboa: Edições 70, 2011.

BEZERRA, B. H. S.; AMARAL, E. M. R. Identificando Compromissos Epistemológicos, Ontológicos e Axiológicos em Falas de Licenciandos Quando Discutem uma Questão Sociocientífica. Química Nova na Escola, v. 41, n. 1, p. 41-54, 2019.

BOURICHE, B. L'analyse de similitude. Hors collection, p. 221-252, 2003. Disponível em: <http://www.cairn.info/article.php?ID ARTICLE=ERES ABRIC $2003010221>$. Acessado em 29 de abril de 2019.

BRASIL. Presidência da República. Casa Civil. Subchefia para Assuntos Jurídicos. Lei no 11.502, de 11 de Julho de 2007. Modifica as competências e a estrutura organizacional da fundação Coordenação de Aperfeiçoamento de Pessoal de Nível Superior - CAPES Brasília: Presidência da República do Brasil, 2007.

CAPES-DEB. Relatório de Gestão PIBID 2009-2011. Brasília: Diretoria de Formação de Professores da Educação Básica - DEB. Brasília. 2012. Disponível em: $<$ http://www.capes.gov.br/images/stories/download/bolsas/RelatorioGestaoOBEDUC-20092011 27jul12.pdf>. Acessado em: 30 de abril de 2019.

CAPES-DEB. Relatório de Gestão PIBID 2009-2013. Brasília: Diretoria de Formação de Professores da Educação Básica - DEB. Brasília. 2013. Disponível em: 
<http://www.capes.gov.br/images/stories/download/bolsas/1892014-relatorio-PIBID.pdf> .

Acessado em: 30 de abril de 2019.

CAPES-DEB. Relatório de Gestão 2009-2014. Brasília: Diretoria de Formação de Professores da Educação Básica - DEB. Brasília. 2014. Disponível em: <https://capes.gov.br/images/stories/download/bolsas/20150818 DEB-relatorio-de-gestaovol-1-com-anexos.pdf $>$. Acessado em: 30 de abril de 2019.

CAPES-DEB. Portaria Normativa no 122, de 16 de setembro de 2009. Dispõe sobre o PIBID - Programa Institucional de Bolsa de Iniciação à Docência, no âmbito da CAPES. Brasília: Ministério da Educação. 2009. Disponível em:

<http://www.capes.gov.br/images/stories/download/bolsas/PortariaNormativa122 PIBID.pdf> . Acessado em: 30 de abril de 2019.

CAPES-DEB. Portaria no 72, de 09 de abril de 2010. Dá nova redação a Portaria que dispõe sobre o Programa Institucional de Bolsa de Iniciação à Docência - PIBID, no âmbito da CAPES. Brasília. Diário Oficial da União, n. 62, seção 1, p. 26-27, 2010a.

CAPES-DEB. Portaria no 260, de 30 de dezembro de 2010. Aprova as normas do Programa Institucional de Bolsa de Iniciação à Docência - PIBID. Brasília. 2010b. Disponível em: $<$ https://www.capes.gov.br/images/stories/download/legislacao/Portaria260 PIBID2011 NomasGerais.pdf>. Acessado em 30 de abril de 2019.

CAPES-DEB. Portaria no 96 de 18 de julho de 2013. Aprova as novas normas do Programa Institucional de Bolsa de Iniciação à Docência - PIBID. Brasília. 2013. Disponível em:<https://www.capes.gov.br/images/stories/download/legislacao/Portaria 096 18jul13 Ap rovaRegulamentoPIBID.pdf>. Acessado em 30 de abril de 2019.

CAPES-DEB. Portaria no 46 de 11 de abril de 2016. Aprova o Regulamento do Programa Institucional de Bolsa de Iniciação à Docência - Pibid. Brasília. 2016a. Disponível em: $<$ https://www.capes.gov.br/images/stories/download/legislacao/15042016-Portaria-46-

Regulamento-PIBID-completa.pdf>. Acessado em 30 de abril de 2019.

CAPES-DEB. Portaria no 84 de 15 de junho de 2016. Revoga a Portaria no 46, de 11 de abril de 2016. Brasília. Diário Oficial da União, n. 113, seção 1, p. 19, 2016b.

CAPES-DEB. Portaria no 38, de 28 de fevereiro de 2018. Institui o Programa de Residência Pedagógica. Brasília. Diário Oficial da União, n. 41, Seção 1, pág. 28, 2018a.

CAPES-DEB. Portaria CAPES no 175 de 7 de Agosto de 2018. Altera o Anexo I da Portaria nㅇ 45, de 12 de março de 2018. Brasília. 2018b. Disponível em: $<$ http://capes.gov.br/images/stories/download/legislacao/09082018-

Portaria 175 Altera Portaria 45 de 2018.pdf>. Acessado em 30 de abril de 2019.

CAPES-DEB. Edital CAPES no 07/2018. 2018c. Disponível em: $<$ https://www.capes.gov.br/images/stories/download/editais/01032018-Edital-7-2018PIBID.pdf>. Acessado em 30 de abril de 2019.

CAPES-DEB. Edital CAPES no 06/2018. 2018d. Disponível em: $<$ https://www.capes.gov.br/images/stories/download/editais/01032018-Edital-6-2018Residencia-pedagogica.pdf>. Acessado em 30 de abril de 2019.

CAPES-MEC. Relatório de Avaliação 2013-2016 - Quadrienal 2017, Área de Avaliação: Ensino. 2018. Disponível em: 
$<$ https://capes.gov.br/images/stories/download/avaliacao/relatorios-finais-quadrienal2017/20122017-ENSINO-quadrienal.pdf>. Acessado em 30 de abril de 2019.

CAPES-MEC. Relatório de Gestão de Exercício de 2015. Brasília: Ministério da Educação - MEC, 2016. Disponível em:

$<$ http://www.capes.gov.br/images/stories/download/Contas Publicas/2015 Relatorio de Ge stao.pdf>. Acessado em: Acessado em 30 de abril de 2019.

CAPES-MEC. Relatório de Gestão de Exercício de 2016. Brasília: Ministério da Educação - MEC, 2017. Disponível em:

$<$ https://capes.gov.br/images/stories/download/acessoainformacao/Relatorio de Gestao CA PES 2016.pdf>. Acessado em: Acessado em 30 de abril de 2019.

CARMO, T.; LEITE, J. C.; MAGALHÃES JÚNIOR, C. A. O.; RANGEL, M. O cenário metodológico das pesquisas em Representações Sociais no Brasil: um olhar sobre o campo educacional entre os anos de 2010 a 2015. Ensenanza de Las Ciencias, v. 1, p. 49554960, 2017.

CASA CIVIL. Lei no 12.796, de 4 de abril de 2013. Altera a Lei no 9.394, de 20 de dezembro de 1996, que estabelece as diretrizes e bases da educação nacional, para dispor sobre a formação dos profissionais da educação e dar outras providências. 2013. Disponível em: $<$ http://www.planalto.gov.br/CCIVIL 03/ Ato20112014/2013/Lei/L12796.htm >.Acessado em 30 de abril de 2019.

COLAGRANDE, E. A.; MARTORANO, S. A. A.; ARROIO, A. Assessment on How PreService Science Teachers View the Nature of Science. Journal of Turkish Science Education, v. 13, n. 4, 2016.

COLAGRANDE, E. A.; MARTORANO, S. A. A.; ARROIO, A. Views of a group of pre-service science teachers on the use of experimental activities in science teaching. Problems of Education in the $21^{\text {st }}$ Century, v. 75, n. 6, 2017.

CORRALLO, M. V. Atividades práticas experimentais para o ensino de Física: uma investigação utilizando a Teoria do Núcleo Central. 2017. 228 f. Tese (Doutorado) Instituto de Física, Instituto de Química, Instituto de Biociências e Faculdade de Educação, Universidade de São Paulo, SP, 2017.

DURKHEIM, É. O Suicídio: estudo de sociologia. São Paulo: Martins Fontes, 2000.

DUIT, R.; TESCH, M. On the role of the experiment in science teaching and learning Visions and the reality of instructional practice. In: M. Kalogiannakis, D. Stavrou \& P. Michaelidis. Proceedings of the 7th International Conference on Hands-On Science. 21 - 30 July, Rethymno, Greece. p. 17-30, 2010.

FARR, R. M. Representações Sociais: a teoria e sua história. In: Textos em Representações Sociais. GUARESCHI, P. A; JOVCHELOVITCH, S. (Orgs). $14^{\mathrm{a}}$ ed. Petrópolis, RJ: Vozes, 2013.

FELÍCIO, H. M. S; GOMES, C; ALLAIN, L. R. O PIBID na ótica dos licenciandos: possibilidades e limites no desenvolvimento do programa. Educação, v. 39, n. 2, p. 339-352, 2014.

GALIAZZI, M. C.; GONÇALVES, F. P. A Natureza Pedagógica da experimentação: uma pesquisa na Licenciatura em Química. Química Nova, v. 27, n. 2, p. 326-331, 2004. 
GATTI, B.; ANDRÉ, M.; GIMENES, N.; FERRAGUT, L. Um estudo avaliativo do Programa Institucional de Bolsa de Iniciação à Docência (Pibid). São Paulo: FCC, 2014.

GIMENES, C. I. O Programa Institucional de Bolsa de Iniciação à Docência (PIBID) e a formação de professores de Ciências Naturais: possibilidade para a práxis na formação inicial? 2016. 247f. Tese (Doutorado em Educação) - Faculdade de Educação, Universidade de São Paulo, SP, 2016.

GOLDSCHMIDT, A. I. GOLDSCHMIDT, J. L. J. LORETO, E. L. S. Concepções Referentes à Ciência e aos Cientistas entre Alunos de Anos Iniciais e Alunos em Formação Docente. Contexto \& Educação, v. 29, n. 92, p. 132-164, 2014.

GONÇALVES, F. P. A MARQUES, C. A. Circulação inter e intracoletiva de pesquisas e publicações acerca da experimentação no ensino de Química. Revista Brasileira de Pesquisa em Educação em Ciências, v. 12, n. 1, p. 181-204 2012.

GONÇALVES, F. P.; MARQUES, C. A. Contribuições pedagógicas e epistemológicas em textos de experimentação no ensino de química. Investigações em Ensino de Ciências, v. 11, n. 2, p, 219-238, 2006.

GOUVÊA, F. O primeiro decênio da Capes: uma campanha extraordinária (1951-1960). Revista Brasileira de Estudos Pedagógicos, v. 91, n. 229, p. 528-542, 2010.

GYLLENPALM, J.; WICKMAN, P.-O. The uses of the term hypothesis and the inquiry emphasis conflation in science teacher education. International Journal of Science Education, v.33 n. 14, p. 1993-2015, 2011.

HARRES, J. B. S. Uma revisão de pesquisas nas concepções de professores sobre a Natureza da Ciência e suas implicações para o ensino. Investigações em Ensino de Ciências, v. 4, n. 3, p. 197-211, 1999.

HASHWEH, M. Z. Effects of science teacher's epistemological beliefs in teaching. Journal of Research in Science Teaching, v. 33, n. 1, p. 47- 63, 1996.

HODSON, D. Investigación y experiencias didácticas: hacia un enfoque más crítico del trabajo de laboratorio. Enseñanza de las Ciencias, v. 12, n. 3, p. 299-313, 1994.

HODSON, D. Philosophy of Science, Science and Science Education. Studies in Science Education, v. 12, n. 1, p. 25-57, 1985.

HOFSTEIN, A.; LUNETTA, V. The Role of the Laboratory in Science Teaching: Neglected Aspects of Research. Review of Educational Research Summer. v. 52, n. 2, p. 201-217, 1982.

HOFSTEIN, A.; LUNETTA, V. The Laboratory in Science Education: Foundations for the Twenty-First Century. Science Education, v. 88, n. 1, p. 28-54, 2003.

HOFSTEIN, A. The laboratory in chemistry education - Thirty years of experience with developments, implementation, and research. Chemistry Rducation Research and Practice, v. 5, n. 3, p. 247-264, 2004.

JODELET, D. On Structuring and Outlining Processes in the Study of Social Representations. Papers on Social Representations, v. 26, n. 2, p. 2.1-2.11, 2016.

KOSMINSKY, L.; GIORDAN, M. Visões de ciências e sobre cientista entre estudantes do ensino médio. Química Nova na Escola, v. 15, p. 11-18 2002. 
LAGE, M. C.; GODOY, A. S. O uso do computador na análise de dados qualitativos: questões emergentes. Revista de Administração Mackenzie, v. 9, n. 4, p. 75-98, 2008.

LEMES, A. F. G. Aspectos filosóficos e educacionais da química: investigando as concepções de doutorandos em química. 2013.179f. Dissertação (Mestrado) - Instituto de Química, Instituto de Física, Instituo de Biociências, Faculdade de Educação, Universidade de São Paulo, SP, 2013.

LIRA, F. L. C. O PIBID e a construção da prática docente do curso de licenciatura em Química da Universidade Federal de Alagoas: concepção, contribuição e interação. 2016. 131 f. Dissertação (Mestrado) - Programa de Pós-Graduação em Educação, Universidade Tiradentes, UNIT, 2016.

MALDANER, O. A. A formação inicial e continuada de professores de química. ljuí: UNIJUİ, 2008.

MARTIN, G. F. S.; ARRUDA, S. M.; PASSOS, M. M. O modelo de quatro fases do desenvolvimento do interesse aplicado à aprendizagem da docência. Investigações em Ensino de Ciências, v. 21, n. 1, p. 46-61, 2016.

MATIELLO, J. R. (2017). Uma análise das Teses e Dissertações sobre experimentação no Ensino de Química, no Brasil: 2000 a 2012. 2017. 68p. (Dissertação). Programa de Pós-Graduação Interunidades em Ensino de Ciências, Universidade de São Paulo, SP, 2017.

MEC-CAPES-FNDE. Edital MEC/CAPES/FNDE: seleção pública de propostas de projetos de iniciação à docência voltados ao programa institucional de iniciação à docência - pibid. 2007. Disponível em:

$<$ https://www.capes.gov.br/images/stories/download/editais/Edital PIBID.pdf >. Acessado em 30 de abril de 2019.

MEC-INEP. Instituto Nacional de Estudos e Pesquisas Educacionais Anísio Teixeira. Censo da Educação Superior 2017 - Divulgação dos principais resultados. Brasília, DF. 2018. Disponível em: <http://portal.mec.gov.br/docman/setembro-2018-pdf/97041-apresentac-a-ocenso-superior-u-Itimo/file>. Acessado em 30 de abril de 2019.

MELO, É G. S.; TENÓRIO, A.; ACCIOLY, H. J. Representações sociais de ciência de um grupo de licenciandos em Física. Revista Electrónica de Enseñanza de las Ciencias v. 9, n. 2, p. 457-466, 2010.

MORI, R. C.; CURVELO, A. A. S. A polissemia da palavra "Experimentação" e a Educação em Ciências. Química Nova na Escola. v. 39, n. 3, p. 291-304, 2017.

MOSCOVICI, S. Representações Sociais. 5ª ed. Petrópolis, RJ: Vozes, 2007.

OBARA, C. E.; BROIETTI, F. C. D.; PASSOS, M. M. P. Contribuições do PIBID para a construção da identidade docente do professor de Química. Ciência e Educação, Bauru, v. 23, n. 4, p. 979-994, 2017.

OLIVEIRA, D. C. D.; FISCHER, F. M.; MARTINS, I. S.; TEIXEIRA, L. R. Futuro e liberdade: o trabalho e a instituição escolar nas representações sociais de adolescentes. Estudos de Psicologia, v. 6, n. 2, p. 245-258, 2001. 
OLIVEIRA, J. R. S. Contribuições e abordagens das atividades experimentais no ensino de ciências: reunindo elementos para a prática docente. Acta Scientiae, v. 12, n. 1, p. 139-153. 2010.

OLIVEIRA, M. S. B. S. Representações Sociais e Sociedades: a contribuição de Serge Moscovici. Revista Brasileira de Ciências Sociais, v. 19, n. 55, p. 180-186, 2004.

PEREIRA, C. S.; REZENDE, D. B. Representações Sociais da Química: como um grupo de estudantes da educação de jovens e adultos significa o termo "química"?. Química Nova na Escola, v. 38, n. 4, p. 369-374, 2016.

PEREIRA, C. S. Representação social de licenciandos em Química sobre seu objeto de estudo - a química. 2016, 98p.Tese. (Doutorado) Programa de Pós-Graduação Interunidades em Ensino de Ciências, Universidade de São Paulo, SP. 2016.

PICONEZ, S. C. B. A prática de ensino e o estágio supervisionado: a aproximação da realidade escolar e a prática da reflexão. In: PICONEZ, S. C. B.; FAZENDA, I. C. A. A prática de ensino e estagio supervisionado. $12^{\mathrm{a}}$ ed. Campinas. SP: Papirus, 2006.

RATEAU, P.; MOLINER, P.; GUIMELLI, C.; ABRIC, J.-C. Teoria da Representação Social. In: VANLANGE, P.; KROGLANSKI, A.; HIGGINS, E. (Ed.). Handbook of theories of social psychology. London: Sage, v. 2, p. 477-497, 2012.

RATINAUD, P.; DEJEAN, S. IRAMUTEQ: Interface de $R$ pour les analyses multidimensionnelles de textes et de questionnaires. [S.I.]: Laboratoire LERASS, 2008. Disponível em: <http://www.iramuteq.org>.

REIS, A. O. A; JUNIOR, V. S; NETO, B; MINIUSSI, M; NETO, M. L. R. Tecnologias Computacionais Para O Auxilio Pesquisa Qualitativa - Software Evoc. $1^{\text {a }}$ ed. São Paulo: Schoba, 2013.

ROSA, D. L.; MENDES, A. N. F.; LOCATELI, A. B. A constituição da identidade docente a partir dos saberes experienciais na formação inicial de professores para o ensino de Química. Kiri-kerê: Pesquisa em Ensino, n. 1, p. 87-100, 2016.

SÁ, C. P. Núcleo Central das Representações Sociais. $2^{\mathrm{a}}$ ed. revista. Petrópolis-RJ: Vozes, 2002.

SANTOS, V. C.; ARROIO, A. A formação de professores em comunidades de prática: o caso de um grupo de professores de química em formação inicial. Química Nova, v. 38, n. 1, p. 144-150, 2015.

SARRICA, M., MINGO, I., MAZZARA, B., \& LEONE, G. L. The effects of lemmatization on textual analysis conducted with IRaMuTeQ: results in comparison. In 13ème Journées internationales d'Analyse statistique des Données Textuelles. Nice: Université de Nice Sophia Antipolis.

SAVIANI, D. Formação de professores: aspectos históricos e teóricos do problema no contexto brasileiro. Revista Brasileira de Educação, v. 14, n. 40, p. 143-155, 2009.

SCHAFFER, D. Z. Representações sociais de alunos universitários sobre o termo "ORGÂNICO". 2007. 87 f. Dissertação. Programa de Pós-Graduação Interunidades em Ensino de Ciências - Universidade de São Paulo, SP, 2007. 
SIDONE, O.J.G.; HADDAD, E.A. e MENA-CHALCO, J.P. A ciência nas regiões brasileiras: evolução da produção e das redes de colaboração científica. Transinformação, v. 28, n. 1 , p. 15-32, 2016.

SILVA, F.; CUNHA, A. M. Método científico e prática docente: as representações sociais de professores de ciências do ensino fundamental. Ciência \& Educação, v. 18, n. 1, p. 41-54, 2012.

SILVA, F. L. Coordenadores de área do PIBID: um olhar sobre o desenvolvimento profissional. 2015. 154f. (Dissertação). Programa de Pós-Graduação Interunidades em Ensino de Ciências, Universidade de São Paulo, SP. 2015.

SILVA, P. B.; CAVALCANTE, P. S.; MENEZES, M. G.; FERREIRA, A. G.; SOUZA, F. N. O Valor Pedagógico da Curiosidade Científica dos Estudantes. Química Nova na Escola. v. 40, n. 4, p. 241-248, 2018.

SILVA, R. M. G.; SCHNETZLER, R. P. Concepções e ações de formadores de professores de Química sobre o estágio supervisionado: propostas brasileiras e portuguesas. Química Nova. v. 31, n. 8, p. 2174-2183, 2008.

SIMÕES, C. A.; SIMÕES, A. V. As representações sociais do cientista entre alunos do ensino fundamental de Manaus: indicações para o ensino de Ciências. In: ENCONTRONACIONAL DE PESQUISA EM EDUCAÇÃO EM CIÊNCIAS, 7., 2009, Florianópolis. Atas... Florianópolis: ABRAPEC, 2009.

STANZANI, E. L; BROIETTI, F. C. D; PASSOS, M. M. As Contribuições do PIBID ao Processo de Formação Inicial de Professores de Química. Química Nova na Escola. v. 34, n. 4, p. 210-219, 2012.

SUART, R. C.; MARCONDES, M. E. R. A manifestação de habilidades cognitivas em atividades experimentais investigativas. Ciências \& Cognição, v. 14 , n. 1, p. 50-74, 2009.

SUART, R. C.; MARCONDES, M. E. R. O Processo de Reflexão Orientada na Formação Inicial de um licenciando de Química visando o ensino por investigação e a promoção da Alfabetização Científica. Ensaio, Pesquisa em Educação em Ciências, v. 20, e9666, 2018.

TARDIF, M. Saberes docentes e formação profissional. $17^{\mathrm{a}}$ ed. 1 reimpressão, Petrópolis: Vozes, 2014.

THIBAUT, L.; KNIPPRATH, H.; DEHAENE, W.; DEPAEPE, F. The influence of teachers' attitudes and school context on instructional practices in integrated STEM education. Teaching and Teacher Education, v. 71, p. 190-205, 2018.

TOBIN, K. G. (1990). Research on science laboratory activities. In pursuit of better questions and answers to improve learning. School Science and Mathematics, v. 90, n. 5, 403-418.

UCAR, S. How Do Pre-Service Science Teachers' Views on Science, Scientists, and Science Teaching Change Over Time in a Science Teacher Training Program? Journal of Science Education and Technology, v. 21, p. 255-266, 2012.

VERGĖS, P. L'évocation de l'argent: une méthode pour la définition du noyau central d'une représentation. Bulletin de Psychologie, v. 45, n. 405, p. 203-209, 1992. 
VERGĖS, P.; JUNIQUE, C.; BARBRY, W.; SCANO, S.; ZELIGER, R. Ensembles de programmes permettant l'analyse des evocations. Aix en Provence: Université Aix en Provence (Manual), 2003.

VOGEL, M. Influências do PIBID na Representação Social de licenciandos em Química sobre ser "professor de Química". 2016. 218f. (Tese). Programa de Pós-Graduação Interunidades em Ensino de Ciências, Universidade de São Paulo, SP. 2016.

WACHELKE, J. F. R; WOLTER, R. Critérios de construção e relato da análise prototípica para representações sociais. Psicologia: Teoria e Pesquisa, v. 27, n. 4, p. 521-526, 2011.

WACHELKE, J. F. R. Índice de centralidade de representações sociais a partir de evocações (INCEV): exemplo de aplicação no estudo da representação social sobre envelhecimento. Psicologia: Reflexão e Crítica, v. 22, n. 1, p. 102-110, 2009.

WACHELKE, J. F. R.; WOLTER, R; MATOS, F. R. Efeito do tamanho da amostra na análise de evocações para Representações Sociais. LIBERABIT, v. 22, n.2, p. 153-160, 2016.

WEI, B.; LI, X. Exploring science teachers' perceptions of experimentation: implications for restructuring school practical work. International Journal of Science Education, v. 39, n. 13, p. 1775-1794, 2017.

World Economic Forum (WEF). The Global Gender Gap Report 2016. Geneva, Switzerland. 2016.

ZEICHNER, K. Repensando as conexões entre a formação na universidade $\mathrm{e}$ as experiências de campo na formação de professores em faculdades e universidades. Revista Educação, v.35, n. 3, p. 479-504, 2010. 


\section{APÊNDICES}




\section{APÊNDICE A - Questionário de Pesquisa}<smiles>CC12CC3CC(C)(C1)CC(C)(C3)C2</smiles>

\section{Universidade de São Paulo Instituto de Química}

Prezado(a) colega:

Estamos pedindo sua colaboraçấo no sentido de responder a este questionário, fornecendo informaçöes muito importantes para o desenvolvimento do trabalho de pesquisa sobre o PIBID desenvolvido no âmbito do Programa de Pós-graduaçăo Interunidades em Ensino de Ciências da USP pelo mestrando Caian C. Receputi, sob minha orientaçăo (Profa. Dra. Daisy de Brito Rezende, do Departamento de Quimica Fundamental do Instituto de Química da USP, em São Paulo). As informaçóes fornecidas por vocé serāo tratadas com o mais rigoroso sigilo. Este questionário tem como objetivo recolher informaçāes para uma pesquisa em ensino o năo avaliàlo(a). Assim sendo, o que nos interessa é a SUA OPINIǍ́, não importande qual seria nossa suposta opiniäo, "no momento de sua resposta.

Agradecemos muitíssimo pela sua colaboração, nesses tempos tảo conturbados. Mas, entendemos que pesquisar sobre o PIBID, hoje, é uma forma de resistència.

\section{Caro participante:}

Comprometo-me a garantir seu sigilo em todos os trabalhos decorrentes da anélise destes questionários. Coloco-me à disposição para quaisquer informaçōes ulteriores que Ihes sejam necessárias.

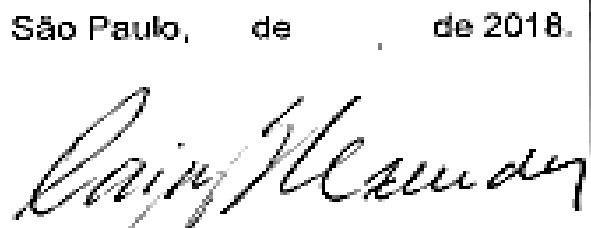

Profa, Dra: Daisy de Brito Rezende $N^{2}$ USP: 65775

Departamento de Quimica Fundamental Instituto de Quimica Universidade de São Paulo Tel: +551130912160 Email; dbrezend@iq.usp.br 


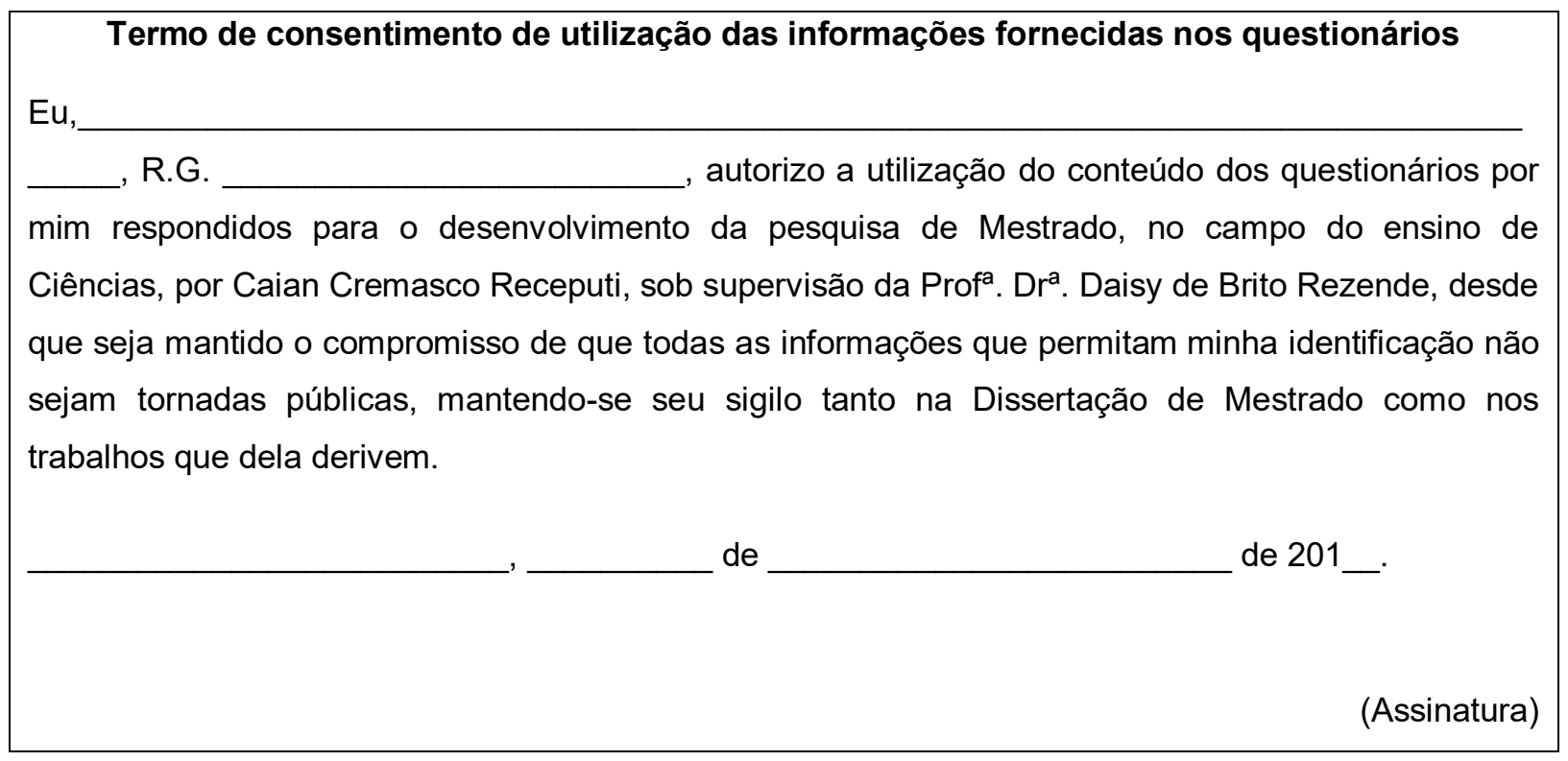

1. Você participa ou já participou do Programa Institucional de Bolsas de Iniciação à Docência (PIBID)? (Caso você tenha respondido afirmativamente à pergunta acima, responda as questões 1.1 a 1.5. Caso sua resposta tenha sido negativa, pule para a questão 2.)

( ) Nim

1.1 Você fez parte de qual subprojeto?
) Física
( ) Química
( ) Matemática
( ) Interdisciplinaridade
( ) Outros
1.2 Você fez parte do PIBID de qual(is) instituição(ções)?

\subsection{Participou como}

( ) Coordenador institucional
( ) Coordenador de área
( ) Cupervisor
( ) Outros

1.3 Qual foi seu tempo total de participação no programa PIBID? meses.

1.5 Descreva sucintamente as ações desenvolvidas no subprojeto em que você fez parte.

2. Qual é o título do seu curso de graduação?

$\begin{array}{ll}\text { ( ) Bacharelado em } & \text { Data de titulação__ } \\ \text { ( }) \text { Licenciatura em } & \text { Data de Titulação__ } \\ \text { ( ) Outros } & \text { Data de Titulação_}\end{array}$

3. Em que ano você concluiu curso de graduação? 
4. Qual sua titulação mais recente?

( ) Mestrado em Data de titulação

( ) Doutorado em Data de titulação

( ) Outro Data de titulação

5. Informe a área da sua última titulação

6. Descreva sucintamente seus interesses atuais de pesquisa.

7. Você já lecionou no Ensino Básico?

( ) Sim.

Por quantos anos? anos.

Há quanto tempo não leciona no Ensino Básico? Há anos

\section{( ) Não}

8. Há quanto tempo você leciona no Ensino Superior? Há anos.

9. Informe as disciplinas que você leciona com maior frequência no Ensino Superior, em ordem decrescente de frequência.

10. Escreva as 6 (seis) palavras ou expressões sobre "EXPERIMENTAÇÃO" que lhe venham à mente mais imediatamente.

11. Agora, numere as palavras que você escolheu na questão anterior de 1 a 6 , atribuindo número 1 àquela que, em sua opinião, seja mais representativa do termo "EXPERIMENTAÇÃO" e, o número 6 , à que menos o represente para você.

1. [mais importante]

2.

3.

4.

5.

6. [menos importante]

12. Explique sucintamente as razões que o(a) levaram à escolha de cada palavra.

1.

3

4.

5.

6. 
13. Organize as palavras que você citou na questão $12 \mathrm{em}$ tantos pares quantos você considere necessários para expressar o significado de "EXPERIMENTAÇÃO" para você (pode haver repetição das palavras na elaboração dos pares).

\begin{tabular}{|l|l|}
\hline & \\
\hline & \\
\hline & \\
\hline & \\
\hline & \\
\hline & \\
\hline
\end{tabular}




\section{APÊNDICE B - Lista de Palavras Evocadas}

\begin{tabular}{|c|c|c|c|}
\hline Sujeito & Termo 01 & Termo 02 & Termo 03 \\
\hline sujeito 1 & conhecimento & analise & questionamento \\
\hline sujeito 2 & investigacao & analise & comprovacao-da-teoria \\
\hline sujeito 3 & pratica & melhoria & ensino \\
\hline sujeito 4 & pratica-e-teoria & aulas-praticas & laboratorio \\
\hline sujeito 5 & compreensao & didatico & cotidiano \\
\hline sujeito 6 & articulacao & observacao & mediacao \\
\hline sujeito 7 & pratica & pesquisa & tese \\
\hline sujeito 8 & ensino-de-ciencias & ensino-aprendizagem & pratica-docente \\
\hline sujeito 9 & metodologia & ensino & didatica \\
\hline sujeito 10 & $\begin{array}{l}\text { construcao-de- } \\
\text { conhecimento }\end{array}$ & planejamento & seguranca \\
\hline sujeito 11 & investigacao & $\begin{array}{l}\text { interacao-com-os- } \\
\text { discentes }\end{array}$ & construcao-de-conceitos \\
\hline sujeito 12 & ensino & fenomeno & hipoteses \\
\hline sujeito 13 & metodo-cientifico & motivacao & Iudico \\
\hline sujeito 14 & investigativa & problematizadora & observacao \\
\hline sujeito 15 & investigacao & resolucao-de-problemas & analise \\
\hline sujeito 16 & investigacao & interpretacao & vidraria \\
\hline sujeito 17 & aluno-alegre & aula-diferenciada & desafios \\
\hline sujeito 18 & laboratorio & pesquisa-extra-sala & $\begin{array}{l}\text { producao-de-material- } \\
\text { didatico }\end{array}$ \\
\hline sujeito 19 & aprendizagem & quimica & pratica \\
\hline sujeito 20 & hipotese & ciencias & pratica \\
\hline sujeito 21 & util & interessante & emocionante \\
\hline sujeito 22 & aulas-dinamicas & estimulo-ao-aprendizado & materiais-alternativos \\
\hline sujeito 23 & contextualizacao & descoberta & construcao \\
\hline sujeito 24 & aprendizagem & $\begin{array}{l}\text { desenvolvimento- } \\
\text { cognitivo }\end{array}$ & investigacao \\
\hline sujeito 25 & $\begin{array}{l}\text { otima-alternativa-de- } \\
\text { ensino }\end{array}$ & relacao-teoria-e-pratica & maior-atencao-do-aluno \\
\hline sujeito 26 & conhecimento & investigacao & hipoteses \\
\hline sujeito 27 & criacao & construcao & entender \\
\hline sujeito 28 & acao & metodologia-de-ensino & atividade-alternativa \\
\hline sujeito 29 & investigacao & $\begin{array}{l}\text { construcao-do- } \\
\text { conhecimento }\end{array}$ & contextualizacao \\
\hline sujeito 30 & ferramenta & ensino & conhecimento \\
\hline sujeito 31 & problematizacao & laboratorio-aberto & autonomia \\
\hline sujeito 32 & alfabetizacao-cientifica & atividade-colaborativa & investigacao \\
\hline sujeito 33 & investigacao & observacao & habilidade \\
\hline sujeito 34 & $\begin{array}{l}\text { experimentacao- } \\
\text { investigativa }\end{array}$ & $\begin{array}{l}\text { experimentacao- } \\
\text { problematizadora }\end{array}$ & $\begin{array}{l}\text { pedagogia-freireana- } \\
\text { problematizadora }\end{array}$ \\
\hline sujeito 35 & atividade-pratica & pesquisar & metodo-cientifico \\
\hline sujeito 36 & reacoes-quimicas & reagentes & materiais \\
\hline sujeito 37 & investigacao & observacao & $\begin{array}{l}\text { construcao-do- } \\
\text { conhecimento }\end{array}$ \\
\hline sujeito 38 & problematizacao & relacao-teoria-pratica & metodologia-ativa \\
\hline sujeito 39 & $\begin{array}{l}\text { despertar-a-curiosidade- } \\
\text { dos-alunos }\end{array}$ & investigacao & contextualizacao \\
\hline sujeito 40 & descoberta & curiosidade & transformacao \\
\hline sujeito 41 & investigativa & contextuzalizada & $\begin{array}{l}\text { aprendizagem- } \\
\text { signi ¡cativa }\end{array}$ \\
\hline
\end{tabular}




\begin{tabular}{|c|c|c|c|}
\hline sujeito 42 & interpretacao & infraestrutura & formacao \\
\hline sujeito 43 & investigacao & articulacao-teoria-pratica & materiais-alternativos \\
\hline sujeito 44 & eficiencia-das-aulas & aprendizagem & contexto \\
\hline sujeito 45 & $\begin{array}{l}\text { despertar-o-interesse- } \\
\text { do-aluno }\end{array}$ & contextualizacao & $\begin{array}{l}\text { relacionar-teoria-e- } \\
\text { pratica }\end{array}$ \\
\hline sujeito 46 & pesquisa & $\begin{array}{l}\text { aprendizagem- } \\
\text { signi ¡cativa }\end{array}$ & ciencia \\
\hline sujeito 47 & aprendizagem & ativo & hipotese \\
\hline sujeito 48 & metodologias & ensino & praticas \\
\hline sujeito 49 & aprendizado & materiais-alternativos & contextualizacao \\
\hline sujeito 50 & laboratorio & experimentos & quimica \\
\hline sujeito 51 & investigacao & problematizacao & apropriacao \\
\hline sujeito 52 & investigacao & questionamento & debate \\
\hline sujeito 53 & observacao & fenomeno & pratica \\
\hline sujeito 54 & provovacao & $\begin{array}{l}\text { elaboracao-de- } \\
\text { problemas }\end{array}$ & $\begin{array}{l}\text { acesso-a-construcao-de- } \\
\text { conhecimentos- } \\
\text { cientificos }\end{array}$ \\
\hline sujeito 55 & metodologia-de-ensino & quimica & $\begin{array}{l}\text { observacao-de- } \\
\text { fenomenos }\end{array}$ \\
\hline sujeito 56 & abordagem & aprendizagem & abstrato-empirico \\
\hline sujeito 57 & baixo-custo & tecnologia & inclusao \\
\hline sujeito 58 & investigacao & problematizacao & erro \\
\hline sujeito 59 & observacao & curiosidade & investigacao \\
\hline sujeito 60 & experimento & acao & laboratorio \\
\hline sujeito 61 & panaceia & descontextualizada & teoria \\
\hline sujeito 62 & investigacao & procedimento & materiais-alternativos \\
\hline sujeito 63 & conceito-quimico & efeito-visual & roteiro-experimental \\
\hline sujeito 64 & investigar & ensaio & desenvolver \\
\hline sujeito 65 & curiosidade & observacao & analisar \\
\hline sujeito 66 & $\begin{array}{l}\text { ambiente-de- } \\
\text { aprendizagem }\end{array}$ & problematizar & reflexao-acao \\
\hline sujeito 67 & $\begin{array}{l}\text { nao-tem-como-dissociar- } \\
\text { da-teoria }\end{array}$ & pode-ser-investigativa & $\begin{array}{l}\text { aumenta-interesse-dos- } \\
\text { alunos }\end{array}$ \\
\hline sujeito 68 & $\begin{array}{l}\text { observacao-de-um- } \\
\text { fenomeno-natural }\end{array}$ & investigacao & ensino-e-aprendizagem \\
\hline sujeito 69 & investigacao & metodo & pratica \\
\hline sujeito 70 & pratica & professor & aluno \\
\hline sujeito 71 & observacao & investigacao & descoberta \\
\hline sujeito 72 & $\begin{array}{l}\text { observacao-de- } \\
\text { fenomenos }\end{array}$ & empirico & medidas \\
\hline sujeito 73 & ensino-e-aprendizagem & estimulo & pesquisa-bibliografica \\
\hline sujeito 74 & $\begin{array}{l}\text { construcao-do- } \\
\text { pensamento-quimico }\end{array}$ & problematizacao & historia-da-ciencia \\
\hline sujeito 75 & observacao & aprendizagem & reacoes \\
\hline sujeito 76 & ludico & criatividade & mao-na-massa \\
\hline sujeito 77 & relacao-teoria-e-pratica & reacoes & evidencias-de-reacoes \\
\hline sujeito 78 & evidencias & investigacao & apropriacao \\
\hline sujeito 79 & problematizacao & atividade-pratica & curiosidade \\
\hline sujeito 80 & pratica & metodologias & manipulacao \\
\hline sujeito 81 & investigacao & $\begin{array}{l}\text { construcao-do- } \\
\text { conhecimento }\end{array}$ & laboratorio \\
\hline sujeito 82 & investigacao & aprendizagem & habilidades-intelectuais \\
\hline sujeito 83 & evidencias & demonstracoes & materiais \\
\hline sujeito 84 & $\begin{array}{l}\text { oportunidade-de- } \\
\text { investigacao }\end{array}$ & $\begin{array}{l}\text { provoca-entusiasmos-e- } \\
\text { cooperacao }\end{array}$ & nao-e-show \\
\hline sujeito 85 & curiosidade & hipotese & aprendizado \\
\hline sujeito 86 & pratica & vivencia & cotidiano \\
\hline
\end{tabular}




\begin{tabular}{|c|c|c|c|}
\hline sujeito 87 & investigativo & motivacao & concepcoes-alternativas \\
\hline sujeito 88 & motivacao & curiosidade & alegria \\
\hline sujeito 89 & $\begin{array}{l}\text { tornar-conceitos- } \\
\text { cientificos-menos- } \\
\text { abstratos }\end{array}$ & contextualizacao & habilidades-manuais \\
\hline sujeito 90 & $\begin{array}{l}\text { experimento-de-baixo- } \\
\text { custo }\end{array}$ & novas-tecnologias & ensino \\
\hline sujeito 91 & ajuda-a-fixacao & esclarece-a-teoria & fundamenta-o-conceito \\
\hline sujeito 92 & relacao-teoria-pratica & investigadora & contextualizacao \\
\hline sujeito 93 & fazer-ciencia & atividade-didatica & alunos-ativos \\
\hline sujeito 94 & ensino & aprendizagem & praticas \\
\hline sujeito 95 & conceito-quimico & $\begin{array}{l}\text { escolher-um- } \\
\text { experimento }\end{array}$ & planejar \\
\hline sujeito 96 & $\begin{array}{l}\text { reacoes-no-escopo-do- } \\
\text { cotidiano }\end{array}$ & $\begin{array}{l}\text { analise-critica-do- } \\
\text { fenomeno }\end{array}$ & $\begin{array}{l}\text { analise-fenomenologica- } \\
\text { da-quimica }\end{array}$ \\
\hline sujeito 97 & paciencia & persistencia & repeticao \\
\hline sujeito 98 & integracao-teoria-pratica & visualizacao & $\begin{array}{l}\text { seguranca-no- } \\
\text { laboratorio }\end{array}$ \\
\hline sujeito 102 & reflexao & fenomenos & teoria \\
\hline sujeito 103 & essencial & $\begin{array}{l}\text { combinacao-de- } \\
\text { tecnicas-com-teoria }\end{array}$ & alto-custo \\
\hline sujeito 105 & $\begin{array}{l}\text { construcao-do- } \\
\text { conhecimento }\end{array}$ & motivacao & cotidiano \\
\hline sujeito 106 & experiencia & laboratorio & quimico \\
\hline sujeito 107 & vivencia & alunos & laboratorio \\
\hline sujeito 108 & laboratorio & contextualizacao & experimentos \\
\hline sujeito 109 & teoria & sinais-vitais & persepcoes-sensoriais \\
\hline sujeito 110 & aprendizagem & interpretacao & contextualizacao \\
\hline sujeito 111 & conhecimento-da-teoria & seguranca & habilidade \\
\hline sujeito 112 & observacao & descoberta & aprendizagem \\
\hline sujeito 115 & fibroina-da-seda & solubilizacao & compositos \\
\hline sujeito 121 & problematizacao & $\begin{array}{l}\text { obstaculos- } \\
\text { epistemologicos }\end{array}$ & laboratorio-tradicional \\
\hline sujeito 122 & atividade-investigativa & $\begin{array}{l}\text { conteudos- } \\
\text { procedimentais }\end{array}$ & fenomenos \\
\hline sujeito 123 & metodologia-ativa & investigacao-cientifica & pratica \\
\hline sujeito 124 & recurso & $\begin{array}{l}\text { participacao-ativa-dos- } \\
\text { estudantes }\end{array}$ & $\begin{array}{l}\text { construcao-de- } \\
\text { conceitos-cientificos }\end{array}$ \\
\hline sujeito 125 & construtivismo & investigacao & $\begin{array}{l}\text { concepcao-de-erro- } \\
\text { bachelard }\end{array}$ \\
\hline sujeito 126 & investigacao & observacao & processo \\
\hline sujeito 128 & reflexao & investigacao & questionamento \\
\hline sujeito 129 & ludicidade & investigacao & descoberta \\
\hline sujeito 130 & relacao-teoria-e-pratica & laboratorio & $\begin{array}{l}\text { experimento- } \\
\text { investigativo }\end{array}$ \\
\hline sujeito 131 & visualizacao & pratica & manuseio \\
\hline sujeito 132 & reacaes-quimicas & $\begin{array}{l}\text { visualizacao-de- } \\
\text { processos-quimicos }\end{array}$ & motivacao \\
\hline sujeito 134 & teoria-na-pratica & interatividade & compreensao \\
\hline sujeito 135 & $\begin{array}{l}\text { autonomia-e-liberdade- } \\
\text { intelectual }\end{array}$ & $\begin{array}{l}\text { aprender-com-o-outro-e- } \\
\text { reelaborar-ideias }\end{array}$ & investigacao \\
\hline sujeito 136 & experimentos & pratica & aprendizagem \\
\hline sujeito 140 & ludico & materiais-alternativos & $\begin{array}{l}\text { modelos- } \\
\text { representacionais }\end{array}$ \\
\hline sujeito 141 & aprendizagem-ativa & investigacao & motivacao \\
\hline sujeito 142 & $\begin{array}{l}\text { aprendizagem- } \\
\text { significativa }\end{array}$ & assimilacao & reflexao \\
\hline sujeito 143 & pesquisa & inovacao & educacao \\
\hline
\end{tabular}




\begin{tabular}{|c|c|c|c|}
\hline sujeito 144 & aprendizagem & recurso-didatico & motivacao \\
\hline sujeito 145 & relacao-com-a-teoria & tecnociencia & bachelard \\
\hline sujeito 146 & laboratorio & reacao-quimica & erro \\
\hline sujeito 147 & investigacao & pratica & motivacao \\
\hline sujeito 148 & pratica & teste & contato-inicial \\
\hline sujeito 149 & reagentes & vidraria & laboratorio \\
\hline sujeito 150 & laboratorio & $\begin{array}{l}\text { aprender-e- } \\
\text { compreender-o-por-que- } \\
\text { fazer }\end{array}$ & investigacao \\
\hline sujeito 151 & investigacao & pesquisa & estudo \\
\hline sujeito 152 & metodologia & problemaizacao & estimulo \\
\hline sujeito 153 & $\begin{array}{l}\text { construcao-do- } \\
\text { conhecimento }\end{array}$ & $\begin{array}{l}\text { postura-ativa-dos- } \\
\text { estudantes }\end{array}$ & motivacao \\
\hline sujeito 154 & pratica & realidade & facilidade \\
\hline sujeito 155 & pesquisa & curiosidade & hipotese \\
\hline sujeito 156 & investigacao & problema & conteudo-procedimental \\
\hline sujeito 157 & investigacao & observacao & hipotese \\
\hline sujeito 158 & didatica & pratica & tecnologia \\
\hline sujeito 159 & $\begin{array}{l}\text { construcao-do- } \\
\text { conhecimento }\end{array}$ & investigacao & formacao \\
\hline sujeito 160 & $\begin{array}{l}\text { favorecer-postura-de- } \\
\text { investigacao }\end{array}$ & $\begin{array}{l}\text { deve-prezar-relacao- } \\
\text { integracao-teoria-pratica }\end{array}$ & $\begin{array}{l}\text { nao-deve-ficar-somente- } \\
\text { em-aspectos-perifericos }\end{array}$ \\
\hline sujeito 161 & $\begin{array}{l}\text { facilitacao-da- } \\
\text { aprendizagem }\end{array}$ & estimulo & ludico \\
\hline sujeito 162 & recurso-didatico & $\begin{array}{l}\text { efetivacao-do- } \\
\text { conhecimento }\end{array}$ & verificacao-da-teoria \\
\hline sujeito 163 & equipe & pratica & testes \\
\hline sujeito 164 & experimentos & testes & recursos-financeiros \\
\hline sujeito 165 & ciencia & empirismo & logica \\
\hline sujeito 166 & explorar & $\begin{array}{l}\text { forma-de-descobrir-o- } \\
\text { mundo }\end{array}$ & investigacao \\
\hline sujeito 167 & curiosidade & mao-na-massa & interesse-pela-ciencia \\
\hline sujeito 168 & investigativa & problematizadora & fenomeno \\
\hline sujeito 169 & problematizacao & hipotese & tomada-de-decisao \\
\hline sujeito 170 & curiosidade & investigacao & resultados \\
\hline sujeito 171 & relacao-teoria-pratica & investigacao & o-papel-do-erro \\
\hline sujeito 172 & aprendizagem & fixacao & contextualizacao \\
\hline sujeito 173 & aprendizagem & ensino & criatividade \\
\hline sujeito 174 & estereosseletividade & conclusao & sintese \\
\hline sujeito 175 & essencial & $\begin{array}{l}\text { complementacao-do- } \\
\text { ensino }\end{array}$ & importante \\
\hline sujeito 176 & planejamento & interdisciplinaridade & $\begin{array}{l}\text { ensino-por-situacao- } \\
\text { problema }\end{array}$ \\
\hline sujeito 177 & motivacao & curiosidade & aprendizagem \\
\hline sujeito 178 & $\begin{array}{l}\text { teoria-associada-a- } \\
\text { pratica }\end{array}$ & $\begin{array}{l}\text { construcao-do- } \\
\text { conhecimento }\end{array}$ & prazer-em-ensinar \\
\hline sujeito 179 & praticar & contextualizacao & laboratorio \\
\hline sujeito 180 & ideia & hipotese & conhecimento \\
\hline sujeito 181 & ludicidade & pratica & laboratorio \\
\hline sujeito 182 & raciocinio & hipoteses & $\begin{array}{l}\text { altas-habilidades- } \\
\text { cognitivas }\end{array}$ \\
\hline sujeito 183 & conhecimento-teorico & treinamento & disciplina \\
\hline sujeito 184 & agua & ph & alimentos \\
\hline sujeito 185 & problema-de-pesquisa & pesquisa & autonomia \\
\hline sujeito 186 & metodologia & procedimentos & inovacao \\
\hline sujeito 187 & desafio & habilidades & pesquisa \\
\hline sujeito 188 & nao-dicotomia-entre- & aprendizagem & formacao-de-conceitos \\
\hline
\end{tabular}




\begin{tabular}{|c|c|c|c|}
\hline & teoria-e-pratica & & \\
\hline sujeito 189 & pratica & fixacao & interesse \\
\hline sujeito 190 & ensino & didatica & aprendizagem \\
\hline sujeito 191 & necessaria & metodo & observacao \\
\hline sujeito 192 & $\begin{array}{l}\text { evidencias-sensoriais- } \\
\text { da-ocorrencia-de- } \\
\text { reacoes-quimicas }\end{array}$ & cotidiano & $\begin{array}{l}\text { conhecimento- } \\
\text { tradicional }\end{array}$ \\
\hline sujeito 193 & $\begin{array}{l}\text { relacao-entre-fazer-e- } \\
\text { pensar }\end{array}$ & visitas-tecnicas & atividade-experimentais \\
\hline sujeito 194 & $\begin{array}{l}\text { agora-eu-gosto-de- } \\
\text { quimica }\end{array}$ & $\begin{array}{l}\text { a-quimica-nao-e-tao- } \\
\text { complicada }\end{array}$ & a-aula-foi-otima \\
\hline sujeito 195 & observacao & interdisciplinaridade & $\begin{array}{l}\text { estimulo-a- } \\
\text { aprendizagem }\end{array}$ \\
\hline sujeito 196 & $\begin{array}{l}\text { auxiliar-na- } \\
\text { aprendizagem }\end{array}$ & $\begin{array}{l}\text { nao-deve-ser-realizada- } \\
\text { para-comprovar-teorias }\end{array}$ & investigativa \\
\hline sujeito 197 & comprovacao & responsabilidade & objetividade \\
\hline sujeito 198 & investigativa & interacao & problematizacao \\
\hline sujeito 199 & visualizacao & aprendizagem & teste \\
\hline sujeito 200 & experimento & interdisciplinaridade & $\begin{array}{l}\text { construcao-do- } \\
\text { conhecimento }\end{array}$ \\
\hline sujeito 201 & ferramenta & motivacao & aprendizagem \\
\hline sujeito 203 & investigacao & hipotese & articulacao \\
\hline sujeito 204 & quimica & transformacao & mostrar \\
\hline sujeito 205 & ciencias-naturais & curiosidade & cotidiano \\
\hline sujeito 206 & laboratorio & reacoes-quimicas & capela \\
\hline sujeito 207 & atividade & hipotese & instrumento \\
\hline sujeito 208 & $\begin{array}{l}\text { visualizacao-de- } \\
\text { conceitos }\end{array}$ & reacoes-quimicas & bom-de-fazer \\
\hline sujeito 210 & estrategia-didatica & fenomenos-quimicos & $\begin{array}{l}\text { atencao-e-observacao- } \\
\text { orientadas }\end{array}$ \\
\hline sujeito 211 & aprendizagem-ativa & envolvimento & descoberta \\
\hline sujeito 212 & aprendizado-significativo & relacao-teoria-pratica & acao \\
\hline sujeito 213 & discusao & nivel-concreto & percepcao \\
\hline sujeito 215 & ensino-aprendizagem & contextualizacao & estimulo \\
\hline sujeito 216 & fazendo-e-aprendendo & pratica & realizacao \\
\hline sujeito 217 & investigativa & problematizadora & ativo \\
\hline sujeito 218 & curiosidade & ciencias-exatas & pratica \\
\hline sujeito 219 & aprendizagem & descoberta & ensino \\
\hline sujeito 220 & pesquisa & questionamento & observacao \\
\hline sujeito 222 & macroscopica & fenomenos & visualizacao \\
\hline sujeito 224 & pensamento-raciocinio & autonomia & criticidade \\
\hline sujeito 226 & metodo-cientifico & hipotese & ensaios \\
\hline sujeito 227 & pratica & experiencia & teoria-pratica \\
\hline sujeito 228 & questionamentos & fazer-quimica & ciencia \\
\hline sujeito 229 & descoberta & verificacao-de-hipoteses & dialogo-com-a-natureza \\
\hline sujeito 230 & investigacao-cientifica & analise-de-dados & hipotese \\
\hline sujeito 232 & laboratorio & seguranca & epis \\
\hline sujeito 233 & aprendizagem & curiosidade & dedicacao \\
\hline sujeito 234 & $\begin{array}{l}\text { ferramenta-para-ensino- } \\
\text { e-aprendizagem- } \\
\text { conceitual-e-contextual }\end{array}$ & $\begin{array}{l}\text { articulada-a-resolucao- } \\
\text { de-problemas-no- } \\
\text { ensino-de-quimica }\end{array}$ & $\begin{array}{l}\text { ferramenta-do-ensino- } \\
\text { por-investigacao }\end{array}$ \\
\hline sujeito 235 & experimento & aprendizagem & exemplificacao \\
\hline sujeito 236 & vivencia & pratica & $\begin{array}{l}\text { aprendizagem- } \\
\text { signijcativa }\end{array}$ \\
\hline sujeito 237 & metodo-cientifico & senso-critico & mecanismo \\
\hline sujeito 238 & metodo-cientifico & observacao & evidencia \\
\hline sujeito 239 & investigacao & aprendizagem & metodologia-cientifica \\
\hline
\end{tabular}




\begin{tabular}{|c|c|c|c|}
\hline sujeito 241 & investigacao-narrativa & experiencia & conhecimento \\
\hline sujeito 242 & nivel-fenomenologico & fenomenotecnica & problematizacao \\
\hline sujeito 243 & quimica-experimental & ultrasom & metatase \\
\hline sujeito 245 & investigacao & questionamento & argumentacao \\
\hline sujeito 246 & problematizacao & concepcao-alternativa & desafio \\
\hline sujeito 248 & seguranca & observacao & confiabilidade \\
\hline sujeito 249 & $\begin{array}{l}\text { transmissao-do- } \\
\text { conhecimento-via- } \\
\text { atividades-experimentais }\end{array}$ & contextualizacao & trabalho-em-grupo \\
\hline sujeito 250 & pesquisa & novos-materiais & tratamento-de-efluentes \\
\hline sujeito 251 & estudo & trabalho & observacao \\
\hline sujeito 253 & investigacao & estudo-pratico & ensaio \\
\hline sujeito 254 & manipulacao & bancada & observacao \\
\hline sujeito 256 & por-em-pratica-a-teoria & fixacao-de-conceitos & $\begin{array}{l}\text { desenvolvimento-de- } \\
\text { habilidades }\end{array}$ \\
\hline sujeito 258 & ensino-dinamico & aprendizagem & ensino-demonstrativo \\
\hline sujeito 259 & experimento & alunos-reunidos & cores \\
\hline sujeito 260 & metodo-cientifico & investigacao & condicoes-controladas \\
\hline sujeito 261 & metodo-cientifico & testes & reprodutibilidade \\
\hline sujeito 264 & quimica & laboratorio & didatica \\
\hline sujeito 265 & ensaio & analise & experimento \\
\hline sujeito 267 & teste & laboratorio & trabalho \\
\hline sujeito 268 & desenvolvimento & desafio & prova \\
\hline sujeito 269 & motivacao & contextualizacao & questionar \\
\hline sujeito 273 & atividade-experimental & laboratorio & conhecimento-pratico \\
\hline sujeito 276 & pratica & confirmacao-da-teoria & laboratorio \\
\hline sujeito 277 & $\begin{array}{l}\text { planejamento-e- } \\
\text { excecucao }\end{array}$ & seguranca-e-habilidade & observacao \\
\hline sujeito 278 & alunos & laboratorio & investimento \\
\hline sujeito 279 & investigativa & motivacao & planejamento \\
\hline sujeito 280 & contextualizacao & motivacao & aprendizagem \\
\hline sujeito 281 & $\begin{array}{l}\text { aprendizagem- } \\
\text { significativa }\end{array}$ & criatividade & contextualizacao \\
\hline sujeito 282 & aprendizado & conhecimento & pratica \\
\hline sujeito 286 & $\begin{array}{l}\text { complementa-o- } \\
\text { aprendizado-teorico }\end{array}$ & criatividade & $\begin{array}{l}\text { habilidades-no- } \\
\text { laboratorio }\end{array}$ \\
\hline sujeito 288 & investigacao & contextualizacao & $\begin{array}{l}\text { construcao-de- } \\
\text { conceitos-cientificos }\end{array}$ \\
\hline sujeito 289 & $\begin{array}{l}\text { aprendizagem- } \\
\text { significativa }\end{array}$ & contextualizacao & questionamento \\
\hline sujeito 290 & modelagem & formulacao & desenvolvimento \\
\hline sujeito 291 & comprovacao-da-teoria & realiacao & observacao \\
\hline sujeito 293 & praticas & procedimentos & materiais \\
\hline sujeito 294 & $\begin{array}{l}\text { explicacao-de- } \\
\text { conteudos }\end{array}$ & conceitos-na-pratica & aprendizado-ludico \\
\hline sujeito 295 & resultados & manuseio & observacao \\
\hline sujeito 296 & metodologia & acao-e-reacao & questionar \\
\hline sujeito 298 & pesquisa & $\begin{array}{l}\text { planejamento-de- } \\
\text { experimentos }\end{array}$ & estatistica \\
\hline sujeito 300 & aprendizado & pratica & observacao \\
\hline sujeito 302 & relacao-teoria-pratica & $\begin{array}{l}\text { possibilidades- } \\
\text { ampliadas-de- } \\
\text { aprendizado }\end{array}$ & autonomia \\
\hline sujeito 303 & $\begin{array}{l}\text { elo-da-teoria-com-a- } \\
\text { pratica }\end{array}$ & $\begin{array}{l}\text { fundamental-para-o- } \\
\text { ensino }\end{array}$ & $\begin{array}{l}\text { processo-de-ensino-e- } \\
\text { aprendizagem }\end{array}$ \\
\hline sujeito 304 & investigacao & $\begin{array}{l}\text { experimentacao- } \\
\text { contextualizada }\end{array}$ & material-alternativo \\
\hline
\end{tabular}




\begin{tabular}{|c|c|c|c|}
\hline sujeito 305 & $\begin{array}{l}\text { visualizacao-do- } \\
\text { fenomeno }\end{array}$ & $\begin{array}{l}\text { ferrramenta-para- } \\
\text { melhoria-do-processo- } \\
\text { de-ensino-aprendizagem }\end{array}$ & $\begin{array}{l}\text { desenvolvimento-da- } \\
\text { autonomia-do-estudante }\end{array}$ \\
\hline sujeito 308 & quimica & reacoes & aula-exerimental \\
\hline sujeito 314 & $\begin{array}{l}\text { desenvolvimento-da- } \\
\text { capacidade-de- } \\
\text { interpretacao }\end{array}$ & envolvimento-intelectual & participacao-ativa \\
\hline sujeito 315 & $\begin{array}{l}\text { capacidade-de- } \\
\text { interpretacao }\end{array}$ & motivacao & resolver-problemas \\
\hline sujeito 317 & pratica & fixacao & conhecimento \\
\hline sujeito 318 & $\begin{array}{l}\text { observacao-de- } \\
\text { fenomenos }\end{array}$ & pesquisa & domímio-de-tecnica \\
\hline sujeito 320 & desenvolvimento & aplicacao & escrita \\
\hline sujeito 322 & $\begin{array}{l}\text { deveria-ser-vivenciada- } \\
\text { antes-da-teoria }\end{array}$ & $\begin{array}{l}\text { relacionar-conceitos- } \\
\text { teorico-praticos }\end{array}$ & $\begin{array}{l}\text { compreender-os- } \\
\text { aspectos-tecnicos- } \\
\text { cientificos }\end{array}$ \\
\hline sujeito 323 & metodo & objetividade & ciencias-naturais \\
\hline sujeito 324 & testes-de-hipoteses & $\begin{array}{l}\text { planejamento-de- } \\
\text { atividades-a-serem- } \\
\text { realizadas-em- } \\
\text { laboratorio }\end{array}$ & \\
\hline sujeito 325 & aprendizado & conhecimento & aplicacao \\
\hline sujeito 326 & contextualizacao & investigacao & $\begin{array}{l}\text { organizacao-dos- } \\
\text { conceitos }\end{array}$ \\
\hline sujeito 327 & curiosidade & iniciativa & criatividade \\
\hline sujeito 328 & $\begin{array}{l}\text { persepcao-de- } \\
\text { fenomenos- } \\
\text { microscopicos }\end{array}$ & $\begin{array}{l}\text { aplicacao-de-conceitos- } \\
\text { teoricos }\end{array}$ & $\begin{array}{l}\text { analise-e-interpretacao- } \\
\text { de-dados-experimentais }\end{array}$ \\
\hline sujeito 329 & articulacao & contextualizacao & ambiente \\
\hline sujeito 330 & pratica & laboratorio & relacionar-conceitos \\
\hline --------------- & 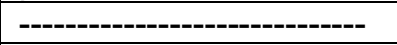 & 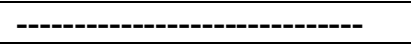 & 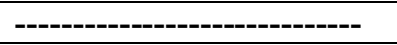 \\
\hline Sujeito & Termo 04 & $\begin{array}{c}\text { Termo } 05 \\
\end{array}$ & Termo 06 \\
\hline sujeito 1 & pratica & interacao & aprendizagem \\
\hline sujeito 2 & pratica & verificacao & contextualizacao \\
\hline sujeito 3 & qualidade & pesquisa & entendimento \\
\hline sujeito 4 & $\begin{array}{l}\text { materiais-iternativos- } \\
\text { para-experimentos }\end{array}$ & ludico & investigacao \\
\hline sujeito 5 & teoria-pratica & sala-de-aula & acessivel \\
\hline sujeito 6 & problematizacao & organizacao & ambiental \\
\hline sujeito 7 & busca & verificacao & comparacao \\
\hline sujeito 8 & quimica & tecnologia & pesquisa \\
\hline sujeito 9 & aprendizagem & quimica & ciencia \\
\hline sujeito 10 & $\begin{array}{l}\text { uso-de-material- } \\
\text { alternativo }\end{array}$ & fazer-ciencia & produzir-experimentos \\
\hline sujeito 11 & vivencia & fenomeno & pratica \\
\hline sujeito 12 & estrategias & investigacao & interpretacoes \\
\hline sujeito 13 & material-alternativo & pratica & laboratorio \\
\hline sujeito 14 & reflexao & demonstrativa & pratica \\
\hline sujeito 15 & reflexao & acao & construcao \\
\hline sujeito 16 & dados & resultados & procedimentos \\
\hline sujeito 17 & carencia-de-material & professor-otimista & projetos \\
\hline sujeito 18 & artes & aula-de-campo & $\begin{array}{l}\text { aprendizagem- } \\
\text { cooperativa }\end{array}$ \\
\hline sujeito 19 & problematizacao & atividades-experimentais & ciencias \\
\hline sujeito 20 & dados-experimentais & problema & teoria \\
\hline sujeito 21 & inspirador & habilidade & auto-explicativo \\
\hline sujeito 22 & metodologia & baixo-custo & interesse \\
\hline sujeito 23 & encantamento & significado & criatividade \\
\hline
\end{tabular}




\begin{tabular}{|c|c|c|c|}
\hline sujeito 24 & observacao & reflexao & trabalho-em-grupo \\
\hline \multicolumn{4}{|l|}{ sujeito 25} \\
\hline sujeito 26 & substancia & verificacao & teste \\
\hline sujeito 27 & descobrir & aprender & curiosidade \\
\hline sujeito 28 & exploracao & vivencia & materiais-de-baixo-custo \\
\hline sujeito 29 & auxilia-na-aprendizagem & despertar-interesse & habilidades-tecnologicas \\
\hline sujeito 30 & simplificacao & descomplicar & pesquisa \\
\hline sujeito 31 & senso-critico & superacao & quebra-de-paradigma \\
\hline sujeito 32 & $\begin{array}{l}\text { construcao-do- } \\
\text { conhecimento }\end{array}$ & reagentes-e-vidrarias & laboratorio \\
\hline sujeito 33 & $\begin{array}{l}\text { desenvolvimento- } \\
\text { cognitivo }\end{array}$ & socializacao & ludicidade \\
\hline sujeito 34 & $\begin{array}{l}\text { experimentacao-no- } \\
\text { ensino }\end{array}$ & $\begin{array}{l}\text { aprendizagem- } \\
\text { significativa }\end{array}$ & $\begin{array}{l}\text { experimentacao- } \\
\text { inclusiva }\end{array}$ \\
\hline sujeito 35 & investigacao & variaveis & laboratorio \\
\hline sujeito 36 & vidrarias & roteiro-experimental & produtos \\
\hline sujeito 37 & estimulos & experimentos & aula-pratica \\
\hline sujeito 38 & conflito-cognitivo & dialogo & motivacao \\
\hline sujeito 39 & senso-critico & materiais-alternativos & materiais-de-laboratorio \\
\hline sujeito 40 & pratica & vivencia & aprendizagem \\
\hline sujeito 41 & colaborativa & demonstrativa & ilustrativa \\
\hline sujeito 42 & aprendizagem & ensino & interesse \\
\hline sujeito 43 & $\begin{array}{l}\text { descarte- } \\
\text { reaproveitamento }\end{array}$ & interesse & motivacao \\
\hline sujeito 44 & discussoes & concreto & visualizacao \\
\hline sujeito 45 & baixo-custo & seguranca & $\begin{array}{l}\text { dificuldades-de- } \\
\text { execucao-em-sala-de- } \\
\text { aula }\end{array}$ \\
\hline sujeito 46 & projetos & aulas-praticas & $\begin{array}{l}\text { demonstracoes-de- } \\
\text { experimentos }\end{array}$ \\
\hline sujeito 47 & grupo & ciencia & abordagem \\
\hline sujeito 48 & educacao & ciencias & quimica \\
\hline sujeito 49 & ensino & laboratorio & ciencias \\
\hline sujeito 50 & pratica & motivacao & observacao \\
\hline sujeito 51 & persepcao & mediacao & observacao \\
\hline sujeito 52 & reflexao & processo-dialogico & criacao \\
\hline sujeito 53 & curiosidade & teste & ciencias \\
\hline sujeito 54 & $\begin{array}{l}\text { aprender- } \\
\text { conhecimentos- } \\
\text { cientificos }\end{array}$ & memorizacao & vivenciar-teorias \\
\hline sujeito 55 & ensino-aprendizagem & ciencias & ensino-dinamico \\
\hline sujeito 56 & demonstrativa & investigativa & baixo-custo \\
\hline sujeito 57 & acessibilidade & cotidiano & regionalismo \\
\hline sujeito 58 & metodo & demonstracao & comprovacao \\
\hline sujeito 59 & laboratorio & reagentes-e-vidrarias & ciencia \\
\hline sujeito 60 & pratica & comunidade & ensino-ativo \\
\hline sujeito 61 & formacao & ausente & fundamental \\
\hline sujeito 62 & temas-quimicos & reagentes & laboratorio \\
\hline sujeito 63 & $\begin{array}{l}\text { demonstracao-em-sala- } \\
\text { de-aula }\end{array}$ & habilidade-manual & $\begin{array}{l}\text { seguranca-de- } \\
\text { laboratorio }\end{array}$ \\
\hline sujeito 64 & teste & descoberta & estimular \\
\hline sujeito 65 & investigacao & conhecimento & fenomeno \\
\hline sujeito 66 & formacao & investigacao & atividades-experimentais \\
\hline sujeito 67 & $\begin{array}{l}\text { os-professores- } \\
\text { precisam-de-tempo-e- } \\
\text { apoio-para-realizar }\end{array}$ & envolvimento-ativo & $\begin{array}{l}\text { costuma-seguir-receitas- } \\
\text { prontas }\end{array}$ \\
\hline sujeito 68 & experimentacao-com- & descarte-correto-de- & metodo-cientifico \\
\hline
\end{tabular}




\begin{tabular}{|c|c|c|c|}
\hline & seguranca & residuos-quimicos & \\
\hline sujeito 69 & experimento & curiosidade & laboratorio \\
\hline sujeito 70 & inovacao & laboratorio & frequencia \\
\hline sujeito 71 & curiosidade & motivacao & visualidade \\
\hline sujeito 72 & dados & analise & tecnicas \\
\hline sujeito 73 & laboratorio & materiais & procedimentos \\
\hline sujeito 74 & $\begin{array}{l}\text { interpretacao-de- } \\
\text { resultados }\end{array}$ & investigacao & contextualizacao \\
\hline sujeito 75 & efeitos & pratica & laboratorio \\
\hline sujeito 76 & orientacao & autonomia & atividade \\
\hline sujeito 77 & reagente & vidrarias & titulacao \\
\hline sujeito 78 & procedimentos & explicacao & atitudes \\
\hline sujeito 79 & solucao-de-problemas & relacionar-teoria-pratica & criatividade \\
\hline sujeito 80 & tentativa & ciencia & cotidiano \\
\hline sujeito 81 & metodo-cientifico & trabalho-em-equipe & teste \\
\hline sujeito 82 & autonomia & desafio & estimulo \\
\hline sujeito 83 & macroscopicos & fenomenos-visiveis & reacoes \\
\hline sujeito 84 & $\begin{array}{l}\text { levantamento-e-teste- } \\
\text { de-hipoteses }\end{array}$ & problematizacao & essencial \\
\hline sujeito 85 & atencao & observacao & repeticao \\
\hline sujeito 86 & contextualizacao & vida & necessidade \\
\hline sujeito 87 & infraestrutura & $\begin{array}{l}\text { formacao-de- } \\
\text { professores }\end{array}$ & laboratorio \\
\hline sujeito 88 & investigacao & cidadania & participacao \\
\hline sujeito 89 & trabalho-em-grupo & $\begin{array}{l}\text { competencia-de- } \\
\text { organizar-e-sistematizar }\end{array}$ & interdisciplinaridade \\
\hline sujeito 90 & aprendizagem & metodos-alternativos & \\
\hline sujeito 91 & aguca-a-curiosidade & interatividade & $\begin{array}{l}\text { experimento-pelo- } \\
\text { experimento }\end{array}$ \\
\hline sujeito 92 & problematizadora & letramento & metodologia \\
\hline sujeito 93 & $\begin{array}{l}\text { verificacao-da- } \\
\text { relatividade-da-exatidao- } \\
\text { das-ciencias }\end{array}$ & $\begin{array}{l}\text { nas-escolas-e- } \\
\text { complicado }\end{array}$ & trabalho-em-grupo \\
\hline sujeito 94 & laboratorios & materiais & alternativos \\
\hline sujeito 95 & executar & testar & avaliar \\
\hline sujeito 96 & momento-ativo & motivacao & concretizacao-da-teoria \\
\hline sujeito 97 & reprodutibilidade & satisfacao & eficacia \\
\hline sujeito 98 & $\begin{array}{l}\text { transformacoes- } \\
\text { quimicas }\end{array}$ & propriedades-fisicas & construcao-de-graficos \\
\hline sujeito 102 & simbolos & gestao & tratamento-de-residuos \\
\hline sujeito 103 & tecnicas-experimentais & desvalorizada & divertida \\
\hline sujeito 105 & contextualizacao & curiosidade & cientifico \\
\hline sujeito 106 & ciencia & cientista & metodologia \\
\hline sujeito 107 & encantamento & olhar & coisas-estranhas \\
\hline sujeito 108 & interpretacao & hipoteses & equipes \\
\hline sujeito 109 & id & concreto & abstrato \\
\hline sujeito 110 & interdisciplinaridade & entendimento & $\begin{array}{l}\text { reducao-das- } \\
\text { dificuldades }\end{array}$ \\
\hline sujeito 111 & planejamento & organizacao & epi \\
\hline sujeito 112 & manipulacao & interpretacao & aplicacao \\
\hline sujeito 115 & hidroxiapatia & nanoparticulas & parafusos \\
\hline sujeito 121 & empiria-vs-empiria & positivismo & relacao-teoria-pratica \\
\hline sujeito 122 & autonomia & criterios-de-analise & aspectos-motivacionais \\
\hline \multicolumn{4}{|l|}{ sujeito 123} \\
\hline sujeito 124 & envolvimento & materiais-e-reagentes & preparo-docente \\
\hline sujeito 125 & colaboracao & materiais-alternativos & pensamento \\
\hline sujeito 126 & analise & reinterpretacao & metodo \\
\hline
\end{tabular}




\begin{tabular}{|c|c|c|c|}
\hline sujeito 128 & observacao & duvidas & curiosidade \\
\hline sujeito 129 & laboratorio & discussao-conceitual & pratica \\
\hline sujeito 130 & abordagem-historica & desperta-o-interesse & atividade-ludica \\
\hline sujeito 131 & grupo & dinamismo & laboratorio \\
\hline sujeito 132 & $\begin{array}{l}\text { facilitacao-da- } \\
\text { aprendizagem }\end{array}$ & $\begin{array}{l}\text { compreensao-de- } \\
\text { fenomenos-quimicos }\end{array}$ & interesse \\
\hline sujeito 134 & motivacao & aprendizagem & efetividade \\
\hline sujeito 135 & $\begin{array}{l}\text { conceitos-quimicos- } \\
\text { outras-areas-do- } \\
\text { conhecimento }\end{array}$ & $\begin{array}{l}\text { propor-e-comunicar- } \\
\text { estrategias }\end{array}$ & atitudes-e-valores \\
\hline sujeito 136 & ensino & conteudo & interacao \\
\hline sujeito 140 & baixo-custo & laboratorio & demonstracao \\
\hline sujeito 141 & resposta-a-problema & ilustracao & aplicacao \\
\hline sujeito 142 & curiosidade & motivacao & dinamicidade \\
\hline sujeito 143 & interessante & futuro & visual \\
\hline sujeito 144 & tecnicas & conhecimento-cientifico & visao-do-cientista \\
\hline sujeito 145 & pratica & positivismo & inducao \\
\hline sujeito 146 & tempo & alto-gasto & felicidade \\
\hline sujeito 147 & aprendizagem & ensino & laboratorio \\
\hline sujeito 148 & experiencia & experimental & contato-com-a-realidade \\
\hline sujeito 149 & seguranca & reacao & emocao \\
\hline sujeito 150 & $\begin{array}{l}\text { descobertas- } \\
\text { experimentais }\end{array}$ & $\begin{array}{l}\text { montagem } \\
\text { experimentos }\end{array}$ & ligando-teoria-e-pratica \\
\hline sujeito 151 & conhecimento & aprendizagem & descoberta \\
\hline sujeito 152 & curiosidade & positivismo & confirmacao-da-teoria \\
\hline sujeito 153 & & & \\
\hline sujeito 154 & estimulo & compreensao & satisfacao \\
\hline sujeito 155 & explicacao & visualizacao & concreto \\
\hline sujeito 156 & relacao-teoria-pratica & conscientizacao & estudo-de-caso \\
\hline sujeito 157 & analise & aprendizagem & motivacao \\
\hline sujeito 158 & atratividade & elucidacao & observacao \\
\hline sujeito 159 & materiais-didaticos & laboratorio & $\begin{array}{l}\text { precariedade-das- } \\
\text { escolas }\end{array}$ \\
\hline sujeito 160 & $\begin{array}{l}\text { nao-serve-somente- } \\
\text { para-motivar }\end{array}$ & $\begin{array}{l}\text { nao-deve-se-restringir-a- } \\
\text { laboratorio }\end{array}$ & $\begin{array}{l}\text { experimento-nao- } \\
\text { comprova-teoria }\end{array}$ \\
\hline sujeito 161 & $\begin{array}{l}\text { aumento-da-motivacao- } \\
\text { e-curiosidade }\end{array}$ & envolvimento & investigacao \\
\hline sujeito 162 & $\begin{array}{l}\text { sistematiacao-dos- } \\
\text { dados }\end{array}$ & $\begin{array}{l}\text { procedimento- } \\
\text { metodologico }\end{array}$ & tecnicas-de-analise \\
\hline sujeito 163 & visualizacao & conhecimento & emocao \\
\hline sujeito 164 & laboratorios & materiais-fisicos & hipoteses \\
\hline sujeito 165 & filosofia & matematica & didatica \\
\hline sujeito 166 & observacao-da-realidade & $\begin{array}{l}\text { fundamental-e- } \\
\text { fascinante }\end{array}$ & $\begin{array}{l}\text { forma-didatica-de- } \\
\text { aprender }\end{array}$ \\
\hline sujeito 167 & valor-medio & desvio-padrao & incertezas \\
\hline sujeito 168 & visualizacao & video & demonstrativa \\
\hline sujeito 169 & investigacao-teste & participacao & $\begin{array}{l}\text { construcao-de- } \\
\text { conhecimento }\end{array}$ \\
\hline sujeito 170 & explicacao & descoberta & metodo \\
\hline sujeito 171 & contextualizacao & materiais-alternativos & motivacao \\
\hline sujeito 172 & observacao & ciencia & ensino \\
\hline sujeito 173 & experiencia & ciencia & invencao \\
\hline sujeito 174 & organocatalise & & \\
\hline sujeito 175 & interesse & ativa & animacao \\
\hline sujeito 176 & $\begin{array}{l}\text { ensino-por-mudanca- } \\
\text { conceitual }\end{array}$ & acao & demonstracao \\
\hline sujeito 177 & desenvolvimento- & teoria & ensino \\
\hline
\end{tabular}




\begin{tabular}{|c|c|c|c|}
\hline & conceitual & & \\
\hline sujeito 178 & alegria-em-entender & aprendizagem-do-real & conquistar-um-futuro \\
\hline sujeito 179 & trabalho-em-equipe & seguranca & planejamento \\
\hline sujeito 180 & metodo & independencia & $\begin{array}{l}\text { interpretacao-de- } \\
\text { resultados }\end{array}$ \\
\hline sujeito 181 & materiais & cotidiano & fenomenos \\
\hline sujeito 182 & argumentacao & ctsa & $\begin{array}{l}\text { tres-momentos- } \\
\text { pedagogicos }\end{array}$ \\
\hline sujeito 183 & habilidade & calculo & paciencia \\
\hline sujeito 184 & ambiente & metais & bebidas \\
\hline sujeito 185 & ensino & aprendizagem & desenvolvimento \\
\hline sujeito 186 & testes & criacao & hipoteses \\
\hline sujeito 187 & & & \\
\hline sujeito 188 & investigacao & problematizacao & hipoteses \\
\hline sujeito 189 & cotidiano & memorizacao & aprendizagem \\
\hline sujeito 190 & ciencias & recursos & educacao \\
\hline sujeito 191 & pouco-investigada & incompreendida & panaceia \\
\hline sujeito 192 & vidrarias & laboratorio & estudos-culturais \\
\hline sujeito 193 & demonstracao & investigacao & $\begin{array}{l}\text { resgate-de-saberes- } \\
\text { populares }\end{array}$ \\
\hline sujeito 194 & $\begin{array}{l}\text { os-alunos-nao- } \\
\text { valorizam-o-esforco-do- } \\
\text { professor }\end{array}$ & $\begin{array}{l}\text { falta-de-tempo-para- } \\
\text { preparar-os- } \\
\text { experimentos }\end{array}$ & falta-de-espaco-fisico \\
\hline sujeito 195 & dinamismo & coletividade & protagonismo \\
\hline sujeito 196 & demonstrativa & $\begin{array}{l}\text { em-sala-ou-em- } \\
\text { laboratorio }\end{array}$ & materiais-alternativos \\
\hline sujeito 197 & orqanizacao & reprodutivel & fatos \\
\hline sujeito 198 & facilitador & motivacao & demonstrativo \\
\hline sujeito 199 & tentativa & exercicio & criatividade \\
\hline sujeito 200 & integracao & tratamento-de-dados & metodologia \\
\hline sujeito 201 & significado & praticando & treinamento \\
\hline sujeito 203 & pratica & sequencia & curiosidade \\
\hline sujeito 204 & como & acontece & uma \\
\hline sujeito 205 & quimica & desafios & laboratorio \\
\hline sujeito 206 & vidrarias & caderno-de-laboratorio & animais \\
\hline sujeito 207 & mediacao & epistemologia & pedagogia \\
\hline sujeito 208 & dinamica & $\begin{array}{l}\text { dificil-para-os-alunos- } \\
\text { correlacionarem }\end{array}$ & $\begin{array}{l}\text { necessario-para- } \\
\text { entender-quimica }\end{array}$ \\
\hline sujeito 210 & $\begin{array}{l}\text { dentro-e-fora-do- } \\
\text { laboratorio }\end{array}$ & $\begin{array}{l}\text { expectativa-dos- } \\
\text { estudantes }\end{array}$ & custoso-e-prazeroso \\
\hline sujeito 211 & cotidiano & planejamento & laboratorio \\
\hline sujeito 212 & diversao & curiosidade & envolvimento \\
\hline sujeito 213 & observacao & aproximacao & ensino \\
\hline sujeito 215 & curiosidade & iniciativa & baixo-custo \\
\hline sujeito 216 & ensino & desenvolvimento & habilidade \\
\hline sujeito 217 & protagonista & excecucao & compreensao \\
\hline sujeito 218 & experimental & resultados & relatorio \\
\hline sujeito 219 & quimica & metodo & prazer \\
\hline sujeito 220 & laboratorio & habilidade & ambiente \\
\hline sujeito 222 & manipulacao & relacao-teoria-pratica & pratica \\
\hline sujeito 224 & criatividade & motivacao & pratica \\
\hline sujeito 226 & observacao & $\begin{array}{l}\text { fenomeno-quimico-ou- } \\
\text { fisico }\end{array}$ & laboratorio-quimico \\
\hline sujeito 227 & fazer & compreender & criar \\
\hline sujeito 228 & coleta-de-dados & pratica & orientador \\
\hline sujeito 229 & investigacao & reprodutibilidade & $\begin{array}{l}\text { experimentacao- } \\
\text { computacional }\end{array}$ \\
\hline
\end{tabular}




\begin{tabular}{|c|c|c|c|}
\hline sujeito 230 & manuseio-de-materiais & medicao & sintese \\
\hline sujeito 232 & pratica & observacao & relatorio \\
\hline sujeito 233 & materiais & roteiro & equipamentos \\
\hline sujeito 234 & experimentacao-virtual & $\begin{array}{l}\text { possibilidade-do- } \\
\text { desenvolvimento-de- } \\
\text { habilidades- } \\
\text { argumentativas }\end{array}$ & ferramenta-motivadora \\
\hline sujeito 235 & pedagogia & ensino-medio & inovacao \\
\hline sujeito 236 & visualizacao & ludicidade & \\
\hline sujeito 237 & empirico & replica & racionalizacao \\
\hline sujeito 238 & experimento & analise & visualizacao \\
\hline sujeito 239 & trabalho-em-grupo & ciencias & laboratorio \\
\hline sujeito 241 & aperfeicoar & repensar & reconstruir \\
\hline sujeito 242 & intersse & metodo-cientifico & $\begin{array}{l}\text { experimentacao- } \\
\text { investigativa }\end{array}$ \\
\hline sujeito 243 & reacoes-de-precipitacao & solucoes & hidrotermal \\
\hline sujeito 245 & $\begin{array}{l}\text { reconstrucao-do- } \\
\text { conhecimento }\end{array}$ & contextualizacao & interacao \\
\hline sujeito 246 & curiosidade & relatorio & surpresa \\
\hline sujeito 248 & metodos & repeticao & reproducao \\
\hline sujeito 249 & estudante-professor & dialogo & aplicacao-pedagogica \\
\hline sujeito 250 & laboratorio & alegrias & dificuldades \\
\hline sujeito 251 & experiencia & mudanca & preparacao \\
\hline sujeito 253 & aprender-a-fazer & descoberta & evidenciacao \\
\hline sujeito 254 & operacao & estudo-de-caso & resultado \\
\hline sujeito 256 & & & \\
\hline sujeito 258 & diversao & quimica & laboratorio \\
\hline sujeito 259 & laboratorio & vidraria & bancada \\
\hline sujeito 260 & estudo-de-caso & hipotese & \\
\hline sujeito 261 & resultados & hipotese & observacao \\
\hline sujeito 264 & eletroquimica & instrumentacao & computacao \\
\hline sujeito 265 & realizacao & pratica & excecucao \\
\hline sujeito 267 & planejamento & equipamentos & analise \\
\hline sujeito 268 & superacao & conhecimento & descoberta \\
\hline sujeito 269 & problematizacao & cotidiano & observacao \\
\hline sujeito 273 & $\begin{array}{l}\text { comprovacao-pratica- } \\
\text { de-um-fenomeno-teorico }\end{array}$ & experimentos-didaticos & $\begin{array}{l}\text { desenvolvimento-de- } \\
\text { habilidades }\end{array}$ \\
\hline sujeito 276 & pratica & experimento & hipotese \\
\hline sujeito 277 & anotacao & $\begin{array}{l}\text { questionamento-e- } \\
\text { deducao }\end{array}$ & extrapolacao \\
\hline sujeito 278 & aprendizagem & investigativa & necessaria \\
\hline sujeito 279 & pre-teste & laboratorio & roteiro \\
\hline sujeito 280 & discussao & cooperacao & reflexao \\
\hline sujeito 281 & imersao & visualizacao & laboratorio \\
\hline sujeito 282 & seguranca & ensino & controle \\
\hline sujeito 286 & conhecimento-na-pratica & $\begin{array}{l}\text { manuseio-de-reagentes- } \\
\text { e-vidrarias }\end{array}$ & escrita-de-relatorio \\
\hline sujeito 288 & natureza-da-ciencia & metodologia-de-ensino & $\begin{array}{l}\text { desenvolvimento-de- } \\
\text { habilidades }\end{array}$ \\
\hline sujeito 289 & investigacao & motivacao & organizacao \\
\hline sujeito 290 & criatividade & hipotese & metodo-logico \\
\hline sujeito 291 & pratica & experiencia & virtual \\
\hline sujeito 293 & manipulacao & aprendizado & habilidades \\
\hline sujeito 294 & demonstracao & ensino-nao-formal & divulgacao-cientifica \\
\hline sujeito 295 & relatorio & planejamento & cautela \\
\hline sujeito 296 & duvidar & observar & raciocinar \\
\hline sujeito 298 & laboratorio & campo & anona \\
\hline
\end{tabular}




\begin{tabular}{|c|c|c|c|}
\hline sujeito 300 & investigacao & didatica & socializacao \\
\hline sujeito 302 & hipotese & observacao & registro \\
\hline sujeito 303 & alternativas & aplicadas & vivencia-pratica \\
\hline sujeito 304 & professor-de-caixinha & laboratorio & demonstracao \\
\hline sujeito 305 & curiosidade & paixao & $\begin{array}{l}\text { desafio-para-um-classe- } \\
\text { de-muitos-alunos }\end{array}$ \\
\hline sujeito 308 & mudancas & transformacoes & descoberta \\
\hline sujeito 314 & $\begin{array}{l}\text { levantamento-de- } \\
\text { hipoteses }\end{array}$ & investigacao & questionamento \\
\hline sujeito 315 & $\begin{array}{l}\text { manipulacao-em- } \\
\text { laboratorio }\end{array}$ & habilidade-de-planejar & percepcao-da-quimica \\
\hline sujeito 317 & melhora & interesse & confirmacao \\
\hline sujeito 318 & & & \\
\hline sujeito 320 & criatividade & responsabilidade & agilidade \\
\hline sujeito 322 & $\begin{array}{l}\text { aprender-manipular- } \\
\text { reagentes-e-vidrarias }\end{array}$ & despertar-curiosidade & $\begin{array}{l}\text { buscar-situacoes-e- } \\
\text { fatos-para-sedimentar- } \\
\text { os-conteudos-teoricos }\end{array}$ \\
\hline sujeito 323 & objetividade & laboratorio & tecnologia \\
\hline sujeito 324 & & & \\
\hline sujeito 325 & descoberta & fixacao & treinamento \\
\hline sujeito 326 & estrategias-de-ensino & pratica-de-observacao & habilidade \\
\hline sujeito 327 & $\begin{array}{l}\text { comprovacao- } \\
\text { verificacao }\end{array}$ & adaptacao & laboratorio \\
\hline sujeito 328 & $\begin{array}{l}\text { melhoria-das-praticas- } \\
\text { laboratoriais-pelos- } \\
\text { alunos }\end{array}$ & $\begin{array}{l}\text { exploracao-de- } \\
\text { equipamentos-cientificos }\end{array}$ & $\begin{array}{l}\text { maior-interacao-entre- } \\
\text { os-alunos }\end{array}$ \\
\hline sujeito 329 & vivencia & cotidiano & pratica \\
\hline sujeito 330 & pesquisa & testar & ensaio \\
\hline
\end{tabular}




\section{APÊNDICE C - Lista de Palavras Modificadas}

\begin{tabular}{|c|c|}
\hline Termo Evocado & Termo Modificado \\
\hline acessibilidade & acessivel \\
\hline aguca-a-curiosidade & despertar-curiosidade \\
\hline alegria & alegrias \\
\hline alto-gasto & alto-custo \\
\hline aluno & alunos \\
\hline alternativas & alternativa \\
\hline alternativos & alternativa \\
\hline analisar & analise \\
\hline analises & analise \\
\hline analises-quimicas & analise-quimica \\
\hline aprender & aprendizagem \\
\hline aprendizado & aprendizagem \\
\hline aprendizado-significativo & aprendizagem-significativa \\
\hline articulacao & relacao-teoria-e-pratica \\
\hline articulacao-teoria-pratica & relacao-teoria-e-pratica \\
\hline atividades-praticas & atividade-pratica \\
\hline atividades-experimentais & atividade-experimental \\
\hline aulas-dinamicas & dinamica \\
\hline aulas-experimentais & aula-experimental \\
\hline aulas-praticas & aula-pratica \\
\hline auxiliar-na-aprendizagem & auxilia-na-aprendizagem \\
\hline ciencias & ciencia \\
\hline colaboracao & colaborativa \\
\hline complementa-o-aprendizado-teorico & complementacao-do-ensino \\
\hline compreender & compreensao \\
\hline comprovacao & comprovacao-da-teoria \\
\hline comprovacao-verificacao & comprovacao-da-teoria \\
\hline conceito-quimico & conceitos-quimicos \\
\hline concepcoes-alternativas & concepcao-alternativa \\
\hline concretizacao & concreto \\
\hline concretizacao-da-teoria & concreto \\
\hline confirmacao-da-teoria & confirmacao \\
\hline conhecimento-da-teoria & conhecimento \\
\hline conhecimento-teorico & conhecimento \\
\hline conteudos-procedimentais & conteudo-procedimental \\
\hline contexto & contextualizacao \\
\hline contextualizada & contextualizacao \\
\hline construcao & construcao-do-conhecimento \\
\hline construcao-de-conhecimento & construcao-do-conhecimento \\
\hline dados-experimentais & dados \\
\hline demonstracoes & demonstracao \\
\hline demonstrativo & demonstrativa \\
\hline despertar-a-curiosidade-dos-alunos & despertar-curiosidade \\
\hline desafios & desafio \\
\hline descobrir & descoberta \\
\hline descobrimento & descoberta \\
\hline desperta-o-interesse & despertar-interesse \\
\hline despertar-o-interesse-do-aluno & despertar-interesse \\
\hline deve-prezar-relacao-integracao-teoria-pratica & relacao-teoria-e-pratica \\
\hline didatico & didatica \\
\hline
\end{tabular}




\begin{tabular}{|c|c|}
\hline dinamicidade & dinamica \\
\hline dinamismo & dinamica \\
\hline discussoes & discussao \\
\hline divertida & diversao \\
\hline duvidas & duvida \\
\hline ensino-aprendizagem & ensino-e-aprendizagem \\
\hline entendimento & entender \\
\hline equipes & equipe \\
\hline epis & epi \\
\hline emocionante & emocao \\
\hline empirismo & empirico \\
\hline ensaios & ensaio \\
\hline estimular & estimulo \\
\hline estimulo-ao-aprendizado & estimulo \\
\hline estimulo-a-aprendizagem & estimulo \\
\hline estimulos & estimulo \\
\hline experimentos & experimento \\
\hline evidencia & evidencias \\
\hline evidenciacao & evidencias \\
\hline explorar & exploração \\
\hline facilitador-do-entendimento & facilitador-da-aprendizagem \\
\hline facilitador & facilitador-da-aprendizagem \\
\hline fenomenos & fenomeno \\
\hline habilidades & habilidade \\
\hline habilidade-manual & habilidades-manuais \\
\hline hipoteses & hipotese \\
\hline ideia & ideias \\
\hline ilustrativa & ilustracao \\
\hline incertezas & incerteza \\
\hline integracao-teoria-pratica & relacao-teoria-e-pratica \\
\hline interpretacoes & interpretacao \\
\hline investigativar & investigacao \\
\hline experimento-investigativo & experimentacao-investigativa \\
\hline investigadora & experimentacao-investigativa \\
\hline investigativa & experimentacao-investigativa \\
\hline investigativo & experimentacao-investigativa \\
\hline laboratorios & laboratorio \\
\hline ligando-teoria-e-pratica & relacao-teoria-e-pratica \\
\hline ludicidade & ludico \\
\hline macroscopica & macroscopico \\
\hline macroscopicos & macroscopico \\
\hline medicoes & medicao \\
\hline material-alternativo & materiais-alternativos \\
\hline uso-de-material-alternativo & materiais-alternativos \\
\hline metodo & metodo-cientifico \\
\hline metodos & metodo-cientifico \\
\hline metodologias & metodologia \\
\hline metodologia-cientifica & metodologia \\
\hline mudancas & mudanca \\
\hline nao-dicotomia-entre-teoria-e-pratica & relacao-teoria-e-pratica \\
\hline necessidade & necessaria \\
\hline observar & observacao \\
\hline observacao-de-algum-fenomeno & observacao \\
\hline observacao-de-fenomenos & observacao \\
\hline pesquisar & pesquisa \\
\hline problematizar & problematizacao \\
\hline problematizador & problematizacao \\
\hline
\end{tabular}




\begin{tabular}{|c|c|}
\hline problematizadora & problematizacao \\
\hline eperimentacao-problematizadora & problematizacao \\
\hline procedimento & procedimentos \\
\hline praticas & pratica \\
\hline praticando & pratica \\
\hline praticar & pratica \\
\hline planejar & planejamento \\
\hline protagonista & protagonismo \\
\hline questionamentos & questionamento \\
\hline questionar & questionamento \\
\hline raciocinar & raciocinio \\
\hline reagente & reagentes \\
\hline reacao & reacao-quimica \\
\hline reacoes & reacao-quimica \\
\hline reacoes-quimicas & reacao-quimica \\
\hline recursos & recurso \\
\hline relacao-com-a-teoria & relacao-teoria-e-pratica \\
\hline relacao-teoria-prática & relacao-teoria-e-pratica \\
\hline relacionar-conceitos-teorico-praticos & relacao-teoria-e-pratica \\
\hline relacionar-teoria-e-prática & relacao-teoria-e-pratica \\
\hline reprodutivel & reprodutibilidade \\
\hline resultado & resultados \\
\hline roteiro & roteiro-experimental \\
\hline seguranca-de-laboratorio & seguranca \\
\hline seguranca-no-laboratorio & seguranca \\
\hline significado & significacao \\
\hline testar & teste \\
\hline testes & teste \\
\hline tecnica & tecnicas \\
\hline teoria-associada-a-pratica & relacao-teoria-e-pratica \\
\hline teoria-pratica & relacao-teoria-e-pratica \\
\hline trabalho-em-equipe & trabalho-em-grupo \\
\hline transformacoes & transformacao \\
\hline tratamentos-de-dados & tratamento-de-dados \\
\hline verificar & verificacao \\
\hline vidraria & vidrarias \\
\hline visualidade & visualizacao \\
\hline
\end{tabular}




\section{APÊNDICE D - Localidade e Instituição dos Colaboradores da Pesquisa}

\begin{tabular}{|c|c|c|c|c|c|c|c|}
\hline \multirow[b]{2}{*}{ Região } & \multirow[b]{2}{*}{ Estado } & \multirow[b]{2}{*}{ Universidade } & \multicolumn{2}{|c|}{$\begin{array}{c}\text { Coordenador do } \\
\text { PIBID }\end{array}$} & \multirow[b]{2}{*}{ Universidade } & \multicolumn{2}{|c|}{$\begin{array}{l}\text { Não-Coordenador do } \\
\text { PIBID }\end{array}$} \\
\hline & & & Quantidade & $\begin{array}{l}\text { Total / } \\
\text { Região }\end{array}$ & & Quantidade & $\begin{array}{l}\text { Total / } \\
\text { Região } \\
\end{array}$ \\
\hline \multirow{12}{*}{ Norte } & & IFAC & 1 & \multirow{12}{*}{17} & IFAC & 0 & \multirow{12}{*}{2} \\
\hline & $A C$ & UFAC & 1 & & UFAC & 1 & \\
\hline & & IFAP & 1 & & IFAP & 0 & \\
\hline & AM & UEA & 2 & & UEA & 0 & \\
\hline & & UFAM & 4 & & UFAM & 0 & \\
\hline & AP & UEAP & 2 & & UEAP & 0 & \\
\hline & \multirow{3}{*}{ PA } & IFPA & 1 & & IFPA & 1 & \\
\hline & & UEPA & 1 & & UEPA & 0 & \\
\hline & & UFOPA & 1 & & UFOPA & 0 & \\
\hline & RO & IFRO & 1 & & IFRO & 0 & \\
\hline & RR & UERR & 1 & & UERR & 0 & \\
\hline & TO & IFTO & 1 & & IFTO & 0 & \\
\hline \multirow{25}{*}{ Nordeste } & $\mathrm{AL}$ & UFAL & 1 & \multirow{25}{*}{56} & UFAL & 0 & \multirow{25}{*}{21} \\
\hline & \multirow{8}{*}{ BA } & IFBA & 3 & & IFBA & 0 & \\
\hline & & IF-Baiano & 3 & & IF-Baiano & 2 & \\
\hline & & UEFS & 3 & & UEFS & 0 & \\
\hline & & UESB & 4 & & UESB & 0 & \\
\hline & & UESC & 1 & & UESC & 0 & \\
\hline & & UFBA & 1 & & UFBA & 0 & \\
\hline & & UFOB & 2 & & UFOB & 1 & \\
\hline & & UFRB & 1 & & UFRB & 1 & \\
\hline & \multirow{4}{*}{ CE } & IFCE & 1 & & IFCE & 0 & \\
\hline & & UECE & 4 & & UECE & 0 & \\
\hline & & UFC & 1 & & UFC & 2 & \\
\hline & & UVA & 1 & & UVA & 0 & \\
\hline & \multirow{2}{*}{ MA } & IFMA & 6 & & IFMA & 0 & \\
\hline & & UFMA & 2 & & UFMA & 1 & \\
\hline & \multirow{2}{*}{ PB } & UFCG & 1 & & UFCG & 0 & \\
\hline & & UFPB & 2 & & UFPB & 2 & \\
\hline & \multirow{5}{*}{ PE } & IFPE & 3 & & IFPE & 2 & \\
\hline & & IF-Sertão & 4 & & IF-Sertão & 0 & \\
\hline & & UFPE & 2 & & UFPE & 4 & \\
\hline & & UFRPE & 3 & & UFRPE & 0 & \\
\hline & & UNICAP & 1 & & UNICAP & 0 & \\
\hline & \multirow{2}{*}{ PI } & UESPI & 2 & & UESPI & 3 & \\
\hline & & UFPI & 0 & & UFPI & 3 & \\
\hline & $\mathrm{RN}$ & IFRN & 4 & & IFRN & 0 & \\
\hline \multirow{8}{*}{$\begin{array}{l}\text { Centro- } \\
\text { Oeste }\end{array}$} & SE & UFS & 6 & \multirow{8}{*}{20} & UFS & 0 & \\
\hline & & IFG & 3 & & IFG & 0 & \\
\hline & GO & IF-Goiano & 4 & & IF-Goiano & 3 & \\
\hline & & UFG & 2 & & UFG & 1 & 7 \\
\hline & & UEMS & 1 & & UEMS & 0 & $T$ \\
\hline & MS & UFGD & 2 & & UFGD & 2 & \\
\hline & & UFMS & 1 & & UFMS & 1 & \\
\hline & MT & UNEMAT & 1 & & UNEMAT & 0 & \\
\hline Sudeste & ES & IFES & 2 & 54 & IFES & 0 & 60 \\
\hline
\end{tabular}




\begin{tabular}{|c|c|c|c|c|c|c|c|}
\hline & & UFES & 4 & & UFES & 7 & \\
\hline & \multirow{12}{*}{ MG } & IFNMG & 1 & & IFNMG & 0 & \\
\hline & & IFSEMG & 1 & & IFSEMG & 1 & \\
\hline & & IFTM & 2 & & IFTM & 0 & \\
\hline & & UEMG & 1 & & UEMG & 0 & \\
\hline & & UFJF & 1 & & UFJF & 0 & \\
\hline & & UFLA & 2 & & UFLA & 1 & \\
\hline & & UFSJ & 1 & & UFSJ & 1 & \\
\hline & & UFTM & 2 & & UFTM & 0 & \\
\hline & & UFU & 3 & & UFU & 2 & \\
\hline & & UFV & 2 & & UFV & 2 & \\
\hline & & UNIFAL & 2 & & UNIFAL & 1 & \\
\hline & & UNIFEI & 1 & & UNIFEI & 3 & \\
\hline & \multirow{3}{*}{ RJ } & IFRJ & 2 & & IFRJ & 2 & \\
\hline & & UFF & 2 & & UFF & 4 & \\
\hline & & UFRJ & 2 & & UFRJ & 7 & \\
\hline & \multirow{12}{*}{ SP } & FSA & 2 & & FSA & 0 & \\
\hline & & IFSP & 3 & & IFSP & 1 & \\
\hline & & Mackenzie & 1 & & Mackenzie & 1 & \\
\hline & & UFABC & 2 & & UFABC & 7 & \\
\hline & & UFSCar & 3 & & UFSCar & 1 & \\
\hline & & UNESP & 5 & & UNESP & 10 & \\
\hline & & UNICAMP & 0 & & UNICAMP & 1 & \\
\hline & & UNICENTRO & 1 & & UNICENTRO & 2 & \\
\hline & & UNIFESP & 1 & & UNIFESP & 5 & \\
\hline & & UNISP & 1 & & UNISP & 0 & \\
\hline & & UNIVAP & 1 & & UNIVAP & 0 & \\
\hline & & USP & 3 & & USP & 1 & \\
\hline \multirow{15}{*}{ Sul } & \multirow{4}{*}{ PR } & IFPR & 1 & \multirow{15}{*}{25} & IFPR & 0 & \multirow{15}{*}{13} \\
\hline & & UEL & 2 & & UEL & 6 & \\
\hline & & UFPR & 1 & & UFPR & 0 & \\
\hline & & UTFPR & 6 & & UTFPR & 4 & \\
\hline & \multirow{8}{*}{ RS } & FURG & 1 & & FURG & 0 & \\
\hline & & IF-Sul & 1 & & IF-Sul & 0 & \\
\hline & & PUC & 1 & & PUC & 2 & \\
\hline & & UFRGS & 2 & & UFRGS & 0 & \\
\hline & & ULBRA & 1 & & ULBRA & 0 & \\
\hline & & UNILASALLE & 1 & & UNILASALLE & 0 & \\
\hline & & UNIPAMPA & 2 & & UNIPAMPA & 0 & \\
\hline & & UPF & 3 & & UPF & 1 & \\
\hline & \multirow{3}{*}{ SC } & IFSC & 1 & & IFSC & 0 & \\
\hline & & UDESC & 1 & & UDESC & 0 & \\
\hline & & UFSC & 1 & & UFSC & 0 & \\
\hline
\end{tabular}

